\title{
RHEOLOGICAL PROPERTIES AND FLOW BEHAVIOUR OF WAX-STABILIZED WATER-IN-OIL EMULSIONS
}

\author{
By \\ Samira Haj-shafiei \\ B.A.Sc. University of Toronto, 2009
}

\author{
A thesis \\ Presented to Ryerson University \\ in partial fulfillment of the \\ requirements for the degree of \\ Master of Applied Science \\ in the program of \\ Chemical Engineering \\ Toronto, Ontario, Canada, 2011 \\ CSamira Haj-shafiei 2011
}


I hereby declare that I am the sole author of this thesis or dissertation.

I authorize Ryerson University to lend this thesis or dissertation to other institutions or individuals for the purpose of scholarly research.

* Signature

I further authorize Ryerson University to reproduce this thesis or dissertation by photocopying or by other means, in total or in part, at the request of other institutions or individuals for the purpose of scholarly research.

* Signature 
Abstract

\section{RHEOLOGICAL PROPERTIES AND FLOW BEHAVIOUR OF WAX-STABILIZED WATER-IN-OIL EMULSIONS}

Samira Haj-shafiei

Master of Applied Science, Chemical Engineering, 2011

Department of Chemical Engineering

Ryerson University

The objective of this study was to characterize the flow and rheological behaviour of model waxstabilized water-in-oil (W/O) emulsions consisting of light mineral oil, paraffin wax and glycerol monooleate as the oil phase and water as the dispersed aqueous phase. An laboratory-scale benchtop flowloop system was used to explore the flow behaviour of the emulsions' oil phase (oil, paraffin wax and surfactant).The key contribution from this work was that the higher initial temperature gradient $\left(40{ }^{\circ} \mathrm{C}\right.$ compared to $\left.19{ }^{\circ} \mathrm{C}\right)$ experienced by the rapidly-cooled oil led to more initial deposition on the flowloop inner wall. The rheological properties of $\mathrm{W} / \mathrm{O}$ emulsions with different water cuts (10-50 wt\%) were also studied. Rotational, oscillatory rheology and creep compliance and recovery were characterized on emulsions aged up to 28 days. Overall, the results demonstrated that emulsion composition, and age could significantly influence an emulsion's flow behaviour and rheological properties. 


\section{Acknowledgements}

I wish to express my gratitude to Professor Dérick Rousseau, my supervisor, who was very helpful and offered invaluable assistance, support and guidance during my Master's study.

I also would like to thank all members of the Rousseau lab and the administrators of the Chemical Engineering Department for their support.

I would like to gratefully acknowledge the generous financial assistance provided by the National Science and Engineering Research Council and Ryerson University (School of Graduate Studies).

Finally, I wish to express my love and gratitude to my husband and family for their understanding, supports and endless love throughout my studies. 


\section{Table of contents}

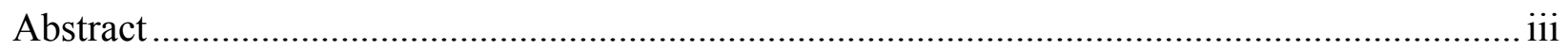

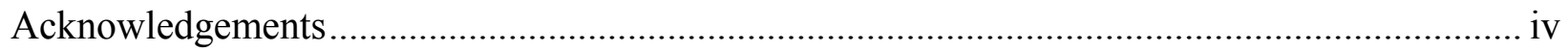

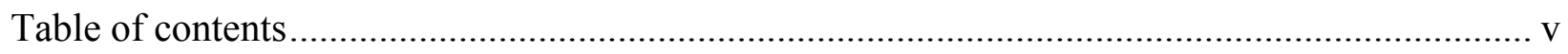

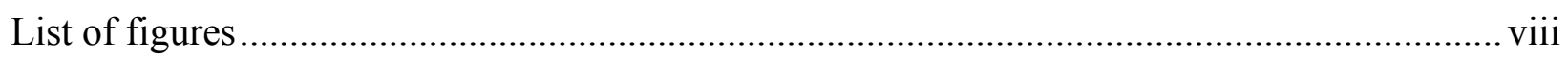

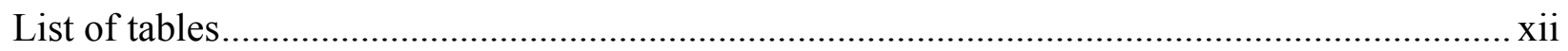

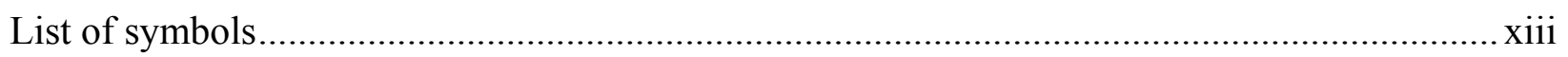

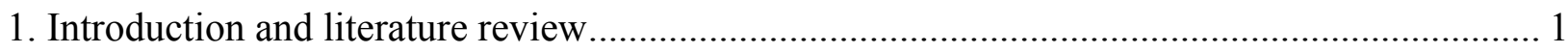

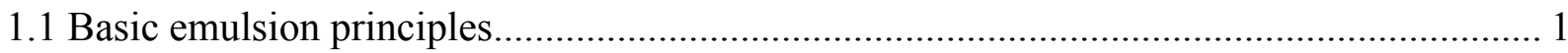

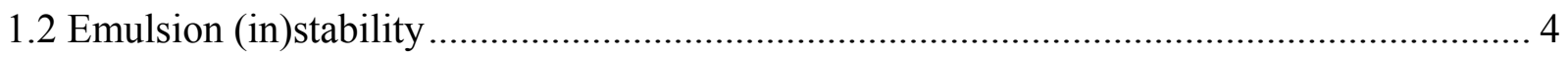

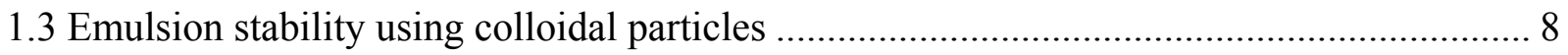

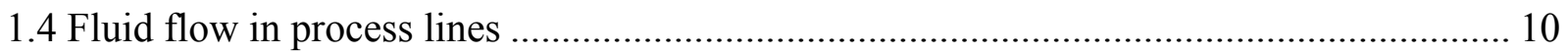

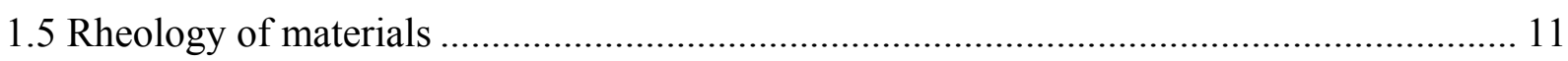

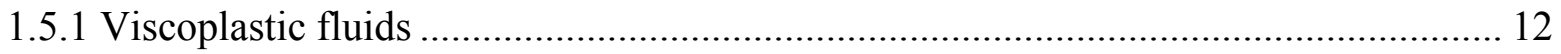

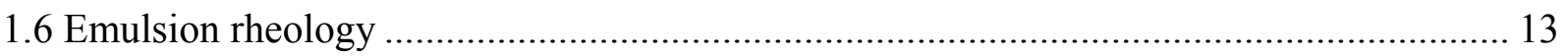

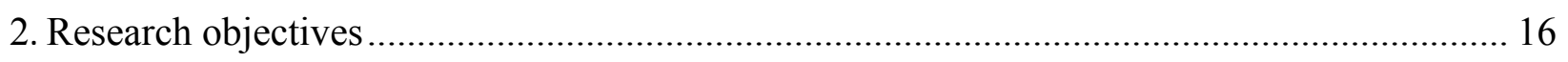

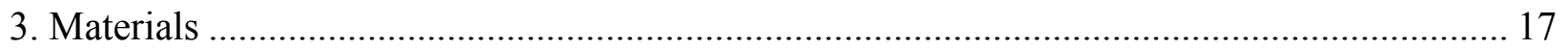

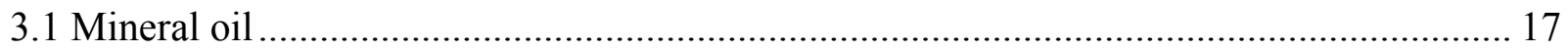

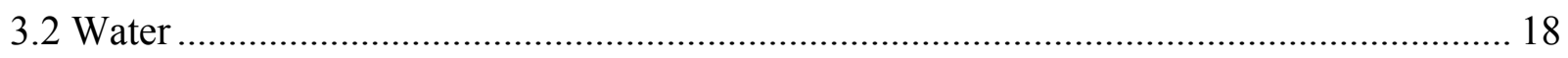

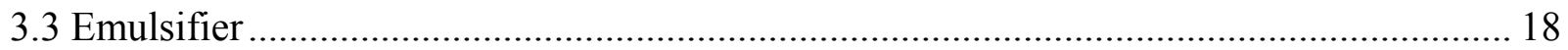

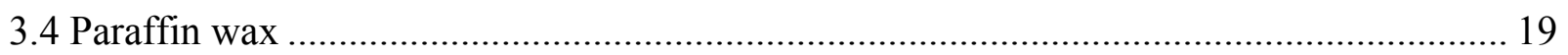

4. Flow behaviour of paraffin oil-wax mixtures in a lab-scale flowloop...................................... 21

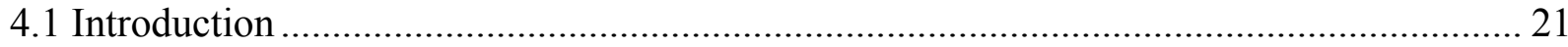

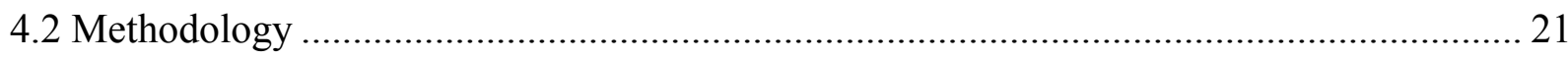

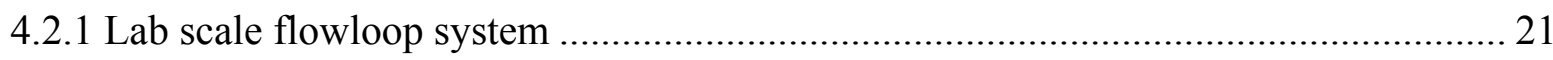

4.2.2 Determination of temperature and pressure drop across the flowloop ......................... 25

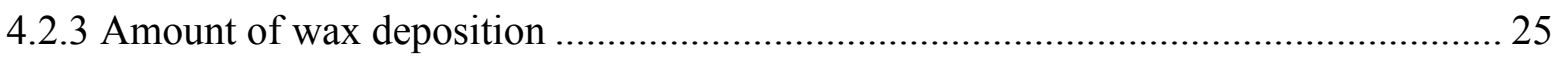

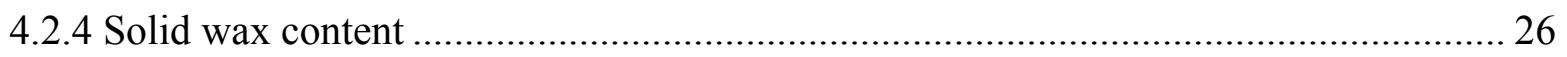

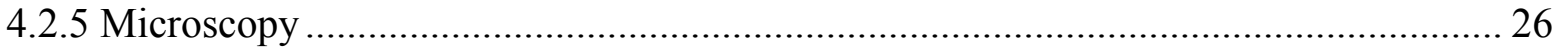

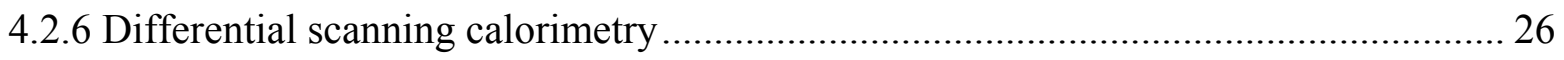

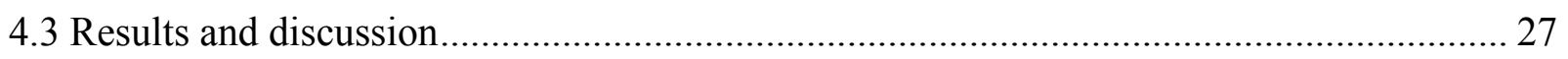




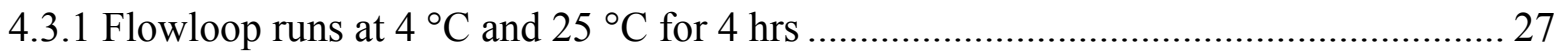

4.3.1.1 Pressure and temperature change during $4 \mathrm{hr}$ flowloop experiments .................. 27

4.3.1.2 Deposition on the flowloop wall................................................................... 29

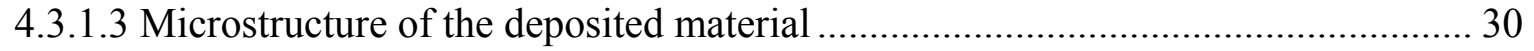

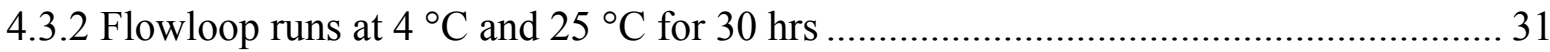

4.3.2.1 Pressure and temperature change during $30 \mathrm{hr}$ flowloop experiments ................ 31

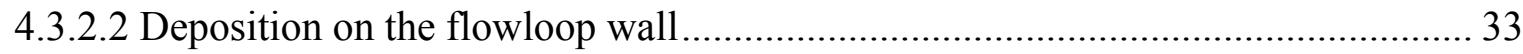

4.3.2.3 Microstructure of the deposited material ........................................................... 35

4.3.2.4 Wax content of samples collected during the $30 \mathrm{hr}$ flowloop runs..................... 37

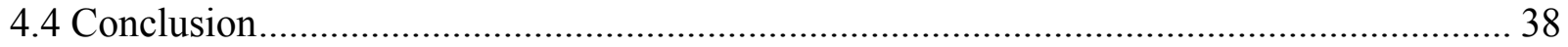

5. Impact of water cut and the role of continuous phase wax crystals on W/O emulsion rheology

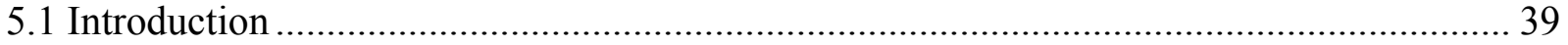

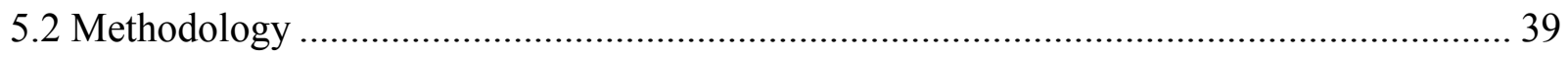

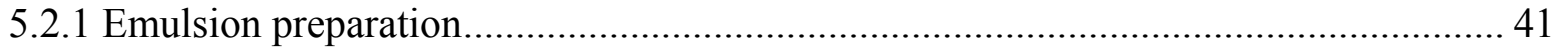

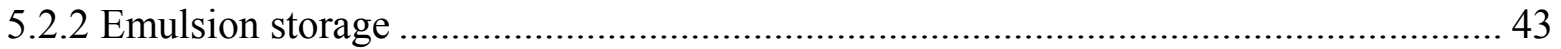

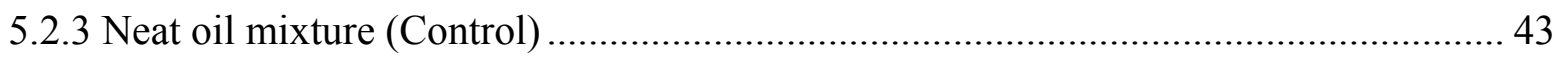

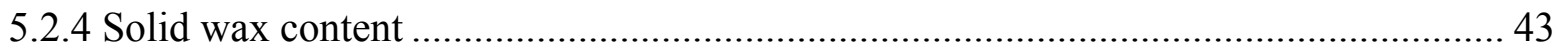

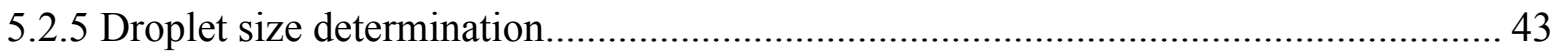

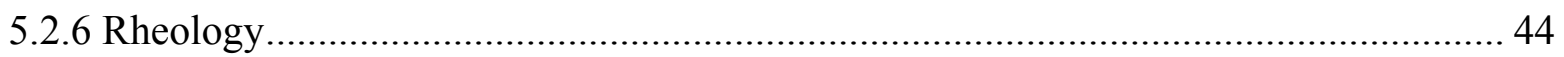

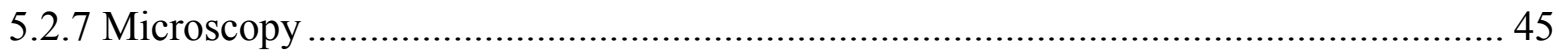

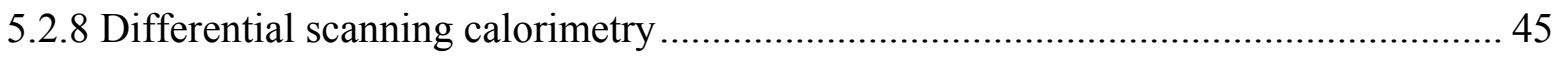

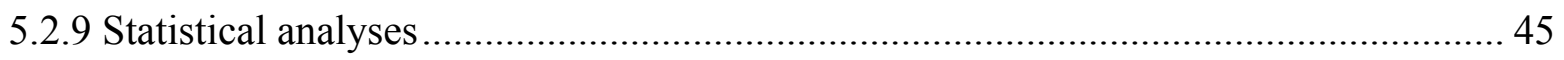

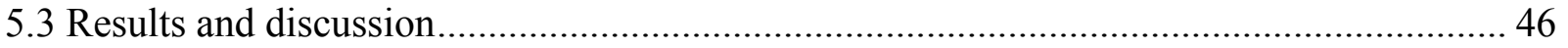

5.3.1 Water droplet size evolution with time for emulsions with different water cuts ........ 46

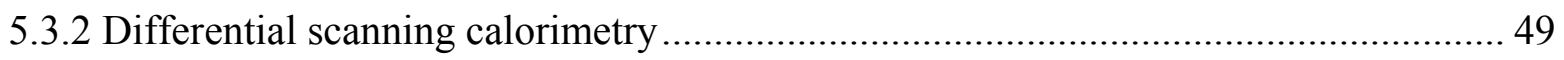

5.3.3 Wax content of emulsion and neat oil samples .................................................. 53

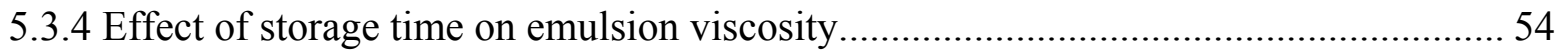

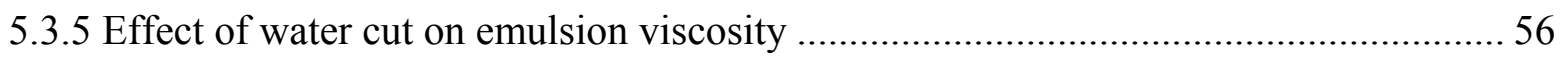

5.3.6 Comparison of emulsion and neat oil samples ................................................. 59

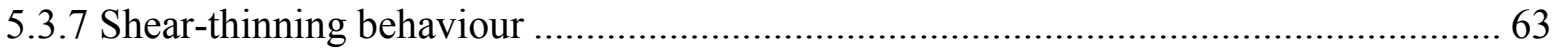




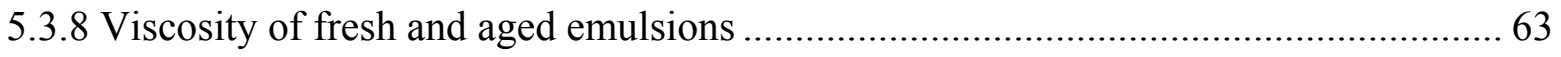

5.3.9 Effect of storage time on creep compliance and recovery....................................... 66

5.3.10 Effect of water cut on creep compliance and recovery ........................................ 69

5.3.11 Viscoelastic properties of emulsion samples................................................ 71

5.3.12 Contribution of SWC, water cut and surfactant (GMO) on emulsion viscosity......... 76

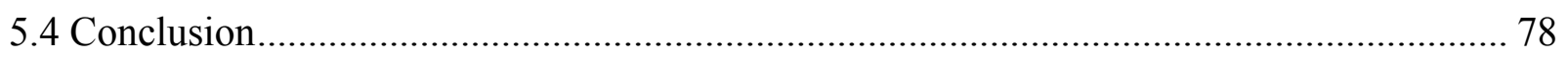

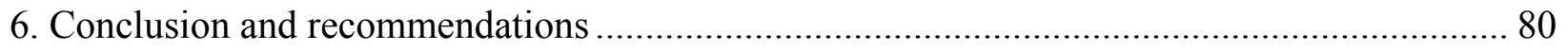

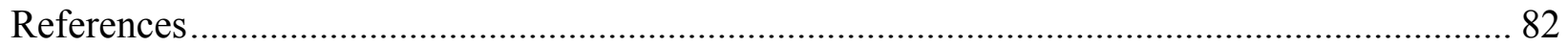




\section{List of figures}

Figure 1: A water-in-oil emulsion stabilized by paraffin wax crystals................................... 3

Figure 2: Mechanism of emulsion destabilization ......................................................... 5

Figure 3: Water-in-oil emulsions stabilized by crystals. A: Pickering stabilization, where crystal monolayers cover the dispersed phase and B: Network stabilization where a crystal network in the continuous phase prevents droplet movements

Figure 4: Molecular structure for glycerol monooleate (GMO) with chemical formula of $\mathrm{C}_{21} \mathrm{H}_{40} \mathrm{O}_{4}$. 18

Figure 5: DSC of paraffin wax showing its melting and crystallization temperatures. 19

Figure 6: Schematic diagram of the lab-scale flowloop system. 23

Figure 7: A PFD diagram of the lab-scale flowloop system.

Figure 8: Calibration curve obtained from enthalpies of crystallization of wax concentrations (520 wt \%) in oil-wax mixtures.

Figure 9: Change in pressure drop as a function of time across the flowloop for the neat oil passed at $25^{\circ} \mathrm{C}$ or $4^{\circ} \mathrm{C}$.

Figure 10: Change in loop outlet and sea-bed sink temperatures as a function of time for the neat oil at $25^{\circ} \mathrm{C}$ and $4^{\circ} \mathrm{C}$ seabed sink temperature.

Figure 11: Amount of deposition in the different loop sections after $4 \mathrm{hr}$ flowloop runs at $25^{\circ} \mathrm{C}$ and $4^{\circ} \mathrm{C}$.

Figure 12: DSC-measured wax content of deposited material in different loop sections after $4 \mathrm{hr}$ flowloop runs at $25^{\circ} \mathrm{C}$ and $4^{\circ} \mathrm{C}$. 30

Figure 13: Microstructure of deposited wax from the different flowloop sections after $4 \mathrm{hr}$ at $25^{\circ} \mathrm{C}$ and $4^{\circ} \mathrm{C}$.

Figure 14: Change in pressure drop as a function of time across the flowloop for $30 \mathrm{hr}$ runs at $25^{\circ} \mathrm{C}$ or $4^{\circ} \mathrm{C}$ 
Figure 15: Change in loop outlet and sea-bed sink temperatures as a function of time for $30 \mathrm{hr}$ runs at $25^{\circ} \mathrm{C}$ and $4^{\circ} \mathrm{C}$.

Figure 16: Loop section pictures at the end of the $30 \mathrm{hr}$ flowloop runs at $25^{\circ} \mathrm{C}$ and $4{ }^{\circ} \mathrm{C}$. 34

Figure 17: Amount of wax deposition in different loop sections after $30 \mathrm{hr}$ flowloop runs at $25^{\circ} \mathrm{C}$ and $4^{\circ} \mathrm{C}$

Figure 18: DSC-measured wax content of the deposited wax in the different loop sections after $30 \mathrm{hr}$ runs at $25^{\circ} \mathrm{C}$ and $4^{\circ} \mathrm{C}$......

Figure 19: Evolution in amount of wax deposition (A) and wax content of the deposition (B) in different loop sections as a function of time. 35

Figure 20: Microstructure of deposited wax from different flowloop sections at $25^{\circ} \mathrm{C}$ and $4^{\circ} \mathrm{C} . .37$

Figure 21: Wax content of samples collected during flowloop runs. All samples were stored at $4^{\circ} \mathrm{C}$ for $24 \mathrm{hr}$ before measuring SWC with NMR.

Figure 22: Summary of emulsion preparation.

Figure 23: Image of the valve homogenizer used to prepare the $\mathrm{W} / \mathrm{O}$ emulsions with different water cuts.

Figure 24: Example of a Petri dish containing an emulsion sample.

Figure 25: Microstructure of a 10\% W/O emulsion..

Figure 26: Droplet size distribution of the $20-50 \mathrm{wt} \% \mathrm{~W} / \mathrm{O}$ emulsions; A: $2.5^{\text {th }}$ percentile droplet size; B: $50^{\text {th }}$ percentile droplet size and C: $97.5^{\text {th }}$ percentile droplet size. 48

Figure 27: Droplet size distribution of the $60 \mathrm{wt} \% \mathrm{~W} / \mathrm{O}$ emulsion with time. 48

Figure 28: Microstructure of the 10-50wt $\% \mathrm{~W} / \mathrm{O}$ emulsions on day 28.

Figure 29: Free water content of the $20-50 \mathrm{wt} \% \mathrm{~W} / \mathrm{O}$ emulsions.

Figure 30: DSC thermograms of a temperature-cycled wax-stabilized $20 \mathrm{wt} \% \mathrm{~W} / \mathrm{O}$ emulsion. Samples were cooled from $4^{\circ} \mathrm{C}$ to $-70^{\circ} \mathrm{C}$ and heated to $70^{\circ} \mathrm{C}$ followed by a second cooling cycle 
to $-70^{\circ} \mathrm{C}$ at a rate of $2^{\circ} \mathrm{C} / \mathrm{min}$. The inset shows a magnified view of the wax crystallization and melting region.

Figure 31: DSC thermograms of pure DI water (A) and $3.5 \% \mathrm{NaCl}$ water solution (B). Heating and cooling rate was $0.5^{\circ} \mathrm{C} /$ minutes.

Figure 32: Temperature dependence of wax-stabilized emulsion sedimentation: (A) cooled to $4^{\circ} \mathrm{C}$ with stirring under quench-cooling, (B) held at $70^{\circ} \mathrm{C}$ for $24 \mathrm{hrs}$.

Figure 33: The thermogram of a $20 \% \mathrm{~W} / \mathrm{O}$ emulsion, showing the stability of emulsion from day 0 to day 21 . The peak at $-41^{\circ} \mathrm{C}$ represents droplet crystallization in the emulsion. All emulsions demonstrated this crystallization behaviour. 52

Figure 34: Temperature-cycled thermograms of a $60 \mathrm{wt} \% \mathrm{~W} / \mathrm{O}$ emulsion. The large peaks in the first and second cooling curves represent bulk water. 53

Figure 35: Wax content of emulsions with different water cuts. All the samples were stored at $4^{\circ} \mathrm{C}$ before measuring the $\%$ SWC using pulsed NMR. 54

Figure 36: Solid wax content of neat oil samples. 54

Figure 37: Viscosity of wax-stabilized emulsions as a function of shear rate and storage time (in days). A to $\mathrm{E}: 10 \mathrm{wt} \%$ to $50 \mathrm{wt} \% \mathrm{~W} / \mathrm{O}$ emulsions. 56

Figure 38: Viscosity of wax-stabilized emulsions as a function of shear rate, water cut and storage time (in days). A to F: day 0 to day 28 . 58

Figure 39: Herschel-Bulkley yield stress of model W/O emulsions as a function of water cut, at $10^{\circ} \mathrm{C}$ and Day 0 . 59

Figure 40: Herschel-Bulkley yield stress of W/O emulsions with different water cuts and at different time points.

Figure 41: Comparison of flow curves for neat oil ( $5 \mathrm{wt} \%$ paraffin wax and $0.05 \mathrm{wt} \% \mathrm{GMO}$ in light mineral oil) and the corresponding $20 \mathrm{wt} \% \mathrm{~W} / \mathrm{O}$ emulsion.

Figure 42: Comparison of flow curves for neat oil ( $5 \mathrm{wt} \%$ paraffin wax and $0.125 \mathrm{wt} \% \mathrm{GMO}$ in light mineral oil) and the corresponding $50 \mathrm{wt} \% \mathrm{~W} / \mathrm{O}$ emulsion. 62 
Figure 43: Flow curve of 10-50 wt $\% \mathrm{~W} / \mathrm{O}$ emulsions [A] and neat oil samples [B] on day 0 (Shear stress versus shear rate).

Figure 44: Microstructure of a freshly-made 20\% W/O emulsion before and after the application of shear at $1000 \mathrm{~s}^{-1}$. 65

Figure 45: Microstructure of an aged 20\% W/O emulsion (day 28) before and after the application of shear at $1000 \mathrm{~s}^{-1}$. 66

Figure 46: Typical creep and compliance recovery curve with various material functions. 67

Figure 47: Creep compliance and recovery of wax-stabilized emulsions as a function storage time (in days). A to $\mathrm{E}: 10 \% \mathrm{~W} / \mathrm{O}$ emulsions to $50 \% \mathrm{~W} / \mathrm{O}$ emulsions.

Figure 48: Creep compliance and recovery of wax-stabilized emulsions as a function of water cut and storage time (in days). A to F: day 0 to day 28. 71

Figure 49: Yield point or flow point of all the water cut emulsions. 72

Figure 50: Storage and loss modulus of a 10\% W/O emulsion on days $0,2,14$ and 28. 72

Figure 51: Storage and loss modulus of a 20\% W/O emulsion on days 0, 2, 14 and 28 73

Figure 52: Storage and loss modulus of a $30 \% \mathrm{~W} / \mathrm{O}$ emulsion on days $0,2,14$ and 28 73

Figure 53: Storage and loss modulus of a 40\% W/O emulsion on days $0,2,14$ and 28 74

Figure 54: Storage and loss modulus of a 50\% W/O emulsion on days 0, 2, 14 and 28. 74

Figure 55: Damping factor as a function of strain for $10-50 \% \mathrm{~W} / \mathrm{O}$ emulsions on days 0 and 28.

Figure 56: A: Emulsion viscosity as a function of water cut over a one month period. B-F: Emulsion viscosity as a function of SWC over a one month period. 78 


\section{List of tables}

Table 1 : Specifications for the light mineral oil used in this research........................................ 17

Table 2: Compositions, ${ }^{\circ} \mathrm{API}$ and molecular weight of light mineral oil used throughout this

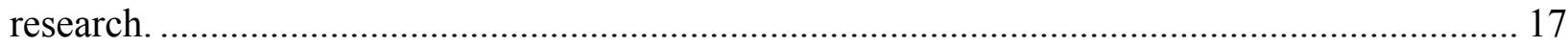

Table 3: Physical properties of the paraffin wax used throughout this study ............................... 20

Table 4: Flowloop operating conditions for the $25^{\circ} \mathrm{C}$ and $4{ }^{\circ} \mathrm{C}$ runs ........................................... 22

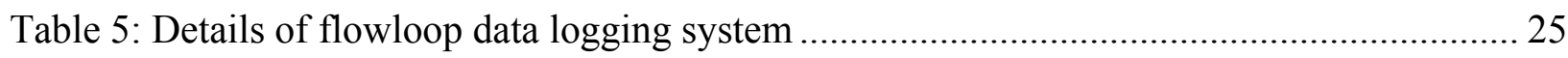

Table 6: Emulsion composition for all water cuts, assuming a $100 \mathrm{~g}$ mass. ................................ 40 


\section{List of symbols}

\begin{tabular}{|c|c|}
\hline $\mathrm{g}$ & Acceleration due to gravity $\left[\mathrm{m} / \mathrm{s}^{2}\right]$ \\
\hline $\mathrm{N}_{\mathrm{A}}$ & Avagadro's number $=6.0221 \times 10^{23}\left[\mathrm{~mol}^{-1}\right]$ \\
\hline $\mathrm{T}_{\text {in }}$ & Average flowloop inlet temperature $\left[{ }^{\circ} \mathrm{C}\right]$ \\
\hline $\mathrm{T}_{\text {out }}$ & Average flowloop outlet temperature $\left[{ }^{\circ} \mathrm{C}\right]$ \\
\hline$\tau_{0}^{\mathrm{B}}$ & Bingham shear stress $[\mathrm{Pa}]$ \\
\hline$\tau_{0}^{\mathrm{C}}$ & Casson shear stress $[\mathrm{Pa}]$ \\
\hline $\mathrm{E}_{\mathrm{c}}$ & Collision efficiency \\
\hline $\mathrm{K}$ & Consistency factor $\left[\mathrm{Pa} . \mathrm{s}^{\mathrm{n}}\right]$ \\
\hline $\mathrm{v}$ & Creaming speed $[\mathrm{m} / \mathrm{s}]$ \\
\hline $\mathrm{J}_{\mathrm{c}}$ & Creep compliance $[1 / \mathrm{Pa}]$ \\
\hline $\mathrm{J}_{\mathrm{r}}$ & Creep recovery $[1 / \mathrm{Pa}]$ \\
\hline$\rho$ & Density $\left[\mathrm{kg} / \mathrm{m}^{3}\right]$ \\
\hline $\mathrm{r}$ & Droplet radius $[\mu \mathrm{m}]$ \\
\hline $\mathrm{k}_{1}$ & Einstein's coefficient \\
\hline $\mathrm{F}_{\mathrm{f}}$ & Frictional force $[\mathrm{N}]$ \\
\hline$\sigma$ & Geometric standard deviation [Dimensionless] \\
\hline$F_{g}$ & Gravitational force $[\mathrm{N}]$ \\
\hline$\tau_{0}^{\mathrm{HB}}$ & Herschel-Bulkley yield stress [Pa] \\
\hline $\mathrm{k}_{2}, \mathrm{k}_{3}$ & Hydrodynamic interaction coefficient between droplets \\
\hline ID & Internal diameter $[\mathrm{mm}]$ \\
\hline $\mathrm{G}^{\prime \prime}$ & Loss modulus $[\mathrm{Pa}]$ \\
\hline $\mathrm{n}$ & Molar concentration of the surfactant $\left[\mathrm{mol} / \mathrm{m}^{3}\right]$ \\
\hline MW & Molecular weight $[\mathrm{g} / \mathrm{mol}]$ \\
\hline $\mathrm{r}_{00}$ & Number-weighted mean droplet radius $[\mu \mathrm{m}]$ \\
\hline$\eta_{\mathrm{r}}$ & Relative viscosity $[\mathrm{Pa} \cdot \mathrm{s}]$ \\
\hline $\mathrm{n}$ & Shear rate index [Dimensionless] \\
\hline$\eta_{1}$ & Shear viscosity $[\mathrm{Pa} \cdot \mathrm{s}]$ \\
\hline$\% \mathrm{SWC}$ & Solid wax content $[\%]$ \\
\hline $\mathrm{J}_{\mathrm{s}}$ & Steady state compliance $[1 / \mathrm{Pa}]$ \\
\hline $\mathrm{G}^{\prime}$ & Storage modulus $[\mathrm{Pa}]$ \\
\hline$\gamma$ & Strain or deformation [\%] \\
\hline$a_{s}$ & Surface area $\left[\mu \mathrm{m}^{2}\right]$ \\
\hline t & Time $[\mathrm{s}]$ \\
\hline$\eta$ & Viscosity $[\mathrm{Pa} \cdot \mathrm{s}]$ \\
\hline$\varphi$ & Volume fraction of the dispersed phase [ $\mathrm{Vol} \%]$ \\
\hline$d_{3,3}$ & Volume-weighted geometric mean diameter $[\mu \mathrm{m}]$ \\
\hline$\tau_{\mathrm{y}}$ & Yield stress $[\mathrm{Pa}]$ \\
\hline
\end{tabular}




\section{Introduction and literature review}

\subsection{Basic emulsion principles}

An emulsion consists of two immiscible liquids where one is dispersed as micron-sized droplets within the other (McClements 1999). Numerous food products depend on the presence of emulsions, either for their final properties (e.g. texture, taste, structure, etc.) or during their processing. Emulsions are also extensively used in other industries such as the petroleum, cosmetics and pharmaceuticals industries (Friberg 1997).In an emulsion, the droplets are referred to as the dispersed phase whereas the surrounding liquid is referred to the continuous phase. Where oil droplets are dispersed in an aqueous phase (e.g., milk, mayonnaise, and soups), an oilin-water $(\mathrm{O} / \mathrm{W})$ emulsion results. In the case of water droplets dispersed within an oil phase, the system is called a water-in-oil (W/O) emulsion (e.g., butter, margarine and spreads). More complex emulsions can also exist, such as multiple emulsions of the oil-in-water-in-oil (O/W/O) and water-in-oil-in-water $(\mathrm{W} / \mathrm{O} / \mathrm{W})$ types (McClements 2004). In a W/O/W emulsion, water droplets are dispersed in larger oil droplets, which are themselves dispersed in an aqueous continuous phase. With $\mathrm{O} / \mathrm{W} / \mathrm{O}$ emulsions, oil droplets are dispersed in larger water droplets which are themselves dispersed in a continuous oil phase. W/O/W emulsions are more commonly used than $\mathrm{O} / \mathrm{W} / \mathrm{O}$ and many have been developed for use in food, pharmaceutical and cosmetic applications. Some of their primary functions in foods are in the controlled release of special ingredients, in isolating one ingredient from another, and in reducing the total fat content of a product.

Emulsifiers are used in the preparation of emulsions. They are amphiphilic molecules that have both polar and non-polar regions on the same molecule (McClements 2004). During emulsion formation, their amphiphilicity (i.e., surface activity) promotes absorption onto the surface of newly-formed droplets during homogenization, thereby creating interfacial membranes that help prevent droplet-droplet aggregation. Such adsorption lowers the interfacial tension between the oil and water phases thus making it easier for the droplets to be broken up into smaller entities (Hunter, Pugh et al. 2008). Emulsifiers are also used to help prevent these newly-formed droplets from coalescing. Emulsifiers will dissolve in either the oil or water phase, depending on their composition and polarity (Dickinson 2010). If the dominant moiety (i.e., size, charge, etc.) is 
hydrophilic, then the emulsifier is more likely to dissolve in water whereas if the surfactant consists primarily of hydrocarbons, it will be oil-soluble (McClements 2004). As there exists diverse families of emulsifiers: small-surfactant molecules, polymers and/or surface-active thickening agents (Rousseau 2000), the selection process of an emulsifier for a particular application is very important as it will impact product formation, stability and functionality.

In the formation of a simple emulsion, an energy input in the form of mixing, shearing, etc. is required to disperse one phase into the other (McClements 1999; Rousseau 2000).However, given the inherent immiscibility between the oil and aqueous phases, these phases will attempt to minimize this energetically-unfavourable contact, usually by phase-separating into bulk water and oil (i.e., where droplets are no longer present) (McClements 1999).

To produce dispersed droplet with micron-sized droplets, high-pressure homogenization is commonly used (Innings 2011). Typically, a coarse emulsion ( 100-200 micron diameter droplets) will be prepared either with an impeller-type mixer or rotor/stator followed by passage through a valve homogenizer. With homogenizer pressures upwards of $40 \mathrm{MPa}$ possible, there is significant turbulence created that further breaks downs the coarse emulsion into a fine suspension, often with sub-micron droplets resulting. During homogenization, the emulsifier molecules surround the dispersed aqueous droplets, thereby stabilizing them. If not enough emulsifier is present, the droplets may re-coalescence. Several parameters such as homogenization pressure, the number of passes through the homogenizer and emulsifier concentration affect the size of the droplets formed. Valve homogenization is suitable for the production of emulsions using low and intermediate viscosity materials (e.g., dairy and food products, chemical products (detergents), cosmetics and pharmaceuticals (e.g., lotions and soaps).

As pertains to this thesis, it has also been shown that colloidal particles such as wax or fat crystals (Hodge and Rousseau 2005), silica (Binks, Clint et al. 2005), clay (Yan, Gray et al. 2001; Binks, Clint et al. 2005), iron oxide (Binks, Clint et al. 2005; Melle, Lask et al. 2005) and polymer lattices (Binks, Clint et al. 2005; Binks and Rodrigues 2005) can provide kinetic stability to the dispersed phase of many oil-continuous emulsions via either the presence of a particle network and/or interfacially-adsorbed colloids (Binks 2002; Binks and Rocher 2009; Macierzanka, Szelag et al. 2009). If solid particles are directly adsorbed to the droplet surface, 
they are known as 'Pickering' crystals and create a steric barrier between adjacent water droplets thereby hindering droplet collisions, film drainage and coalescence (Pickering 1907; Tambe and Sharma 1994). This topic was first studied by Ramsden in 1903 but not noticed by others (Horozov 2006). In 1907, S.U. Pickering published his work on this subject, which to this day bears his name (Pickering 1907; Horozov 2006). Much more recently, it was discovered that a Pickering particle's free energy of adsorption to an interface was very high compared to emulsifier molecules and therefore, could become irreversibly adsorbed (Levine, Bowen et al. 1989; Binks, Clint et al. 2005). Thus, as opposed to emulsifiers, such particles do not necessarily affect emulsion stability by reducing the oil-water interfacial tension (Vignati, Piazza et al. 2003; Hunter, Pugh et al. 2008). Figure 1 shows the typical make-up of a W/O emulsion stabilized by continuous phase crystals. In this polarized light image, dispersed water droplets are present in a continuous oil phase, with wax crystals present in the continuous phase and/or adsorbed to the droplet surface.

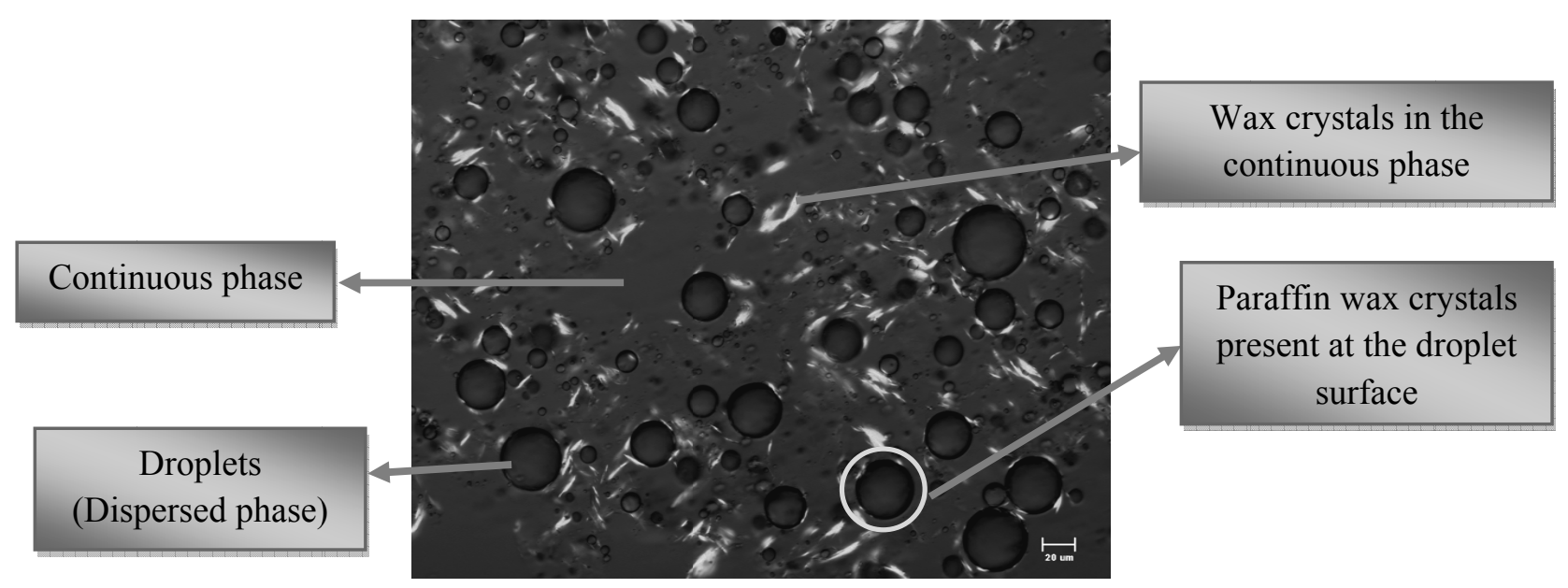

Figure 1: A water-in-oil emulsion stabilized by paraffin wax crystals. The scale bar represents 20 $\mu \mathrm{m}$.

Colloidal particles such as wax crystals can originate via direct solidification at the droplet interface or the migration of previously-formed crystals toward the interface (Friberg 1997). Colloidal particles can either stabilize or destabilize emulsion droplets, depending on whether they are in the dispersed or continuous phase (Johansson, Bergenstahl et al. 1995; Rousseau 2000). When present in the continuous phase, wax crystals will usually act as emulsion stabilizers (Rousseau 2000). However, if present in the dispersed phase, such crystals may protrude through the interface, leading to partial or complete droplet coalescence (Rousseau 
2000; Li, Liu et al. 2009). Key factors influencing the role of crystals on emulsion stabilization include the wettability of crystals at the interface (Friberg 1997; Rousseau 2000), crystal location - either in the dispersed or continuous phase (Darling 1982; Rousseau 2000), crystal detachment energy (Hunter, Pugh et al. 2008), interfacial film rheology (Lucassen - Reynders and Van den Tempel 1963; Rousseau 2000), and finally the maximum capillary pressure leading to dropletdroplet coalescence (Hunter, Pugh et al. 2008).

\subsection{Emulsion (in)stability}

Emulsions are inherently thermodynamically unstable systems as when mixed, the oil and the aqueous phases continually strive to minimize contact (Rousseau 2000). Therefore, providing enough time, an emulsion will collapse as the two phases decrease their interfacial area via gradual phase separation. Common mechanisms of emulsion destabilization include gravitational separation (creaming/sedimentation), flocculation, coalescence, partial coalescence, and Ostwald ripening (Figure 2) (Dickinson 1992; Walstra 1996; McClements 1999; Rousseau 2000; Walstra 2003). Gravitational separation or settling occurs due to the fact that the oil and aqueous phases of an emulsion usually have different densities (Dickinson 1992; M.M. Robins et al 1998; Rousseau 2000; Walstra 2003). In gravitational separation, when the droplets have a lower density than the surrounding liquid, they have the tendency to rise - this is known as creaming. Alternatively, when the droplets have a higher density compared to the continuous phase, they move downwards (settle), and this phenomenon is called sedimentation. Separation of emulsion phases is highly noticeable with regards to appearance (visible phase separation), texture (the droplet-rich area may be significantly more viscous), and finally taste (if the emulsion is to be consumed) (McClements 1999). The sedimentation stability of crystal-containing emulsions was studied by Hodge and Rousseau (Hodge and Rousseau 2005), who examined water-in-canola oil emulsions prepared with $0-2 \mathrm{wt} \%$ solid fat (hydrogenated canola stearine or hydrogenated cottonseed stearine) added to the continuous phase. Pre-crystallized fat (where fat was added prior to emulsification) or post-crystallized fat (fat quench-crystallized in situ following emulsification) were added to the emulsions in order to improve emulsion stability. Postcrystallized emulsions were stable against sedimentation while pre-crystallized fat had very little effect on emulsion sedimentation at levels as high as $2 \mathrm{wt} \%$ (Hodge and Rousseau 2005). The authors concluded that fast crystallization of the solid fat favoured the creation of a network of fine solid fat crystals evenly distributed through the continuous phase. Thus, given enough inter- 
particle bonds, a continuous phase crystal network provided a framework or structure to restrict the movement of water droplets and reduce sedimentation, flocculation and coalescence (Hodge and Rousseau 2005). Additionally, fat crystallization influences creaming rate in $\mathrm{O} / \mathrm{W}$ emulsions. For example, at a solid fat content (SFC) of about $30 \%$, an oil droplet has a similar density as water; therefore, neither creaming nor sedimentation will occur. When SFCs are $<30 \%$ droplets will cream whereas at SFCs $>30 \%$, droplets sediment (McClements 1999). Dickinson stated that when inter-particle interactions were net attractive and the particle concentration sufficient to form a gel-like network with a finite yield stress, sedimentation and flocculation in emulsions could be completely inhibited (Dickinson 2011). Finally, the range of droplet sizes existing in emulsions will impact gravitational separation, with larger droplets tending to cream more rapidly compared to smaller droplets (McClements 2004). This is further explored in Equation 3.

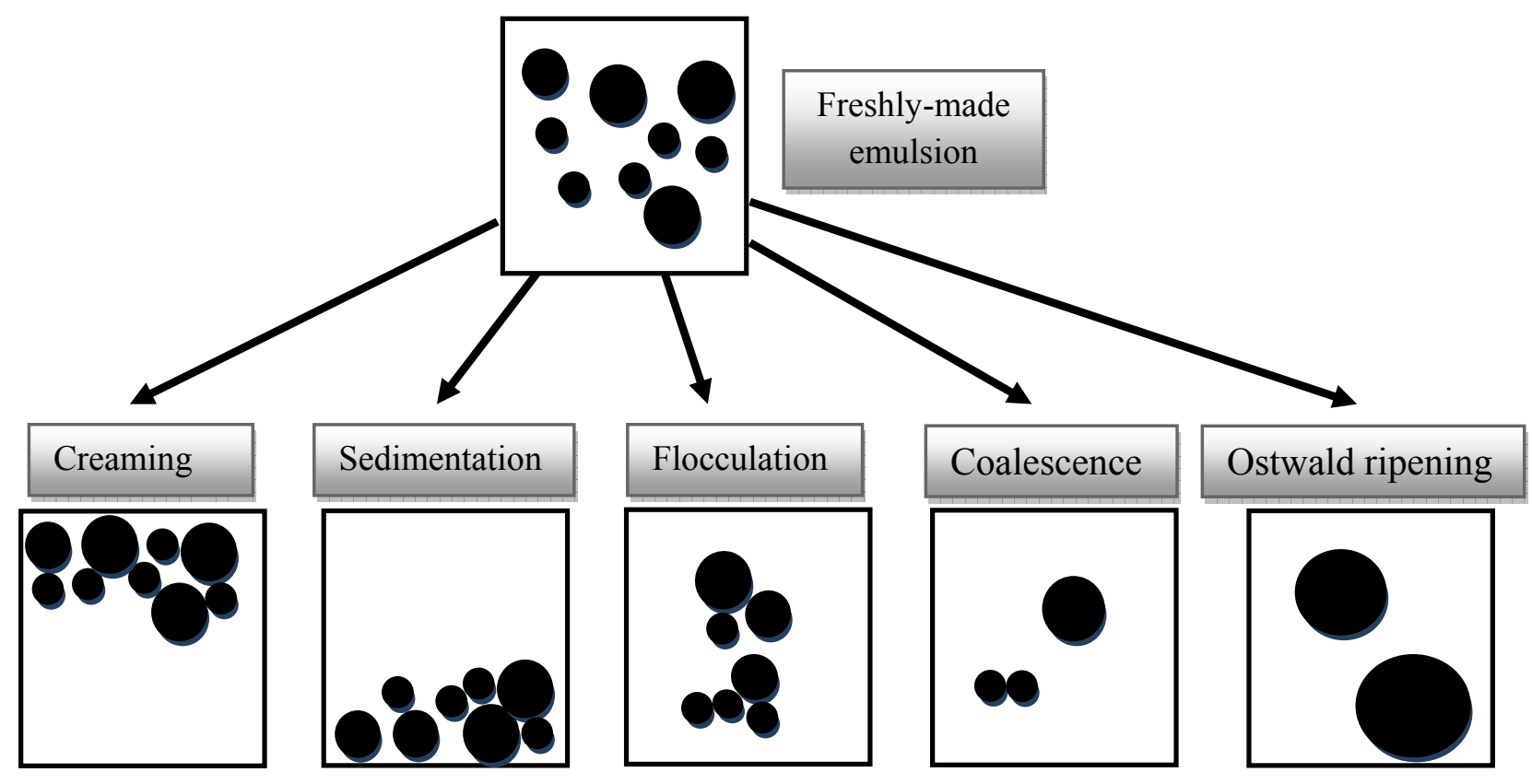

Figure 2: Mechanism of emulsion destabilization

Droplets within an emulsion will experience gravitational and frictional forces acting upon them, with the rate at which droplets cream/settle depending upon the net addition of these forces (Becher 1985). Droplets will rise if its density is less than that of the surrounding liquid, as given by:

$F_{g}=-\frac{4}{3} \pi r^{3}\left(\rho_{2}-\rho_{1}\right) g$

Equation 1 
where $r$ is the radius of the droplet, $g$ is the acceleration due to gravity, $\rho_{1}$ is the density of the continuous phase and $\rho_{2}$ is the density of the dispersed phase. The hydrodynamic frictional force acting upon a droplet as it moves upwards through the system in the opposite direction is described as follows:

$F_{f}=6 \pi \eta_{1} r v$

Equation 2

where $\eta_{1}$ is the shear viscosity and $v$ is the creaming speed. The downward frictional force will be equal the upward gravitational force when a constant velocity is achieved, giving $\mathrm{F}_{g}=\mathrm{F}_{f}$. Solving for $v$, Stokes' equation results, which defines the creaming rate of an isolated droplet with a liquid medium:

$v_{\text {Stokes }}=-\frac{2 g r^{2}\left(\rho_{2}-\rho_{1}\right)}{9 \eta_{1}}$

Equation 3

This equation is relevant to both creaming and sedimentation and the sign of $v$ indicates whether the droplet creams [moves upwards $(+)$ ] or sediments [downwards (-)].

There are some limitations to this equation as several assumptions were made in its derivation, namely: i) the concentration of the droplets in the emulsion is assumed to be low; ii) the droplets are assumed to have a uniform size distribution, as larger droplets tend to cream at a faster rate than smaller droplets, and iii) this equation does not take into account the effect that Brownian motion has on the creaming velocity of droplets within an emulsion (Becher 1965; McClements 2004).

Creaming and sedimentation may also increase the rates of flocculation and coalescence. After some time, in an $\mathrm{O} / \mathrm{W}$ emulsion, a layer of oil may form near the top of the emulsion, which is known as oiling off (McClements 2004). In W/O emulsions, this results in the accumulation of water at the bottom of the emulsion (McClements 2004).

Flocculation is the reversible aggregation of droplets as a result of weak attractive forces between them (Rousseau 2000; McClements 2004). During this process, droplets retain their individual integrity as the film separating two droplets is not ruptured (McClements 2004). As a function of inter-particle distance, flocculation depends on the interaction energy between two 
particles which is due to their mutual attractive and repulsive forces. In emulsions, repulsion occurs given the presence of emulsifiers at the interface whereas attraction is due to London-van der Waals forces (Becher 1965; Rousseau 2000; McClements 2004).

Coalescence occurs when the thin film separating two flocculated droplets breaks resulting in the formation of a single larger droplet (Rousseau 2000; Fredrick, Walstra et al. 2010). Film rupture occurs more readily if the droplets are large, the film is thin, and the oil-water interfacial tension is high (Fredrick, Walstra et al. 2010). However, in crystal-containing emulsions, Norton et al (Norton, Spyropoulos et al. 2009) explained that when crystals are present at the oil-water interface, the rigidity of the droplet interface significantly increased, resulting in a reduced tendency for droplets to deform upon droplet-droplet contact, thereby significantly retarding coalescence (Norton, Spyropoulos et al. 2009).

There are several circumstances that may induce coalescence in an emulsion. Due to Brownian motion, emulsion droplets are in continual motion, and the rate at which coalescence occurs depends on their collision frequency and efficiency (Zinchenko, Rother et al. 2011). Efficiency in this case depends upon whether or not the interfacial membranes surrounding the droplets rupture or not upon colliding. When an emulsifier is not present, the collision efficiency approaches its highest value $\left(\mathrm{E}_{\mathrm{c}} \rightarrow 1\right)$ as there is nothing present to prevent the droplets from merging. In the presence of an emulsifier, however, the collision frequency is much less $\left(\mathrm{E}_{c} \rightarrow 0\right)$ due to short-range repulsive forces between the droplets or the reduced likelihood of the membrane being ruptured (Zinchenko, Rother et al. 2011).

Coalescence may occur in emulsions that have a high concentration of droplets or in emulsions in which creaming, sedimentation or flocculation have occurred. In this case, it is more convenient to describe the rate of coalescence by defining the coalescence time, which is the time required for the droplets to remain in contact before coalescence actually occurs. This is usually given as an average value since all of the droplets in an emulsion do not generally coalesce at the same time (Dickinson 2010).

Coalescence is called partial when there is a network of colloidal crystals within the dispersed droplets that allows the original shape of the droplets to be retained while aggregated (Rousseau 2000). This phenomenon has been studied to a much greater extent in $\mathrm{O} / \mathrm{W}$ than $\mathrm{W} / \mathrm{O}$ emulsions, 
as it is a commonly-used phenomenon in food processing (e.g., during butter churning or preparation of ice cream). If the temperature of the emulsion is high enough to prevent crystallization, partial coalescence will not occur. For partial coalescence to occur, it is necessary to have partially crystallized material within the droplets (Dickinson 2010).

Finally, Ostwald Ripening is a process of growth of large droplets at the expense of smaller ones as a result of mass transport of dispersed phase material from one droplet to another through the continuous phase (Kabalnov and Shchukin 1992; Taylor 1995; Rousseau 2000; McClements 2004). This phenomenon is rather rare in most industrially-relevant emulsions as the mutual inter

solubility of oils and water typically used is very low, thus the mass transport rate is insignificant (McClements 2004).

As discussed in this thesis, there are numerous factors that will impact emulsion stability, including homogenization conditions, dispersed and continuous phase composition (e.g., volume fraction, emulsion type and concentration) and environmental conditions (e.g., storage temperature) (McClements, Dungan et al. 1993; Awad and Sato 2002).

\subsection{Emulsion stability using colloidal particles}

As pertains to this thesis, it has been shown that colloidal particles such as wax and fat crystals (Hodge and Rousseau 2005), silica (Binks, Clint et al. 2005), clay (Yan, Gray et al. 2001; Binks, Clint et al. 2005), iron oxide (Binks, Clint et al. 2005; Melle, Lask et al. 2005) and polymer lattices (Binks, Clint et al. 2005; Binks and Rodrigues 2005)can provide kinetic stability to the dispersed phase of many oil-continuous emulsions via the presence of a particle network and/or interfacially-adsorbed colloids (Binks 2002; Binks and Rocher 2009; Macierzanka, Szelag et al. 2009). If solid particles are directly adsorbed to the droplet surface, they are known as 'Pickering' crystals and create a steric barrier between adjacent water droplets thereby hindering droplet collisions, film drainage and coalescence (Figure 3A) (Pickering 1907; Tambe and Sharma 1994). They can also contribute to the mechanical rigidity and viscosity of the emulsion if a tightly-packed network structure is created in the continuous phase and there are strong particle-particle interactions that prevent droplet movement. The key factors that determine the influence of solid particles on emulsion stabilization are particle size and location, microstructure, interfacial film rheology and wettability (Rousseau, 2000). Emulsion stability will increase with decreasing crystal size and an increase in their concentration (McClements 
2004; Hunter, Pugh et al. 2008). Solid particles should be at least 10 times smaller than the size of the droplet in order to be an effective stabilizer (McClements 2004; Hunter, Pugh et al. 2008).

Emulsion stability may also be enhanced by the presence of a continuous phase crystal network that prevents droplet movement (Figure 3B). Though the formation of a dispersed wax crystal network plays a vital role in the stabilization of product such as crude oil emulsions (Paso, Senra et al. 2005), there remains insufficient knowledge of wax network formation and its role in crude oil emulsion stability. In related work, Miskandar et al. (Miskandar, Man et al. 2004) worked on tablespreads such as butter and margarine (which are W/O emulsions) showed that their flow behaviour during key unit operations (e.g., transport, packaging, etc.) was considerably affected by crystalline fat content (Miskandar, Man et al. 2004). They showed that a slower in-pipe flow rates induced more rapid crystallization in butter, and hence led to an increase in butter's yield stress. It was proposed that its yield stress and viscoelastic behaviour were due to its 3D fat crystal network (held together by van der Waals forces) and its close association with the continuous oil and aqueous phases (Wright, Scanlon et al. 2001). Applying a force greater than the yield stress of butter would cause instantaneous breakdown of the crystalline network followed by a gradual decrease in viscosity with applied shear. Though at different solids contents and in a completely different system, fundamentally this type of behaviour may be quite similar to that of crude oil in the presence of a wax crystalline network, and may be used to gain further insight on its low-temperature flow behaviour.
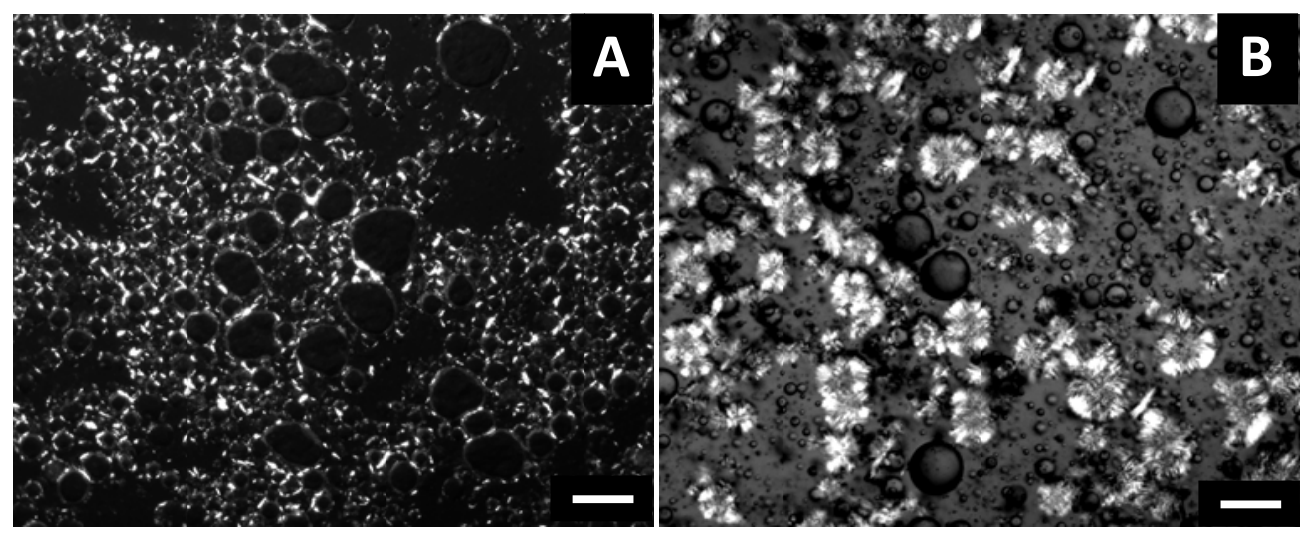

Figure 3: Water-in-oil emulsions stabilized by crystals. A: Pickering stabilization, where crystal monolayers cover the dispersed phase and B: Network stabilization where a crystal network in the continuous phase prevents droplet movements. The scale bar represents $40 \mu \mathrm{m}$. (Ghosh, Tran et al. 2011) 


\subsection{Fluid flow in process lines}

In many chemical, pharmaceutical, food and petroleum manufacturing processes, the various unit operations encountered will be linked through connecting pipes. As well, unit operations may consist of pipes themselves (e.g., heat exchangers). A common problem occurring during the transport of fluids in pipes is the accumulation of organic or inorganic substances on the pipe's internal surface. Continued fouling or deposition may lead to a reduction in the pipe's internal diameter resulting in a pressure drop, which may cause breakdown and/or increased energy consumption and operation costs (Hoteit, Banki et al. 2008). Such deposition or fouling is called soil deposition in food industry (Kulkarni, Maxcy et al. 1974), and may pose serious health hazards (e.g., unwanted microbial contamination). Therefore, removing or limiting deposition is an important requirement in the food process industry. The same phenomenon can occur in the petroleum industry where crude oil is extensively transported in pipelines (Venkatesan, Nagarajan et al. 2005; Visintin, Thomas et al. 2008). At an off-shore reservoir, the temperature range for crude oil is $70-150^{\circ} \mathrm{C}$, and the pressure is in the range of 8,000-15,000 psi (Singh, Venkatesan et al. 2000). Under these conditions, crude oil behaves as a Newtonian fluid (see section 1.5) as the temperature and solubility of the crude oil components are sufficiently high to keep them totally dissolved. However, when crude oil is flowed in subsea pipelines, the temperature may change dramatically. Due to the large temperature gradient that exists, the fluid in submerged pipelines may quickly lose heat to its surroundings. If the temperature of the crude oil drops below the wax appearance temperature (WAT) of any dissolved wax, wax may start to drop out of solution and deposit onto the pipeline's internal surface as crystals (Vieira, Buchuid et al. 2010). Continued deposition may lead to a reduction in the pipeline's internal diameter, resulting in a higher pressure drop and the possibility of operational problems (Hoteit, Banki et al. 2008), with plugged pipelines possibly leading to shutdown or even complete abandoning of the pipeline (Wang, Sarica et al. 2005).

A further complication occurs during the temporary shutdown of a pipeline, when the crude oil stops flowing and cools down. The oil may cool below its solidification (gelation) temperature where the viscosity of the entire crude oil mass will substantially increase. Restarting the flow of the crude oil requires overcoming the yield strength of the gel first. The pressure required to restart the oil flow depends on factors such as the diameter of the pipeline, the composition of the oil, the adhesive strength of the oil to the pipe, and the gel strength (Lee, Singh et al. 2008). 
These properties are not easily measured, but it is known that they depend on the final temperature of the oil (quantity of wax precipitated and amount of gel formed) and the shear and thermal histories of the oil (wax crystal structure) (Ronningsen 1992; Venkatesan, Nagarajan et al. 2005).

A vast amount of work has been dedicated to the wax deposition issues. The mechanisms considered to be responsible for this phenomenon are shear dispersion, molecular diffusion, Brownian diffusion and gravity settling (Bern, Withers et al. 1980; Burger, Perkins et al. 1981; Weingarten and Euchner 1988; Majeed, Bringedal et al. 1990; Hoteit, Banki et al. 2008). It has been found that molecular diffusion of wax molecules is a dominant mechanism at high temperatures and high flux conditions whereas shear dispersion is the governing mechanism at low temperatures and low heat fluxes (Bern, Withers et al. 1980; Burger, Perkins et al. 1981; Weingarten and Euchner 1988; Majeed, Bringedal et al. 1990; Hoteit, Banki et al. 2008). In addition, the contribution of Brownian diffusion and gravity settling is small when compared with other mechanisms (Singh, Venkatesan et al. 2000; Hoteit, Banki et al. 2008). In general, an increase in crude oil shear or flow rate will decrease the rate of deposition (Singh, Venkatesan et al. 2000; Hoteit, Banki et al. 2008). Ahn et al., (Ahn, Wang et al. 2005) suggested that the presence of emulsifiers may be able to selectively inhibit the deposition of higher molecular weight paraffin components (Ahn, Wang et al. 2005). Visintin et al. (Visintin, Lapasin et al. 2005) concluded that crude oil flowing in the pipeline below its WAT temperature will not necessarily block the pipeline, given the fact that the fluid is always in movement (Venkatesan, Singh et al. 2002; Visintin, Lapasin et al. 2005).

\subsection{Rheology of materials}

Rheology is the science of material deformation and behaviour applicable to all solids and fluids. Fluids can be divided into Newtonian and non-Newtonian fluids. Newtonian fluids have a constant viscosity at all shear rates at a constant temperature and pressure. For Newtonian behaviour, the flow curve (shear stress versus shear rate) is linear and passes through the origin $(x=0, y=0)$.Examples include water, glycerin and vegetable oil. For non-Newtonian fluids, the flow curve is non-linear and it does not pass through the origin. For non-Newtonian fluids, at a given temperature and pressure, the apparent viscosity(shear stress divided by shear rate) is not constant but depends on flow parameters such as flow geometry, shear rate, etc. Non-Newtonian 
fluids can be further divided in three specific categories, including, i) time-independent fluids (generalized Newtonian fluids) that refer to purely viscous materials, where their rate of shear at any point depends on the shear stress at that point and at that time; ii) time-dependent fluids, which are both time and shear history dependent, and iii) viscoelastic materials, which have both an elastic and viscous portion, and they show partial elastic recovery when they are deformed. Examples include hand cream, shampoo and ketchup (Chhabra, Richardson 2008). A viscoplastic fluid is a time-independent fluid which is distinguished by the existence of a yield stress $\left(\tau_{0}\right)$. Before the fluid can flow or deform, the yield stress must be exceeded. Once the applied stress has exceeded the value of the yield stress, the resulting flow may be linear or nonlinear and it will not pass through the origin of a shear stress versus shear rate graph. If flow is linear, the resulting fluid is called a Bingham plastic and if flow is non-linear, the fluid is deemed a pseudoplastic (shear-thinning) material. Irrespective, when the stress is greater than the yield stress, the structure of the fluid will break and behave as a viscous material. In some cases, there may be partial post-breakdown recovery of the structure, though this is rarely the case(Barnes 1999).

\subsubsection{Viscoplastic fluids}

There are three common mathematical models for characterizing viscoelastic fluids, namely the Bingham plastic, Herschel-Bulkley and Casson models. The equations for these models are summarized below (Chhabra, Richardson 2008).

Bingham plastic model:

$\begin{array}{lll}\tau=\tau_{0}^{B}+\left(\eta_{\mathrm{B}} \times \gamma^{*}\right) & \text { for }|\tau|>\left|\tau_{0}^{\mathrm{B}}\right| & \text { Equation } 4 \\ \gamma=0 & \text { for }|\tau|<\left|\tau_{0}^{\mathrm{B}}\right| & \text { Equation 5 }\end{array}$

Herschel- Bulkey model:

$\tau=\left(\frac{\tau_{\mathrm{HB}}}{\left[\gamma^{\cdot}\right]}+\mathrm{k} \gamma^{\cdot \mathrm{n}-1}\right) \gamma^{\cdot}$ for $[\tau] \geq \tau_{\mathrm{HB}}$ or simplified to $\tau=\tau_{\mathrm{HB}}+\mathrm{k} \gamma^{\cdot \mathrm{n}} \quad$ Equation 6

Casson fluid model:

$\tau^{\frac{1}{2}}=\tau_{0}^{C^{\frac{1}{2}}}+\left(\eta_{\mathrm{C}} \times \gamma^{\cdot}\right)^{\frac{1}{2}} \quad$ for $[\tau] \geq \tau_{\mathrm{y}}$

Equation 7 


\subsection{Emulsion rheology}

Knowledge of an emulsion's flow behaviour is required when unit operations such as mixing, pumping, and fluid flow in pipelines are present. In qualitative terms, emulsions range from low viscosity milk-like Newtonian liquids through to thicker shear-thinning liquids or cream-like materials with apparent yield stresses. At a fundamental level, the rheology of emulsions is a direct manifestation of the various interaction forces that occur in the system. The basic rheology-determining parameters of an emulsion depend on the continuous and dispersed phase properties and their interactions. These factors equally apply to emulsions encountered in pharmaceuticals, cosmetics, food and crude oil.

There has been extensive work conducted on crude oil rheology, but less so on crude oil emulsions. As sub-sea crude oil is often mixed with seawater, it exists as a W/O emulsion. Emulsion formation results when the fluid is passed though pipes and choke valves under turbulent mixing conditions (Dirand, Chevallier et al. 1998; Paso, Senra et al. 2005). High shear rates encountered lead to the formation of small dispersed water droplets, giving rise to nonNewtonian fluid rheology (Dorset and Snyder 1990; Dirand, Chevallier et al. 1998; Paso, Senra et al. 2005). At low temperatures, shear-thinning behaviour has been recorded for heavy oils as well as for heavy oil emulsions (Paso, Senra et al. 2005). The presence of a dispersed aqueous phase in crude oil results in a significant viscosity increase (Krieger and Dougherty 1959). The increase in viscosity is thought to be due to the bonding of paraffin wax crystals to water droplets contributing to the mechanical strength of the gel (Vieira, Buchuid et al. 2010). When crude oil starts to cool, the wax crystals nucleate in the continuous phase or they may move towards the water/oil interface where they nucleate directly at the interface. Solid crystal network structures are formed as a result of London-van der Waals interactions between paraffin crystals (Paso, Silset et al. 2009). Surface-active molecules and particles such as paraffin wax and asphaltenes present in the crude oil increase the stability of emulsions by forming films around the dispersed water droplets. The driving force for the formation of such an interfacial layer is the large free energy of adsorption for particles of intermediate wettability (e.g., asphaltenes) (Paso, Silset et al. 2009). The films around the droplets counter attractive forces between droplets and therefore a reduction in droplet coalescence occurs (Paso, Silset et al. 2009). 
The volume fraction of the dispersed phase in an emulsion (i.e., the water cut) can have a significant influence on emulsion rheology. In general, for low-volume fraction emulsions, the relative viscosity $\left(\eta_{\mathrm{r}}\right)$ of the system is related to volume fraction of the dispersed phase $(\varphi)$ through Einstein's equation (Tadros 1993):

$\eta_{\mathrm{r}}=1+2.5 \varphi$

Equation 8

For higher volume fraction emulsions, the relative viscosity is as a complex function of $\varphi$. This is represented using a polynomial equation as follows:

$\eta_{\mathrm{r}}=1+\mathrm{k}_{1} \varphi+\mathrm{k}_{2} \varphi^{2}+\mathrm{k}_{3} \varphi^{3}+\ldots$

Equation 9

where $k_{1}$ is Einstein's coefficient ( 2.5 for hard spheres), and $k_{2}$, and $k_{3}$ are coefficients that account for hydrodynamic interactions between droplets (Tadros 1993). Interestingly, Visintin et al. (Visintin, Thomas et al. 2008) experimentally determined that a crude oil emulsion at low temperature could have a similar rheological behaviour to crude oil (with no water added). Differences in rheology between the two became important only above a $25-30 \%$ dispersed phase volume fraction (Visintin, Thomas et al. 2008). They also showed that by increasing water cut to $70 \%$, the yield stress increased from $\sim 60$ to $\sim 550 \mathrm{~Pa}$.

Other factor affecting emulsion rheology includes the composition of the bulk continuous phase, the interfacial rheology of the wax and emulsifier film around the droplets and the deformability of droplets after an applied shear. For emulsions with similar droplet sizes, when the droplets deform more under shear, the increase in viscosity with water cut $(\varphi)$ is more rapid (Tadros 1993).

$\mathrm{Pal}(\mathrm{Pal}$ 1996) found that a reduction in droplet size gave a large increase in the viscosity of both concentrated W/O and O/W emulsions (Pal 1996). In addition, non-Newtonian behaviour such as shear-thinning was more pronounced for fine emulsions ( $\mathrm{Pal}$ 1996). Evdokimov et al. (Evdokimov, Efimov et al. 2008) studied native crude oil, showing that the viscosity of a crude oil emulsion decreased due to stratified flow (W/O emulsion gel + free water) when water emerged as a separate phase at higher water contents $(\varphi \approx 0.83)$ (Evdokimov, Efimov et al. 2008). 
Overall, this literature survey has shown that though extensive research on emulsions has been carried out, there has been comparatively little performed on the role of a dispersed aqueous phase on emulsion properties. 


\section{Research objectives}

This thesis forms part of a long-term research plan investigating the flow behaviour of $\mathrm{W} / \mathrm{O}$ emulsions. The overall objective of this thesis was to characterize the flow behaviour of a model wax-oil mixture in a laboratory-scale flowloop and to determine the rheological behaviour of W/O emulsions made with this mixture.

The specific objectives were as follows:

1. Characterize the flow behaviour of a model wax-containing oil mixture in a lab-scale flowloop;

2. Establish the impact of water cut on W/O emulsion stability and rheology;

3. Characterize the role of continuous phase wax crystals on $\mathrm{W} / \mathrm{O}$ emulsion rheology, and;

4. Correlate the combined effect of water cut and continuous phase wax crystals on $\mathrm{W} / \mathrm{O}$ emulsion rheology. 


\section{Materials}

\subsection{Mineral oil}

Light mineral oil (O-121) was obtained from Fisher Scientific (Nepean, ON, Canada). The stated maximum kinematic viscosity at $40{ }^{\circ} \mathrm{C}$ was $33.5 \mathrm{mPa}$.s. Component analysis, specifications and properties of the mineral oil are given in Table 1 and Table 2, respectively.

Table 1 : Specifications for the light mineral oil used in this research (provided by the manufacturer).

\begin{tabular}{ccc}
\hline $\begin{array}{c}\text { Molar mass } \\
\text { (measured) } \\
394\end{array}$ & Density at $16^{\circ} \mathrm{C}$ & API \\
\hline
\end{tabular}

Table 2: Compositions, ${ }^{\circ} \mathrm{API}$ and molecular weight of light mineral oil used throughout this research. Specifications were provided by the manufacturer.

\begin{tabular}{cccc}
\hline Component & MW & \multicolumn{2}{c}{ Fraction } \\
& $(\mathrm{g} / \mathrm{mole})$ & WT $\%$ & MOLE $\%$ \\
C9 & 121.00 & 0.00 & 0.00 \\
C10 & 134.00 & 0.00 & 0.00 \\
C11 & 147.00 & 0.00 & 0.00 \\
C12 & 161.00 & 0.00 & 0.01 \\
C13 & 175.00 & 0.00 & 0.00 \\
C14 & 190.00 & 0.02 & 0.05 \\
C15 & 206.00 & 0.26 & 0.50 \\
C16 & 222.00 & 0.43 & 0.76 \\
C17 & 237.00 & 0.67 & 1.12 \\
C18 & 251.00 & 0.69 & 1.07 \\
C19 & 263.00 & 1.23 & 1.83 \\
C20 & 275.00 & 2.03 & 2.90 \\
C21 & 291.00 & 2.35 & 3.17 \\
C22 & 300.00 & 4.04 & 5.28 \\
\hline
\end{tabular}




\begin{tabular}{lccc}
\hline C23 & 312.00 & 6.40 & 8.05 \\
C24 & 324.00 & 8.98 & 10.87 \\
C25 & 337.00 & 10.11 & 11.76 \\
C26 & 349.00 & 10.03 & 11.27 \\
C27 & 360.00 & 8.95 & 9.75 \\
C28 & 372.00 & 7.76 & 8.17 \\
C29 & 382.00 & 6.25 & 6.41 \\
C30+ & 685.00 & 29.79 & 17.05 \\
Total & & $\mathbf{1 0 0 . 0 0}$ & $\mathbf{1 0 0 . 0 0}$ \\
\hline
\end{tabular}

*American Petroleum Institute gravity refers to how heavy or light a petroleum liquid is compared to water. With values $<10$, the fluid is heavier and sinks whereas with values $>10$, the fluid is lighter and floats.

\subsection{Water}

A $3.5 \mathrm{wt} \%$ sodium chloride (Fisher Scientific, Nepean, ON, Canada) in de-ionized water $(\mathrm{R} \geq 18.0 \mathrm{M} \Omega \cdot \mathrm{cm}-1)$ solution was used as the dispersed aqueous phase. As discussed later, the presence of a saline solution was required to prevent undue formation of double emulsions.

\subsection{Emulsifier}

The surfactant used was glycerol monooleate (GMO) (Dimodan MO 90®, Danisco, NewCentury, KS, USA). Dimodan MO 90 is a food-grade low-HLB (hydrophilic/ lipophilicbalance) emulsifier composed of $>92 \%$ glycerol monooleate, with the rest consisting of small amounts of glycerol, glycerol dioleate and glycerol trioleate (Figure 4).

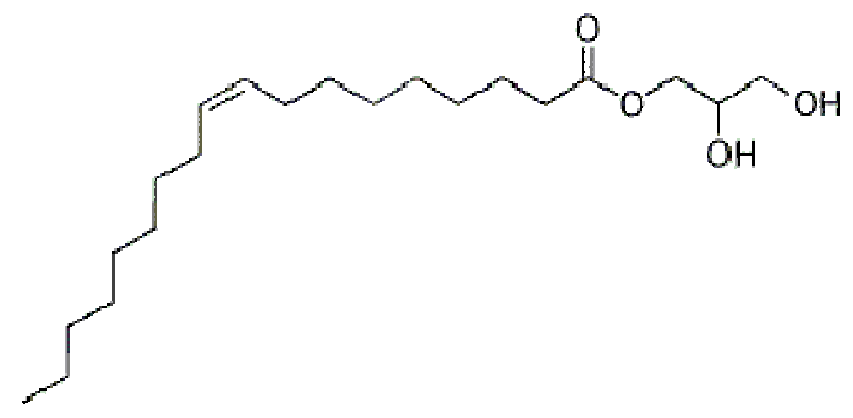

Figure 4: Molecular structure for glycerol monooleate (GMO) with chemical formula of $\mathrm{C}_{21} \mathrm{H}_{40} \mathrm{O}_{4}$. 


\subsection{Paraffin wax}

A highly-refined paraffin wax (IGI-1242) was obtained from The International Group, Inc. (Toronto, ON, Canada). The melting range of the wax was $56.7-58.9^{\circ} \mathrm{C}$. Many slabs of this wax were purchased and used. To ensure compositional homogeneity, multiple wax slabs ( $\sim 5 \mathrm{~kg}$ each) were melted together and re-crystallized in small cubes (in ice cube trays) so that the slight differences in composition between various wax slabs would not affect experimental results. Figure 5shows a differential scanning calorimetry thermogram of the homogeneous wax. On the heating curve, the peak at $\sim 60^{\circ} \mathrm{C}$ was due to the melting of wax crystals. This is in line with the melting point of paraffin wax shown in Table 1. During the cooling cycle, wax crystallized at $\sim 59{ }^{\circ} \mathrm{C}$ (WAT temperature). In addition, the physical properties of the paraffin wax are summarized in Table 1.

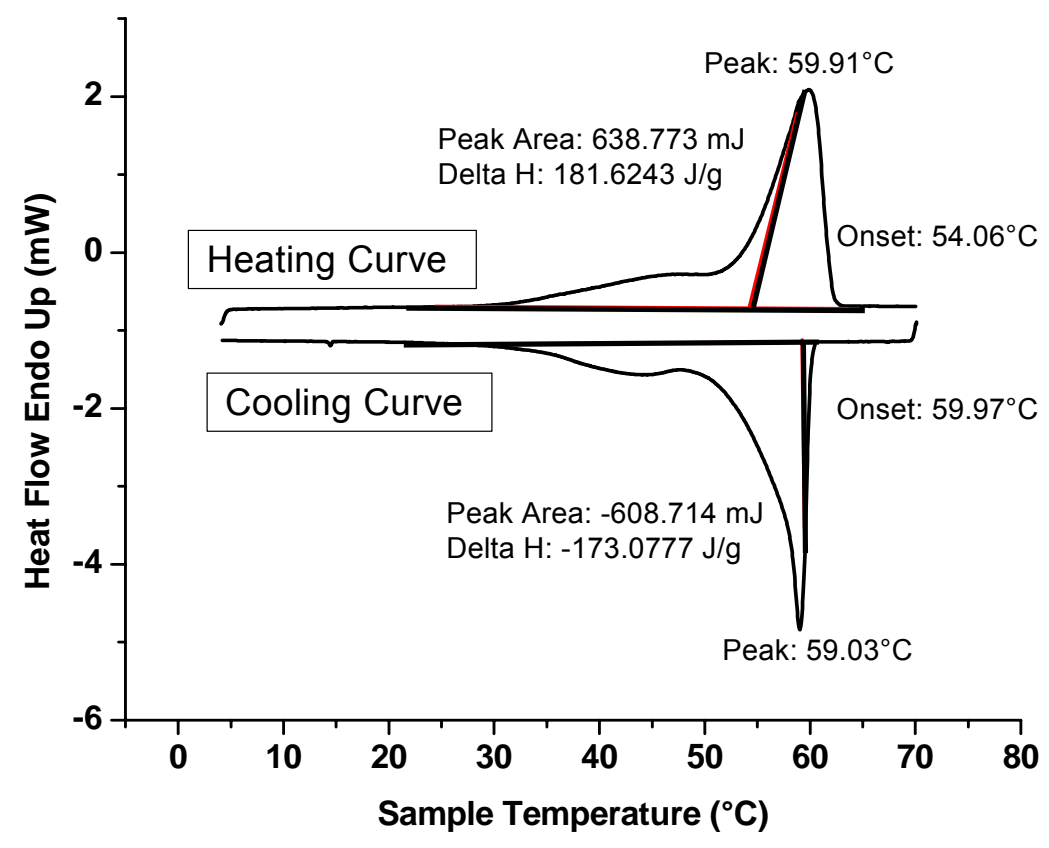

Figure 5: DSC of paraffin wax showing its melting and crystallization temperatures. 
Table 3: Physical properties of the paraffin wax used throughout this study (obtained from the manufacturer ).

\begin{tabular}{ccccc}
\hline Property & ASTM & \multicolumn{2}{c}{ Specification } & Typical \\
& Method & Minimum & Maximum & \\
Melt Point $\left({ }^{\circ} \mathrm{C}\right)$ & D87 & 57.8 & 61.1 & 59.4 \\
$\begin{array}{c}\text { Kinematic } \\
\text { Viscosity, } \mathrm{mm}^{2} / \mathrm{s} @ \\
100^{\circ} \mathrm{C}\end{array}$ & $\mathrm{D} 445$ & 3.8 & 5.0 & 4.3 \\
Oil content, $\mathrm{wt} \%$ & $\mathrm{D} 721$ & --- & & 0.6 \\
\hline
\end{tabular}




\section{Flow behaviour of paraffin oil-wax mixtures in a lab-scale flowloop}

\subsection{Introduction}

As described in the literature review, there are concerns associated with unwanted deposition in pipes and pipelines, notably in crystal-containing emulsions in food and petrochemical products. However, there remains a surprising dearth of fundamental information on this phenomenon. The objective of this chapter was to characterize the flow behaviour of model wax-oil mixture consisting of light mineral oil, paraffin wax (5 wt $\%$ of the oil phase) and the surfactant glycerol monooleate $(0.05 \mathrm{wt} \%)$ to understand how such deposition occurs. A previously-developed inhouse laboratory-scale benchtop flowloop system was optimized and used to explore the flow behaviour of paraffin oil-wax mixtures.

\subsection{Methodology}

\subsubsection{Lab scale flowloop system}

A schematic and Process Flow Diagram (PFD) of the flowloop system is shown in Figure 6 and Figure 7, respectively. The lab-scale flowloop set up was developed to simulate flow behaviour and wax deposition in pipeline at seabed temperatures. The pipe assembly was submerged in a temperature-controlled water bath preset at selected temperature $\left(25^{\circ} \mathrm{C}\right.$ or $\left.4^{\circ} \mathrm{C}\right)$. Because of wax crystallization and deposition on the inner surface of the pipe wall, flow would be hindered and this was monitored by a continuous differential pressure transmitter as a function of temperature. Experiments were conducted for 4 and $30 \mathrm{hrs}$.

The loop (at bottom right in Figure 6) was made with 3/8" diameter stainless steel (SS) tubing (ID: $7.0 \mathrm{~mm}$, OD: 9.5mm, Swagelok, Scarborough, ON, Canada) tubing coiled into $43 \mathrm{~cm}$ diameter loops. The $15 \mathrm{~m}$ loop was divided into three $5 \mathrm{~m}$ sections and the sections were connected through $20 \mathrm{~cm}$ removable sections. The removable sections were used to investigate the amount and properties of wax deposition along the loop wall as a function of time and temperature. At the beginning of each flowloop run, freshly-prepared neat oil-wax mixture (total: $3.5 \mathrm{~kg}$ ) was added to the heating unit (10 L SS container). The heating unit was continuously stirred with a magnetic stirrer at $\sim 500 \mathrm{rpm}$ and maintained at $\sim 44.6 \pm 0.03{ }^{\circ} \mathrm{C}$ with a heating coil attached to waterbath no. 2. Fluid from the heating unit was transferred to the homogenizer by gravity flow where the level of fluid in the homogenizer hopper was maintained by a level controller. At this point, the homogenizer was switched on and the fluid began to pump into the 
tempering unit $\left(1 \mathrm{~L}\right.$ glass beaker) through waterbath no. 1 set at $50^{\circ} \mathrm{C}$. The tempering unit was also connected to waterbath no. 1 in order to maintain a steady temperature of $45 \pm 1{ }^{\circ} \mathrm{C}$. As the level in the tempering unit reached $\sim 1000 \mathrm{ml}$, the progressive cavity pump (PC pump, Seepex MD 012-24, Romatec, Newmarket, ON, Canada) was switched on and the fluid was pumped into the flowloop submerged in the 'sea-bed sink' pre-set at the desired temperature with the help of waterbath no. 3. The pump was used at constant flow rate for all experiments (Table 4). The inlet temperature was maintained at $44 \pm 0.6^{\circ} \mathrm{C}$. Fluid from the loop outlet was recycled back into the heating unit. In order to re-heat the loop outlet fluid to its original temperature $\left(45 \pm 1{ }^{\circ} \mathrm{C}\right)$, it was passed through waterbath no. 2. Re-heated fluid from the heating unit was again transferred into the homogenizer and the system continuously operated for several hours, depending on the experimental conditions chosen. Details of all operating conditions for the $25^{\circ} \mathrm{C}$ and $4{ }^{\circ} \mathrm{C}$ flowloop runs are given in Table 4.

Table 4: Flowloop operating conditions for the $25^{\circ} \mathrm{C}$ and $4{ }^{\circ} \mathrm{C}$ runs

\begin{tabular}{lcc}
\hline & Sea-bed sink $\left(25^{\circ} \mathrm{C}\right)$ & Sea-bed sink (4 $\left.{ }^{\circ} \mathrm{C}\right)$ \\
Average heating unit temp. & $44.6 \pm 0.03{ }^{\circ} \mathrm{C}$ & $48.2 \pm 0.7^{\circ} \mathrm{C}$ \\
Average tempering unit temp. & $45.7 \pm 0.1^{\circ} \mathrm{C}$ & $46.8 \pm 0.3^{\circ} \mathrm{C}$ \\
Average inlet temp (T in) & $43.4 \pm 0.4^{\circ} \mathrm{C}$ & $44.6 \pm 0.1^{\circ} \mathrm{C}$ \\
Average outlet temp (T out) & $25.9 \pm 0.2^{\circ} \mathrm{C}$ & $8.4 \pm 0.9^{\circ} \mathrm{C}$ \\
Water bath 1 & $50{ }^{\circ} \mathrm{C}$ & $50{ }^{\circ} \mathrm{C}$ \\
Water bath 2 & $50{ }^{\circ} \mathrm{C}$ & $60{ }^{\circ} \mathrm{C}$ \\
Water bath 3 & $23{ }^{\circ} \mathrm{C}$ & $1{ }^{\circ} \mathrm{C}$ \\
PC pump flow rate & $406 \mathrm{ml} / \mathrm{min}$ & $406 \mathrm{ml} / \mathrm{min}$ \\
Total loop volume & $246.3 \mathrm{ml}$ & $246.3 \mathrm{ml}$ \\
Loop retention time & $1 \mathrm{~min} 17 \mathrm{~s}$ & $1 \mathrm{~min} 12 \mathrm{~s}$ \\
\hline
\end{tabular}




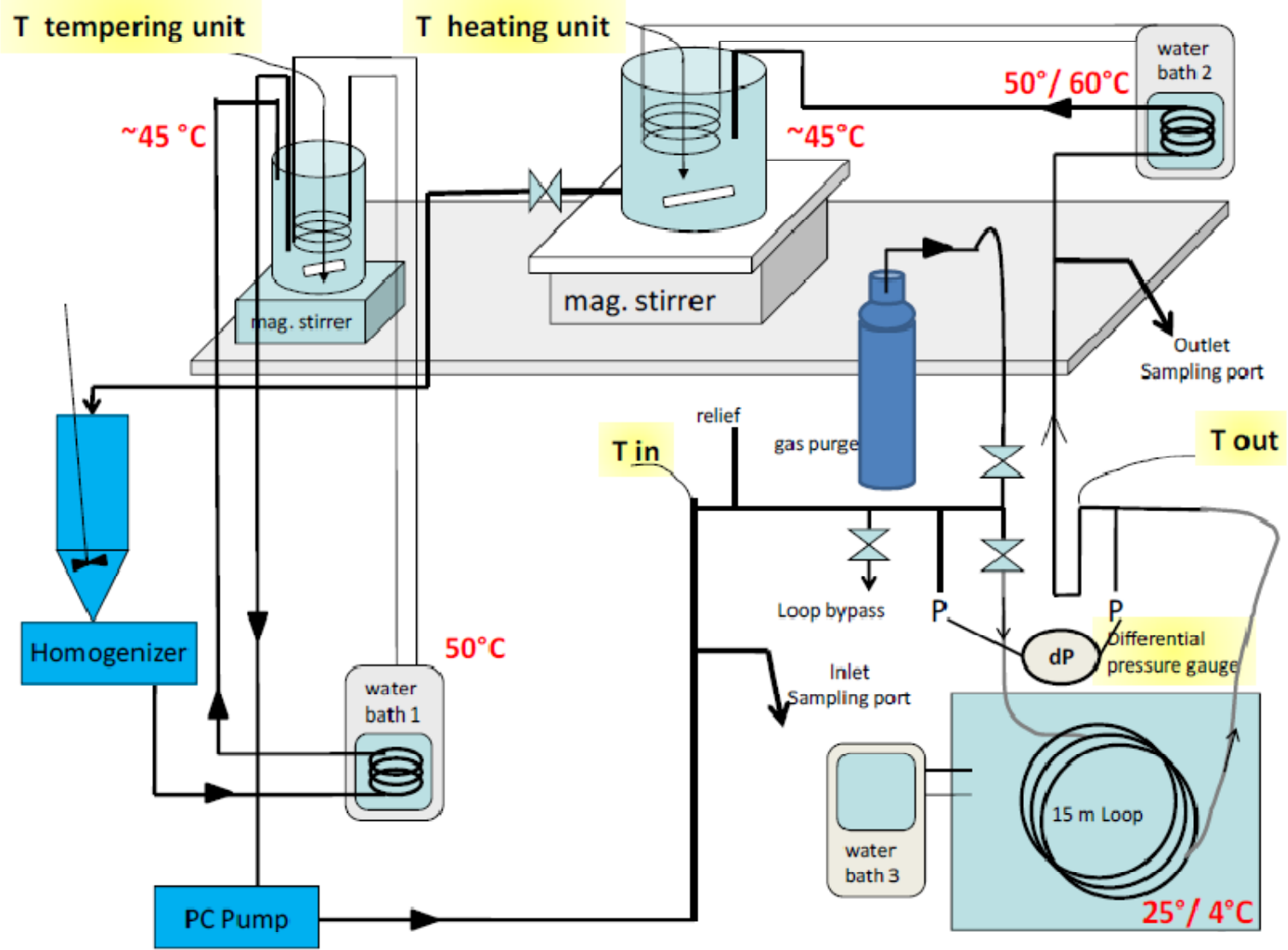

Figure 6: Schematic diagram of the lab-scale flowloop system. 


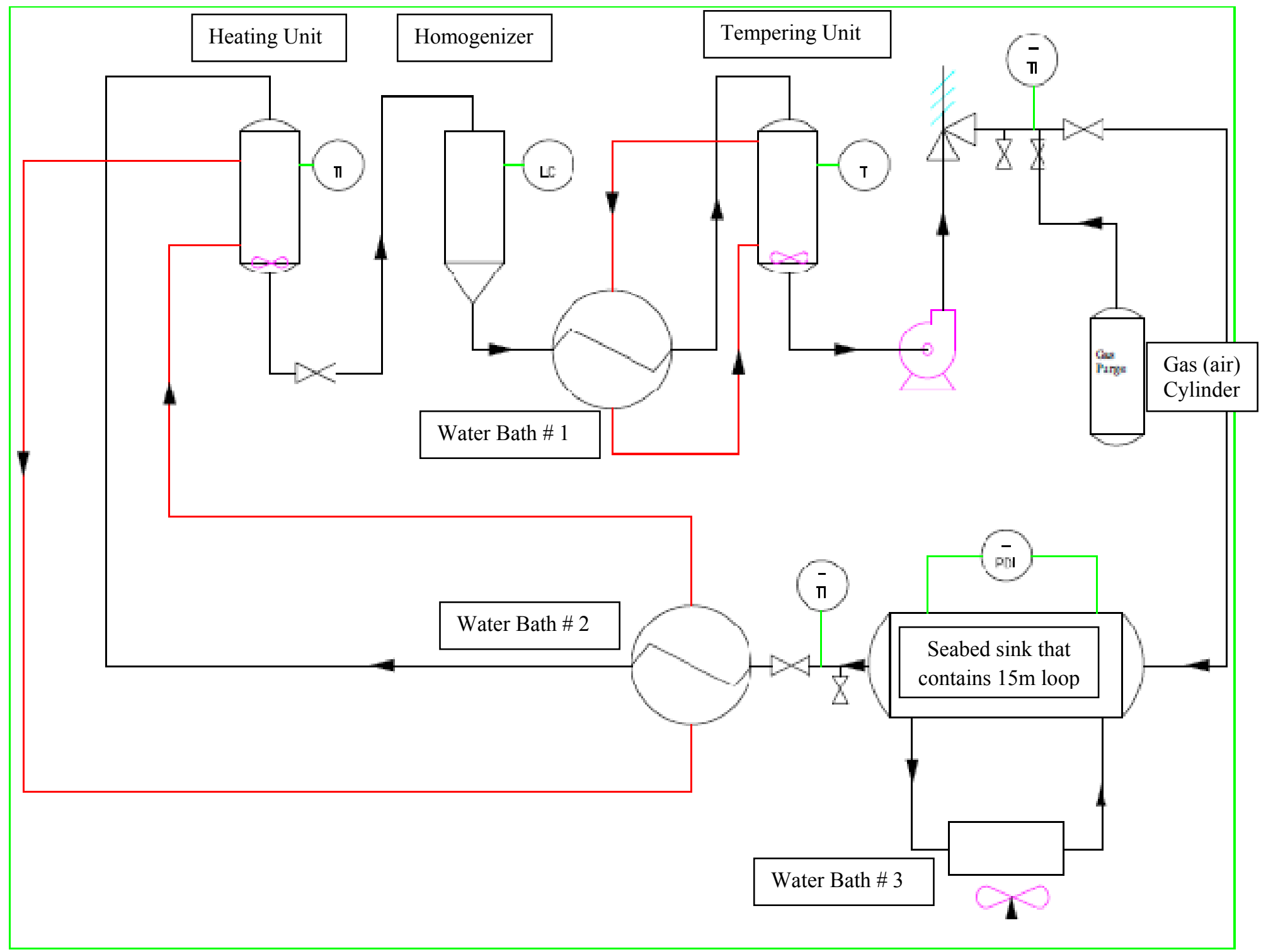

Figure 7: A PFD diagram of the lab-scale flowloop system. 


\subsubsection{Determination of temperature and pressure drop across the flowloop}

The pressure drop across the flowloop was determined using a differential pressure gauge attached to the loop inlet and outlet (Table 5). The change in pressure drop and temperature of the loop inlet and outlet, and the tempering and heating units was continuously recorded on a PC using LabView 8.6 for Windows (National Instruments Canada, Toronto, ON, Canada). Details of the data logging system are given in Table 5 .

Table 5: Details of flowloop data logging system

\begin{tabular}{|c|c|c|}
\hline Description & Model no. & Manufacturer/ supplier \\
\hline Thermocouple input module & NI 9211 & \multirow{5}{*}{$\begin{array}{c}\text { National Instruments } \\
\text { Canada, Toronto, ON, } \\
\text { Canada }\end{array}$} \\
\hline & $4-\mathrm{Ch}, \pm 80 \mathrm{mV}, 24$ bits & \\
\hline Analog input module & NI 9203 & \\
\hline (differential pressure) & $8-\mathrm{Ch}, \pm 20 \mathrm{~mA}, 16$ bits & \\
\hline $\begin{array}{l}\text { USB } 2.0 \text { chassis for data } \\
\text { acquisition modules }\end{array}$ & cDAQ-9172 & \\
\hline Integral pressure manifold & $\begin{array}{l}\text { Rosemount 0305RT32A11 } \\
\text { 3-valve manifold }\end{array}$ & \multirow{2}{*}{$\begin{array}{l}\text { Lakeside Process Controls } \\
\text { Ltd. } \\
\text { Mississauga, ON, Canada }\end{array}$} \\
\hline $\begin{array}{l}\text { Differential pressure } \\
\text { transmitter }\end{array}$ & $\begin{array}{l}\text { 3051CD transmitter } \\
-300-300 \mathrm{psi}, 4-20 \mathrm{~mA} \\
\text { output }\end{array}$ & \\
\hline K-type thermocouple probe & $\begin{array}{l}\text { KMTSS-062G-6 } \\
\text { Length: 6", diameter: 0.062" }\end{array}$ & $\begin{array}{c}\text { Omega Engineering, Inc., } \\
\text { Laval, QC, Canada }\end{array}$ \\
\hline
\end{tabular}

\subsubsection{Amount of wax deposition}

At the end of each flowloop run, the sea-bed sink was drained and the loop sections at $0,5,10$ and $15 \mathrm{~m}$ were removed for further analysis of wax deposition on the inner flowloop wall. After removal, the loop sections were kept vertical for $5 \mathrm{~min}$ to drain any liquid oil present. Pictures of both ends of loop sections were recorded using a digital camera. The pictures provided an indication of the wax deposit thickness on the tube wall as a function of loop length. The weight difference between the 'filled' (i.e., containing deposited material) and empty loop section was used to calculate the mass of the deposited wax inside each loop. Finally, using a glass rod, the 
deposited material was pushed out onto a Petri dish and its visual characteristics were recorded. Deposits were analyzed for wax content using a polarized light microscope (section 4.2.6) and differential scanning calorimetry (section 4.2.7).

\subsubsection{Solid wax content}

Aliquots of material from the flowloop were pipetted into NMR tubes (ID $=0.8 \mathrm{~cm}, \mathrm{~L}=20 \mathrm{~cm}$ ) to a height of $6 \mathrm{~cm}$. Samples were prepared at room temperature (RT) $\left(25.5^{\circ} \mathrm{C} \pm 0.5^{\circ} \mathrm{C}\right)$ and stored at $4{ }^{\circ} \mathrm{C}$ in order to crystallize the wax present. Samples were analyzed using the Bruker Minispec Mq pulsed field gradient nuclear magnetic resonance (pfg-NMR) unit (Bruker Canada, Milton, ON, Canada) with the application sfc_lfc v2.51.

\subsubsection{Microscopy}

Polarized light microscopy was used to characterize the microstructure of the deposited material from the flowloop. Samples were placed on viewing slides (Fisher Scientific, Ottawa, ON, Canada) at different temperatures as per the flowloop run conditions, covered with a cover slip (Fisher Scientific, Nepean, ON, Canada) and analyzed with an inverted Zeiss Axiovert 200M light microscope (Zeiss Inc., Toronto, ON, Canada) equipped with a temperature-controlled stage (model TSA02i with STC200 temperature controller, Instec, Boulder, CO, USA) pre-set at the loop outlet temperature.

\subsubsection{Differential scanning calorimetry}

Aliquots of flowloop samples $(\sim 10 \mathrm{mg})$ were hermetically sealed in aluminum pans and temperature cycled in a differential scanning calorimeter (DSC) (Pyris Diamond model, PerkinElmer Life and Analytical Sciences, Woodbridge, ON, Canada). Samples were cooled from $25{ }^{\circ} \mathrm{C}$ to $-70{ }^{\circ} \mathrm{C}$, re-heated to $70{ }^{\circ} \mathrm{C}$ and then re-crystallized to $-50{ }^{\circ} \mathrm{C}$ at a rate of $2{ }^{\circ} \mathrm{C} / \mathrm{min}$. Both crystallization and melting points were determined from the peak temperatures using the DSC data analysis software (Pyris v.7, PerkinElmer Life and Analytical Sciences, Woodbridge, ON, Canada). An estimate of the wax content present in a given sample was achieved using a calibration curve that correlated wax concentration/crystallization and enthalpy. This approach was necessary as it was not possible to easily gauge the actual wax content present in the deposited material and depleted starting wax-oil mixture. The calibration curve was prepared from the enthalpies of crystallization of a range of wax concentration in different neat oil-wax mixtures (Figure 8). 


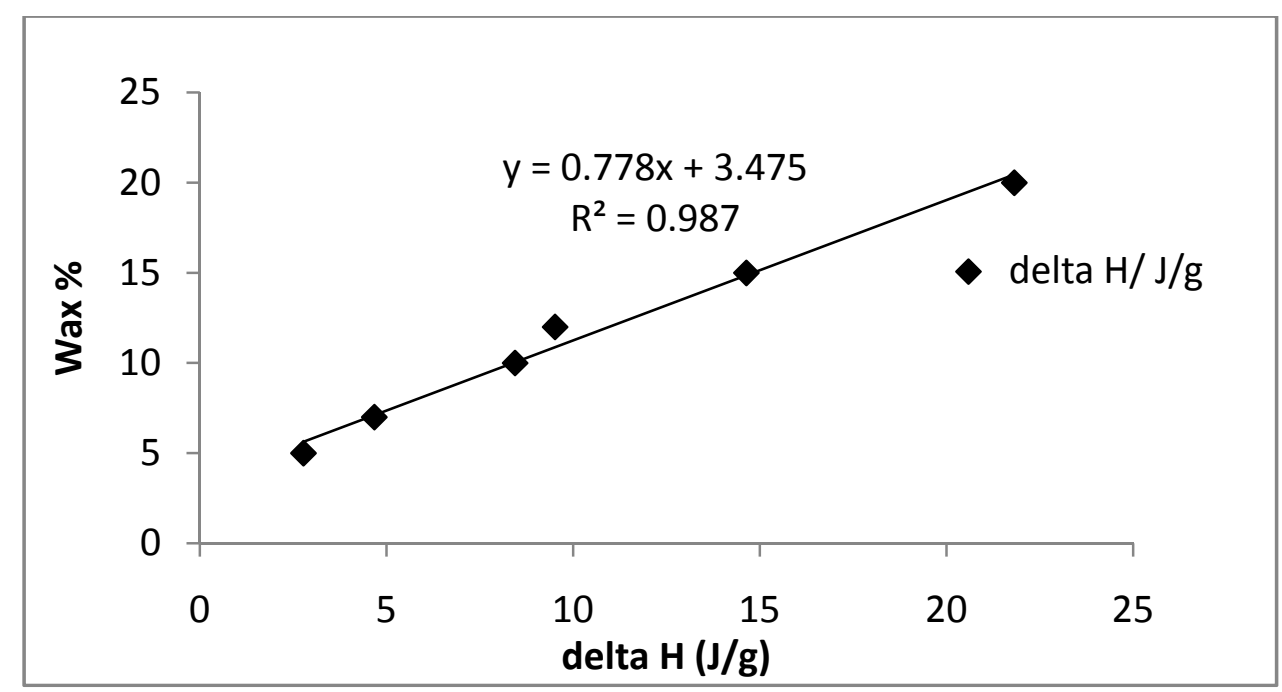

Figure 8: Calibration curve obtained from enthalpies of crystallization of wax concentrations (5$20 \mathrm{wt} \%$ ) in oil-wax mixtures.

\subsection{Results and discussion}

\subsubsection{Flowloop runs at $4^{\circ} \mathrm{C}$ and $25^{\circ} \mathrm{C}$ for $4 \mathrm{hrs}$}

The starting fluid was at $44^{\circ} \mathrm{C}$, which ensured that the wax present in the oil was molten. To ascertain the effect of small and large temperature gradients and their effect on amount of wax deposition, two sets of experiments at $25^{\circ} \mathrm{C}$ and $4{ }^{\circ} \mathrm{C}$ were conducted $\left(25^{\circ} \mathrm{C}\right.$ and $4{ }^{\circ} \mathrm{C}$ are the seabed sink temperatures). As the average fluid inlet temperature was $\sim 44^{\circ} \mathrm{C}$, there was a $19^{\circ} \mathrm{C}$ decrease in temperature for the $25^{\circ} \mathrm{C}$ runs and a $40^{\circ} \mathrm{C}$ decrease for the $4^{\circ} \mathrm{C}$ runs.

\subsubsection{Pressure and temperature change during4hr flowloop experiments}

The average pressure drops across the flowloop for the $25^{\circ} \mathrm{C}$ and $4{ }^{\circ} \mathrm{C}$ runs are shown in Figure 9 $\left(25^{\circ} \mathrm{C}\right.$ and $4^{\circ} \mathrm{C}$ are the seabed sink temperatures). The initial pressure drop ( $\sim 4$ min after the start of the data recording) reached $\sim 30$ psi with the $25^{\circ} \mathrm{C}$ run and $\sim 150$ psi at $4{ }^{\circ} \mathrm{C}$ within 1 min of starting the PC pump (i.e., after the fluid had passed through the $15 \mathrm{~m}$ loop once). The pressure drops for the $4^{\circ} \mathrm{C}$ runs were much higher than with the $25^{\circ} \mathrm{C}$ runs as the fluid inside the pipe faced a larger temperature gradient that led to more rapid depositions and/or gel formation than at $25^{\circ} \mathrm{C}$. After $4 \mathrm{hrs}$, the pressure drop reached $34 \mathrm{psi}$ for the $25^{\circ} \mathrm{C}$ neat oil runs and stay around $150 \mathrm{psi}$ for the $4^{\circ} \mathrm{C}$ runs. The increase in pressure drop with time for $25^{\circ} \mathrm{C}$ runs was due to the formation of a wax deposit on the flowloop wall thereby reducing the actual diameter of the flowloop. 


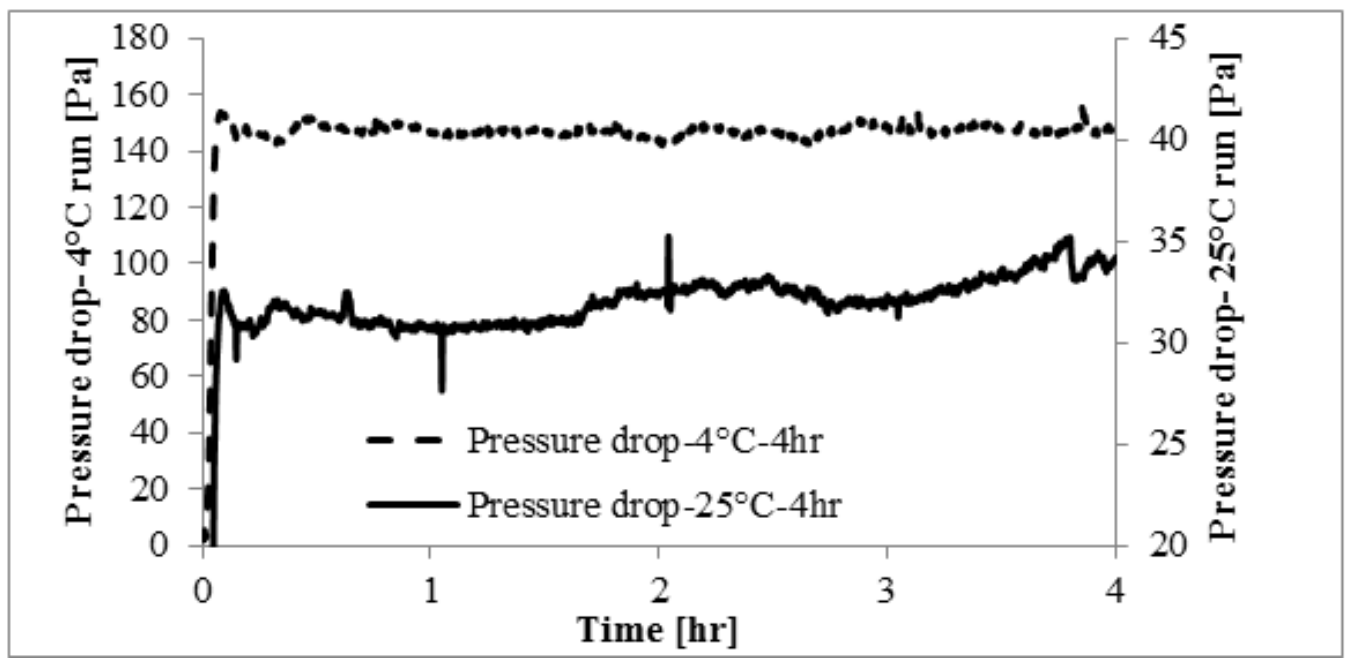

Figure 9: Change in pressure drop as a function of time across the flowloop for the neat oil passed at $25^{\circ} \mathrm{C}$ or $4^{\circ} \mathrm{C}$.

The changes in loop outlet and sea-bed sink temperatures are shown in Figure 10 . At $25^{\circ} \mathrm{C}$, no change in loop outlet temperature $\left(25.9 \pm 0.2^{\circ} \mathrm{C}\right)$ was observed. The sea-bed sink temperature remained almost constant at $25^{\circ} \mathrm{C}$ throughout each flowloop run. For the $4^{\circ} \mathrm{C}$ flowloop runs, no significant change in loop outlet temperature was observed during the $4 \mathrm{hr}$ runs $\left(7.7 \pm 0.2^{\circ} \mathrm{C}\right)$. Therefore, after $4 \mathrm{hr}$, wax deposition did not influence the outlet temperature.

In order to further analyze the effect of the different temperature gradients, the amount of wax deposited in the pipe line was studied at the end of each flowloop run. The results are summarized in the following section.

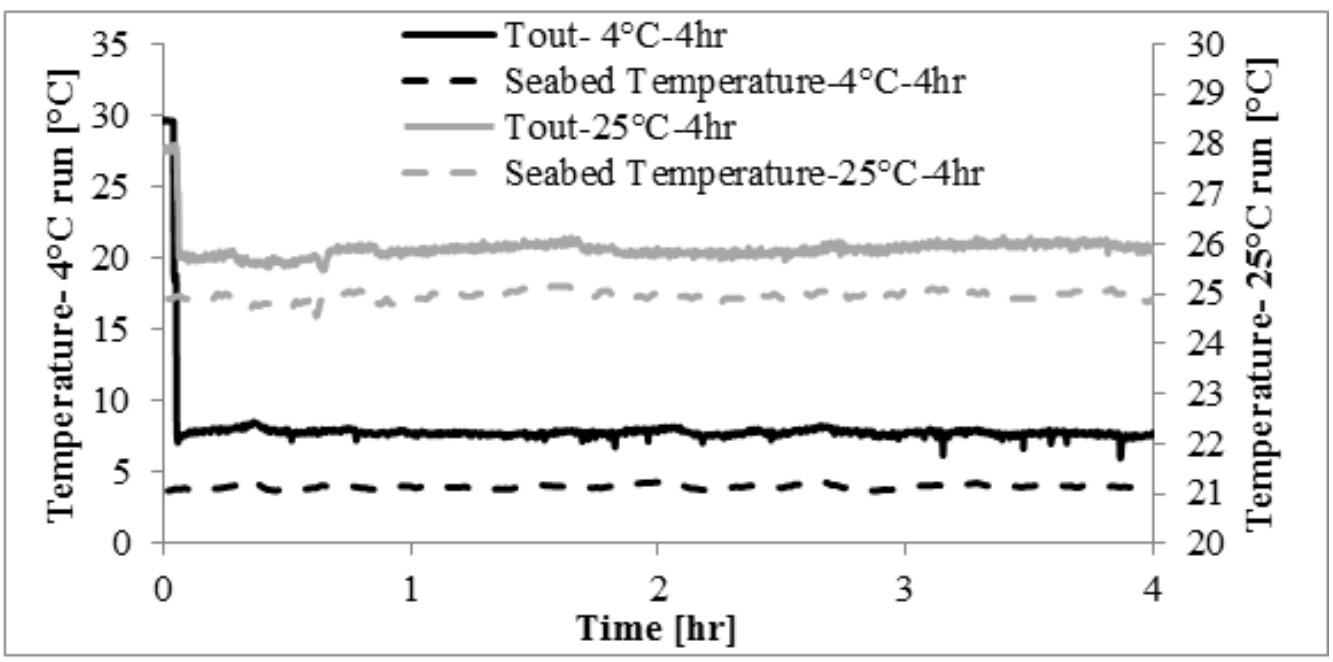

Figure 10: Change in loop outlet and sea-bed sink temperatures as a function of time for the neat oil at $25^{\circ} \mathrm{C}$ and $4^{\circ} \mathrm{C}$ seabed sink temperature. 


\subsubsection{Deposition on the flowloop wall}

Wax deposition was significantly influenced by seabed temperature. The amount of wax deposited on the inside of the removable $20 \mathrm{~cm}$ flowloop tube sections during the $4 \mathrm{hr}$ runs at both $25^{\circ} \mathrm{C}$ and $4^{\circ} \mathrm{C}$ is shown in Figure 11 . The deposition at $4^{\circ} \mathrm{C}$ was only seen in the $0 \mathrm{~m}$ loop section whereas with the $25^{\circ} \mathrm{C}$ runs, deposition was observed in the $0 \mathrm{~m}$ and $5 \mathrm{~m}$ sections. The lack of deposition at $4^{\circ} \mathrm{C}$ was related to temperature gradient experienced by the wax. At $4^{\circ} \mathrm{C}$, the initially large temperature difference between the inlet fluid and flowloop wall led to significant deposition in the $0 \mathrm{~m}$ section. However, as this fluid cooled very quickly, by the end of first $5 \mathrm{~m}$ loop section, it had reached the wall temperature. Hence, no further deposition was observed in the other loop sections (i.e., at 5, 10 and $15 \mathrm{~m}$ ). For the $25^{\circ} \mathrm{C}$ runs, the fluid cooled slowly as the initial temperature gradient was far smaller than with the $4^{\circ} \mathrm{C}$ runs. The slow cooling of the fluid inside the loop led to wall deposition even beyond the $5 \mathrm{~m}$ removable loop section. As the deposition beyond $5 \mathrm{~m}$ removable sections were less than $1 \mathrm{~g}$, they are not shown here. This was presumably associated with the gradual vs. flash-cooling $\left(4^{\circ} \mathrm{C}\right)$ of the wax which led to continued crystallization over a longer distance during the $25^{\circ} \mathrm{C}$ runs.

Figure 12 shows the DSC-measured wax content of the deposited materials from the removable loop sections. For the $25^{\circ} \mathrm{C}$ neat oil run, the $0 \mathrm{~m}$ removable section has higher wax content when compared to $5 \mathrm{~m}$ removable section. Interestingly, with $4 \mathrm{hr}$ runs, the $4^{\circ} \mathrm{C}$ neat oil experiments resulted in the lowest deposited wax amount, but this wax consisted of the highest solid wax content (SWCs). This suggested that a different wax fraction was likely fractionating and being deposited with this composition and temperature combination.

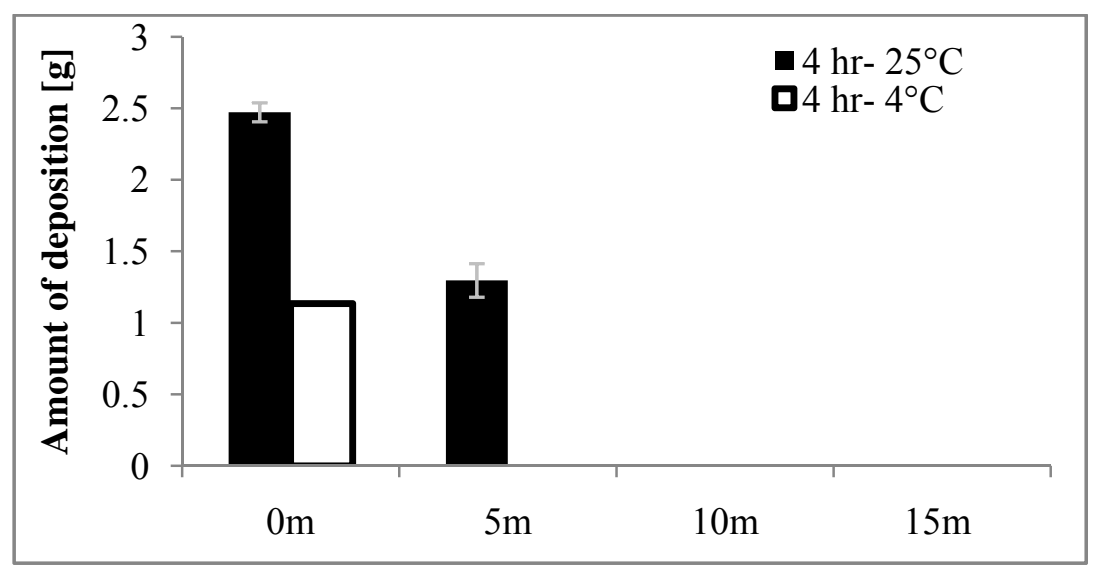

Figure 11: Amount of deposition in the different loop sections after $4 \mathrm{hr}$ flowloop runs at $25^{\circ} \mathrm{C}$ and $4^{\circ} \mathrm{C}$. 


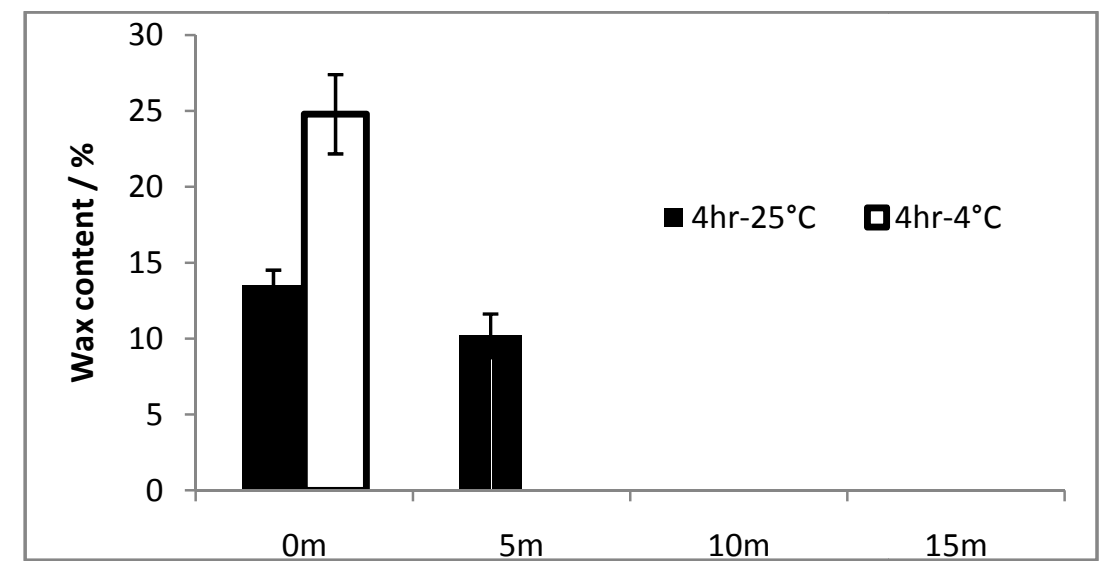

Figure 12: DSC-measured wax content of deposited material in different loop sections after $4 \mathrm{hr}$ flowloop runs at $25^{\circ} \mathrm{C}$ and $4^{\circ} \mathrm{C}$. Calibration is based on Figure 8.

\subsubsection{Microstructure of the deposited material}

Combined polarized and differential interference contrast (DIC) images of the deposited material from the different removable sections are shown in Figure 13 . For the $25^{\circ} \mathrm{C}$ runs, a significant reduction in the amount and size of the deposited wax crystals was seen between the $0 \mathrm{~m}$ and $5 \mathrm{~m}$ sections. The corresponding wax content for these two materials also decreased from $13.5 \%$ to $10.2 \%$, respectively (Figure 12 ). The microstructure in the $0 \mathrm{~m}$ section at $4^{\circ} \mathrm{C}$ consisted of small, fine crystals as a result of the greater crash-cooling experienced by the fluid as compared to the $0 \mathrm{~m} 25^{\circ} \mathrm{C}$ microstructure, which consisted of larger crystals due to the slower cooling.

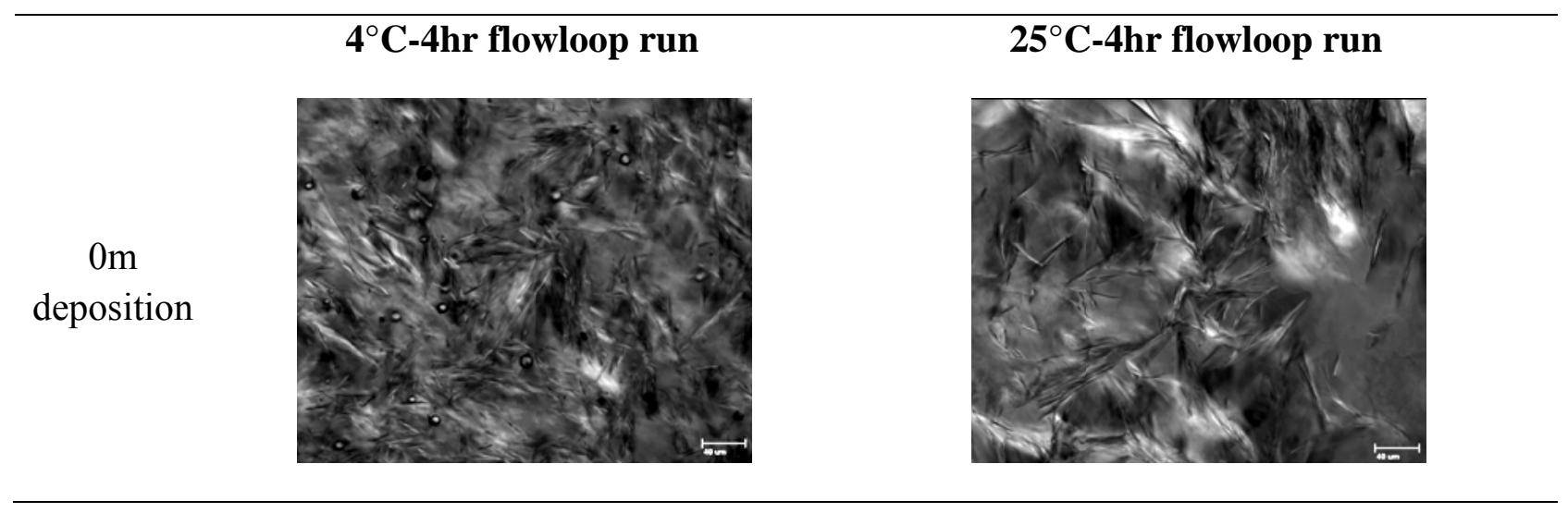


$5 \mathrm{~m}$
deposition

No deposition

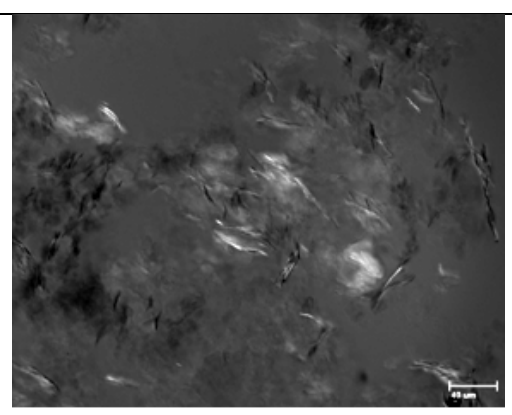

Figure 13: Microstructure of deposited wax from the different flowloop sections after $4 \mathrm{hr}$ at $25^{\circ} \mathrm{C}$ and $4^{\circ} \mathrm{C}$. Scale bar represents $40 \mu \mathrm{m}$.

\subsubsection{Flowloop runs at $4^{\circ} \mathrm{C}$ and $25^{\circ} \mathrm{C}$ for $30 \mathrm{hrs}$}

Although the $4 \mathrm{hr}$ flowloop runs yielded important information on pressure drop and wall deposition, it was necessary to establish the deposition behaviour during longer flowloop runs.

\subsubsection{Pressure and temperature change during $30 \mathrm{hr}$ flowloop experiments}

The pressure drop across the flowloop over $30 \mathrm{hrs}$ is shown in Figure 14. The initial pressure ( 4 min after the start of data recording) reached $\sim 30$ psi with the $25^{\circ} \mathrm{C}$ runs and $\sim 150$ psi with the $4^{\circ} \mathrm{C}$ runs within a minute of starting the PC pump (after the fluid had passed through the $15 \mathrm{~m}$ loop once). After $30 \mathrm{hrs}$, the pressure drop reached $65 \mathrm{psi}$ with the $25^{\circ} \mathrm{C}$ run. The increase in pressure drop with time was due to the formation of a wax deposit on the flowloop wall thereby reducing the inner diameter of the flowloop. At $4^{\circ} \mathrm{C}$, the pressure remained unchanged at around 140 to 150 psi. This was somewhat surprising, as the initial thought was that more solid wax at lower temperature would lead to higher wall deposition and hence a gradual increase in pressure drop would be observed. However, even after $30 \mathrm{hrs}$, the deposit mass was much lower at $4^{\circ} \mathrm{C}$ compared to $25^{\circ} \mathrm{C}$ (Figure 17). However, the average pressure drop at $4^{\circ} \mathrm{C}$ was considerably higher than at $25^{\circ} \mathrm{C}$ given the higher viscosity of the fluid at lower temperatures. The cyclical increase and decrease in pressure drop was thought to result from sloughing (shearing of the deposited wax) from inside the loop. 


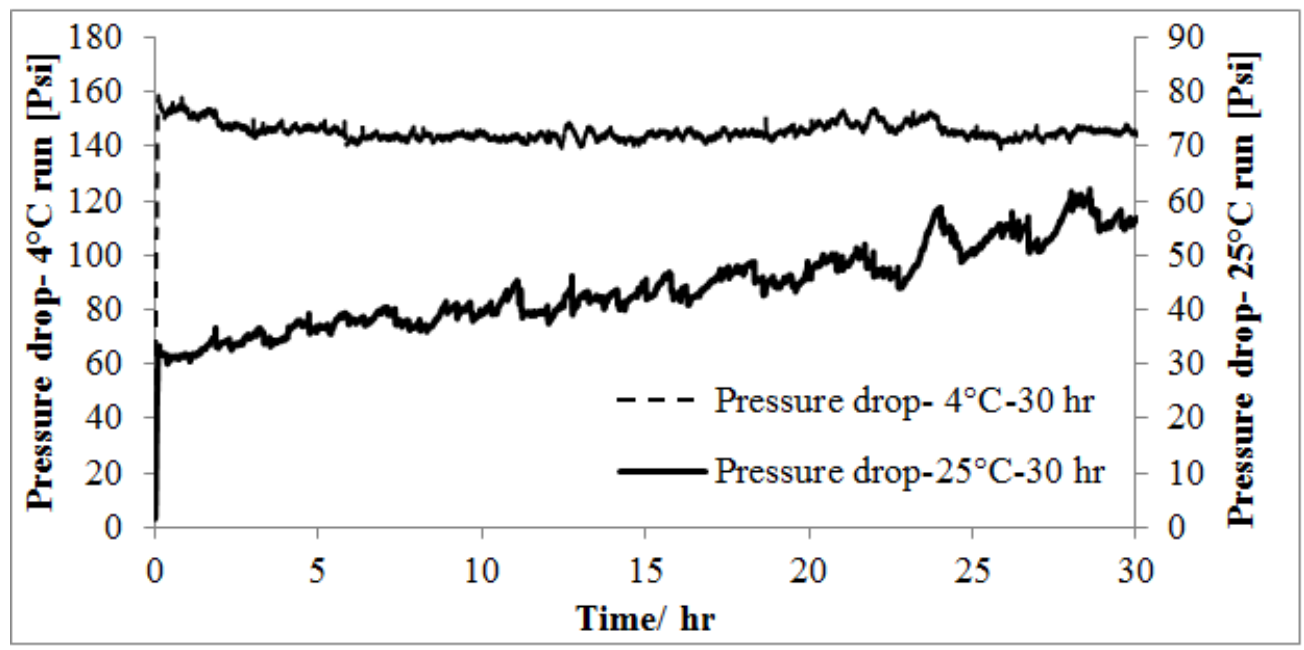

Figure 14: Change in pressure drop as a function of time across the flowloop for $30 \mathrm{hr}$ runs at $25^{\circ} \mathrm{C}$ or $4^{\circ} \mathrm{C}$

The corresponding changes in loop outlet and sea-bed sink temperatures are shown in Figure 15. The overall outlet temperature patterns matched the pressure drop data. At $25^{\circ} \mathrm{C}$, the outlet temperature increased as a function of time from $\sim 25.5^{\circ} \mathrm{C}$ to $\sim 27^{\circ} \mathrm{C}$. The gradual increase in outlet temperature for the $25^{\circ} \mathrm{C}-30 \mathrm{hr}$ runs was due to deposit formation on the loop inner wall. The deposited layer acted as an insulator, which presumable led to a decrease in heat loss from the flowing fluid towards the external seabed. For the $4^{\circ} \mathrm{C}$ neat oil run, no significant changes in loop outlet temperatures were observed during the $30 \mathrm{hr}$ runs (average outlet temperature $7.8 \pm$ $0.2^{\circ} \mathrm{C}$ ) (Figure 14$)$.

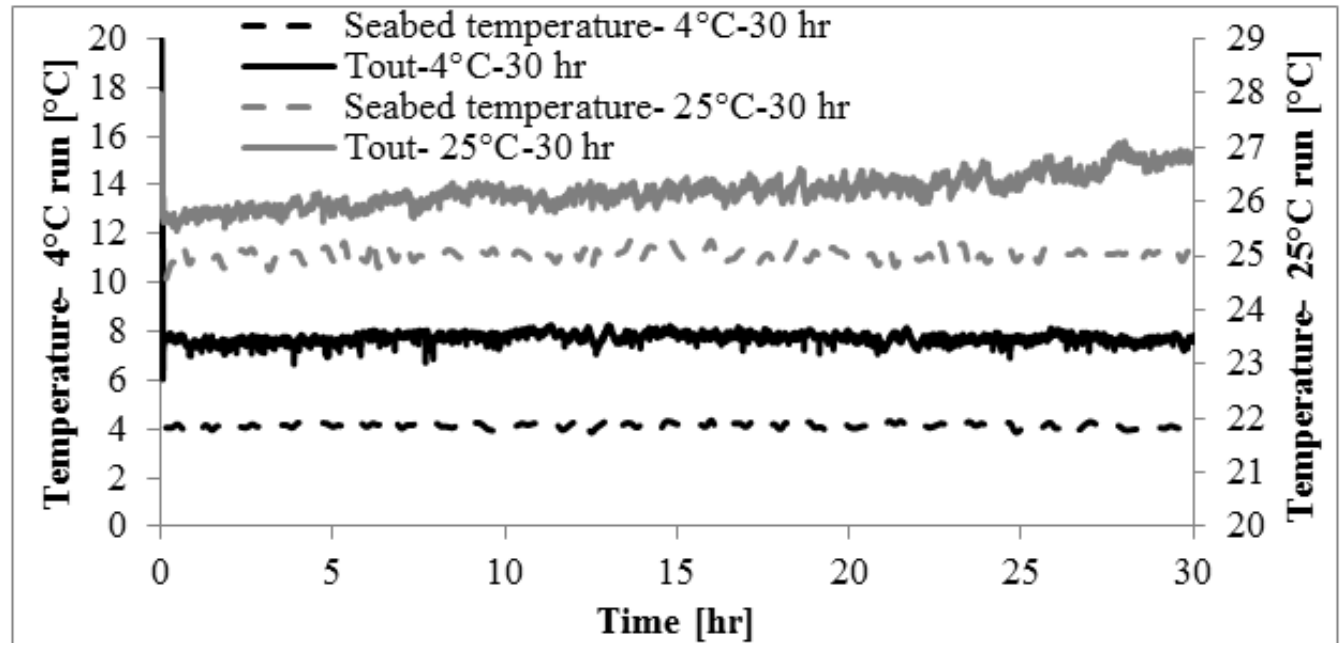

Figure 15: Change in loop outlet and sea-bed sink temperatures as a function of time for $30 \mathrm{hr}$ runs at $25^{\circ} \mathrm{C}$ and $4^{\circ} \mathrm{C}$. 


\subsubsection{Deposition on the flowloop wall}

Photographs of the removable loop sections and the corresponding wall deposits following the $30 \mathrm{hr}$ flowloop runs are shown in Figure 16. For the $4^{\circ} \mathrm{C}$ runs, deposition was only seen in $0 \mathrm{~m}$ and $5 \mathrm{~m}$ loop sections while for the $25^{\circ} \mathrm{C}$ runs, considerable deposition was observed in all loop sections. It can be seen that in the $0 \mathrm{~m}$ loop section, the $4^{\circ} \mathrm{C}$ neat oil runs resulted in significantly higher deposition ( $4.1 \mathrm{~g}$ ) compared to the $25^{\circ} \mathrm{C}$ neat oil ( $2.4 \mathrm{~g}$ ) (Figure 17). The corresponding $\% \mathrm{SWC}$ of the deposited material was also much higher at $4^{\circ} \mathrm{C}$ compared to $25^{\circ} \mathrm{C}$ in the $0 \mathrm{~m}$ section $\left(28.8 \%\right.$ wax for $4^{\circ} \mathrm{C}$ neat oil compared to $13.3 \%$ for $25^{\circ} \mathrm{C}$ neat oil) (Figure 18). At $5 \mathrm{~m}$, deposition during the $4^{\circ} \mathrm{C}$ neat oil run dropped sharply to $0.7 \mathrm{~g}$ while the runs at $25^{\circ} \mathrm{C}$ resulted in the highest deposition ( $4.6 \mathrm{~g}$ ). The little deposition obtained at $4^{\circ} \mathrm{C}$ contained $\sim 20 \%$ solid wax compared to an SWC of $16.6 \%$ for the $25^{\circ} \mathrm{C}$ runs. At $25^{\circ} \mathrm{C}$, deposition was evident in the $10 \mathrm{~m}$ and $15 \mathrm{~m}$ sections though lower than at $5 \mathrm{~m}$. Interestingly, the wax content of the deposit did not follow the same trend, as the wax content in the removable $15 \mathrm{~m}$ loop section was the highest of all for the $25^{\circ} \mathrm{C}$ neat oil.

\section{Neat oil $\left(25^{\circ} \mathrm{C}-30 \mathrm{hr}\right)$}

Loop length/

$\mathrm{m}$

Side2
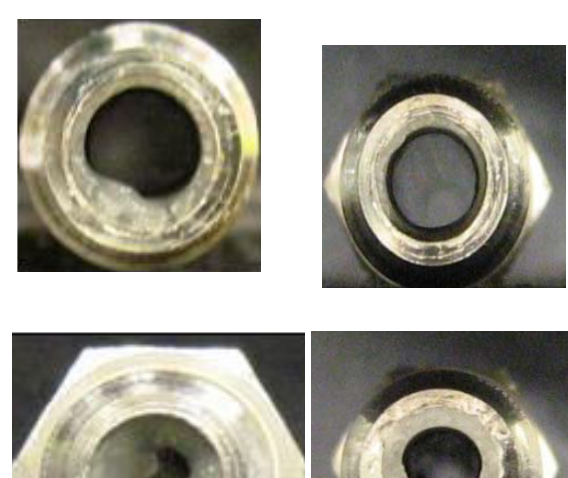

5
Side2

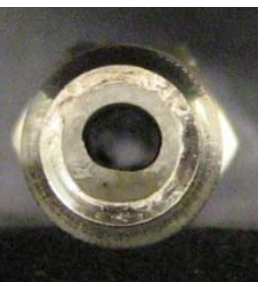

Neat oil $\left(4^{\circ} \mathrm{C}-30 \mathrm{hr}\right)$

Side2

Side2
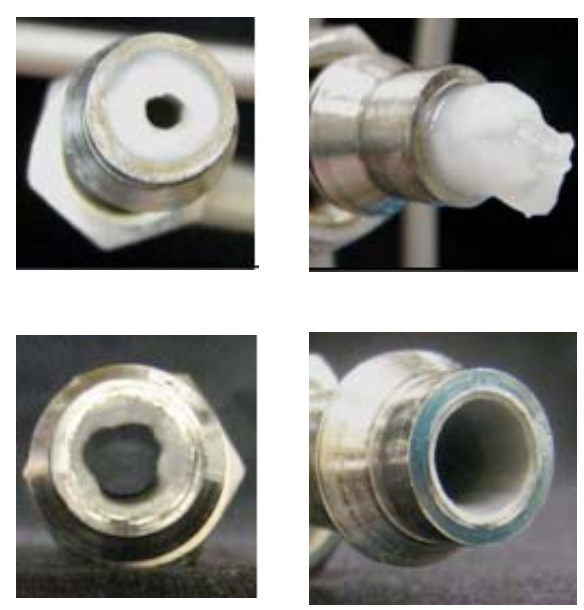


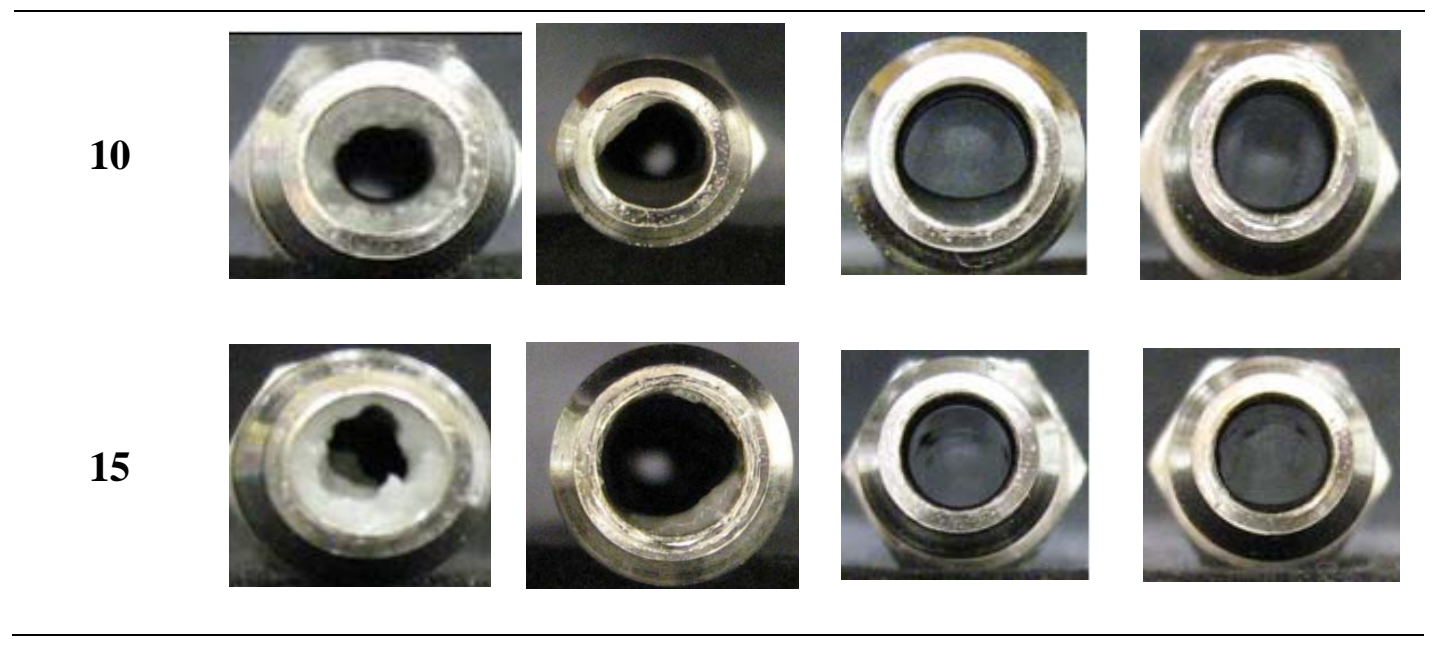

Figure 16: Loop section pictures at the end of the $30 \mathrm{hr}$ flowloop runs at $25^{\circ} \mathrm{C}$ and $4^{\circ} \mathrm{C}$.

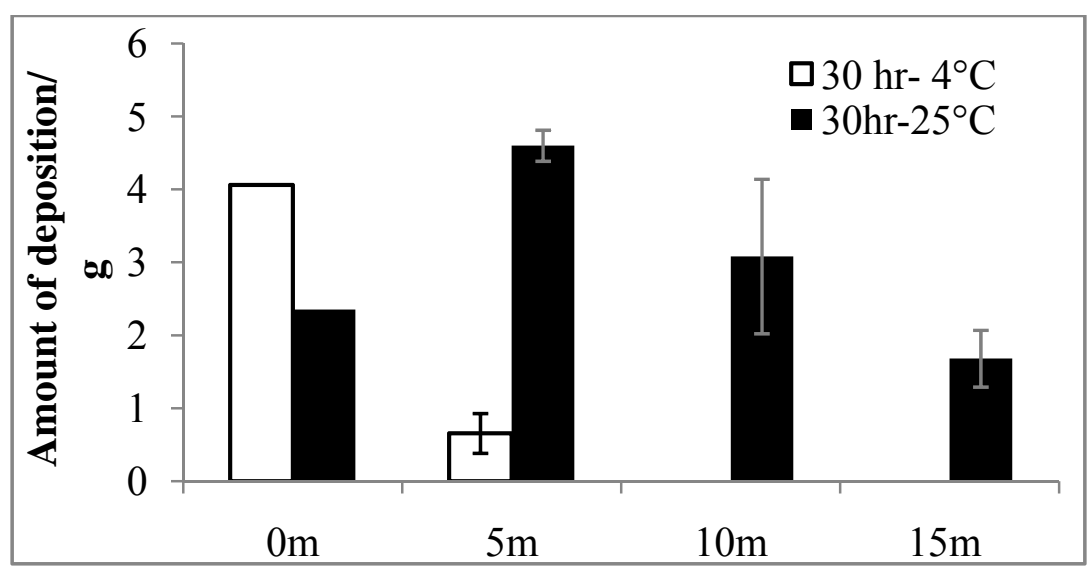

Figure 17: Amount of wax deposition in different loop sections after $30 \mathrm{hr}$ flowloop runs at $25^{\circ} \mathrm{C}$ and $4^{\circ} \mathrm{C}$

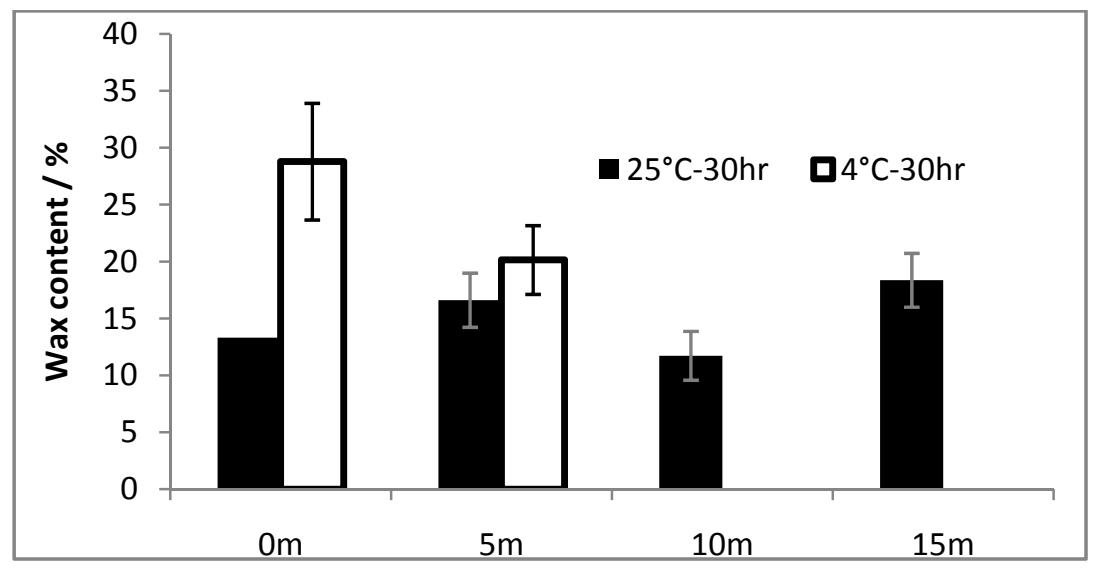

Figure 18: DSC-measured wax content of the deposited wax in the different loop sections after $30 \mathrm{hr}$ runs at $25^{\circ} \mathrm{C}$ and $4^{\circ} \mathrm{C}$ 
Comparing the $30 \mathrm{hr}$ and $4 \mathrm{hr}$ neat oil runs at $4^{\circ} \mathrm{C}$, even though the amount of deposition increased in the $0 \mathrm{~m}$ loop sections (from $1.1 \mathrm{~g}$ after $4 \mathrm{hrs}$ to $4.1 \mathrm{~g}$ after $30 \mathrm{hrs}$ ), no significant difference in the SWC was observed (Figure 12 and Figure 18). The amount of deposition and wax content of the deposition as a function of flowloop run time at $25^{\circ} \mathrm{C}$ is shown in Figure 19. It can be seen that in 0 and $5 \mathrm{~m}$ loop section, the amount of wax deposition did not change after the $4 \mathrm{hr}$ and $30 \mathrm{hr}$ flowloop run (Figure $19 \mathrm{~A}$ ). However, its SWC significantly increased from 4 $\mathrm{hr}(\sim 10 \%)$ to $30 \mathrm{hr}(\sim 15 \%)$ indicating hardening of deposition with time. In the 10 and $15 \mathrm{~m}$ loop sections, no deposition was observed after $4 \mathrm{hrs}$, but after $30 \mathrm{hrs,}$, a remarkable increase in amount of deposition was observed.
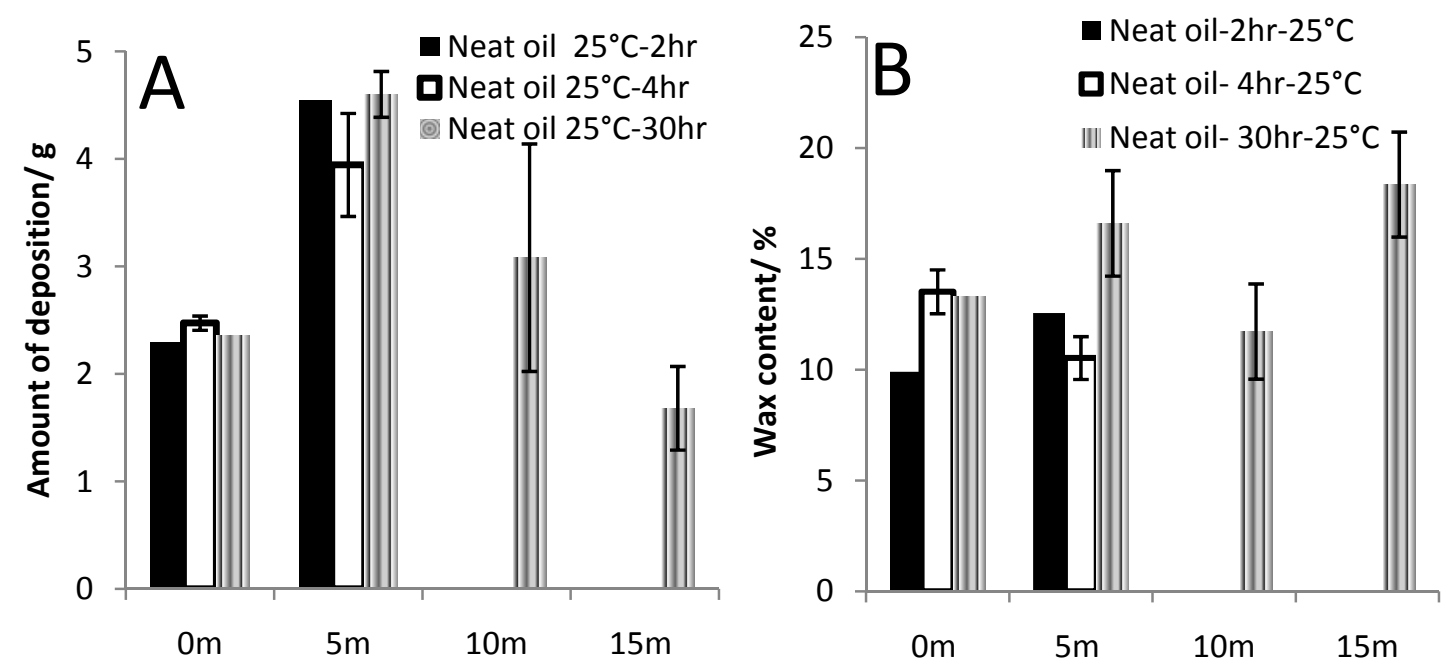

Figure 19: Evolution in amount of wax deposition (A) and wax content of the deposition (B) in different loop sections as a function of time

\subsubsection{Microstructure of the deposited material}

Combined polarized and DIC (Differential Interference Contrast) images of the deposited material from the 4 removable sections after the $30 \mathrm{hr}$ flowloop runs are shown in

Figure 20. For both the $4^{\circ} \mathrm{C}$ and $25^{\circ} \mathrm{C}$ runs, a larger crystal size was observed in the $0 \mathrm{~m}$ section compared to the other removable sections. The deposit from the $0 \mathrm{~m}$ loop section of the $4^{\circ} \mathrm{C}$ neat oil run contained more densely-packed wax crystals compared to the $25^{\circ} \mathrm{C}$ runs, which is in agreement with their corresponding wax content results (Figure 18). Similar to the wax content results (Figure 18), deposit microstructure in the $15 \mathrm{~m}$ loop sections at $25^{\circ} \mathrm{C}$ showed more densely-packed wax crystals compared to the 5 and $10 \mathrm{~m}$ loop sections. A very different 
microstructure was observed in the $5 \mathrm{~m}$ loop section for $4^{\circ} \mathrm{C}$-neat oil ('lumps' of crystals) compared to $25^{\circ} \mathrm{C}$ neat oil (sharp needle-shaped crystals). At the end of the $4 \mathrm{hr}$ run at $4^{\circ} \mathrm{C}$, the $5 \mathrm{~m}$ loop section consisted of small needle-shaped crystals (Figure 13) whereas at the end of $30 \mathrm{hr}$ run, the wax crystals were large. After the $4 \mathrm{hr}$ run, the micrograph showed the effect of crashcooling the fluid. But after the $30 \mathrm{hr}$ runs, this effect seemed to have disappeared as a result of the continuing deposition. The deposit acted as an insulator, which may have altered the crystal morphology observed.

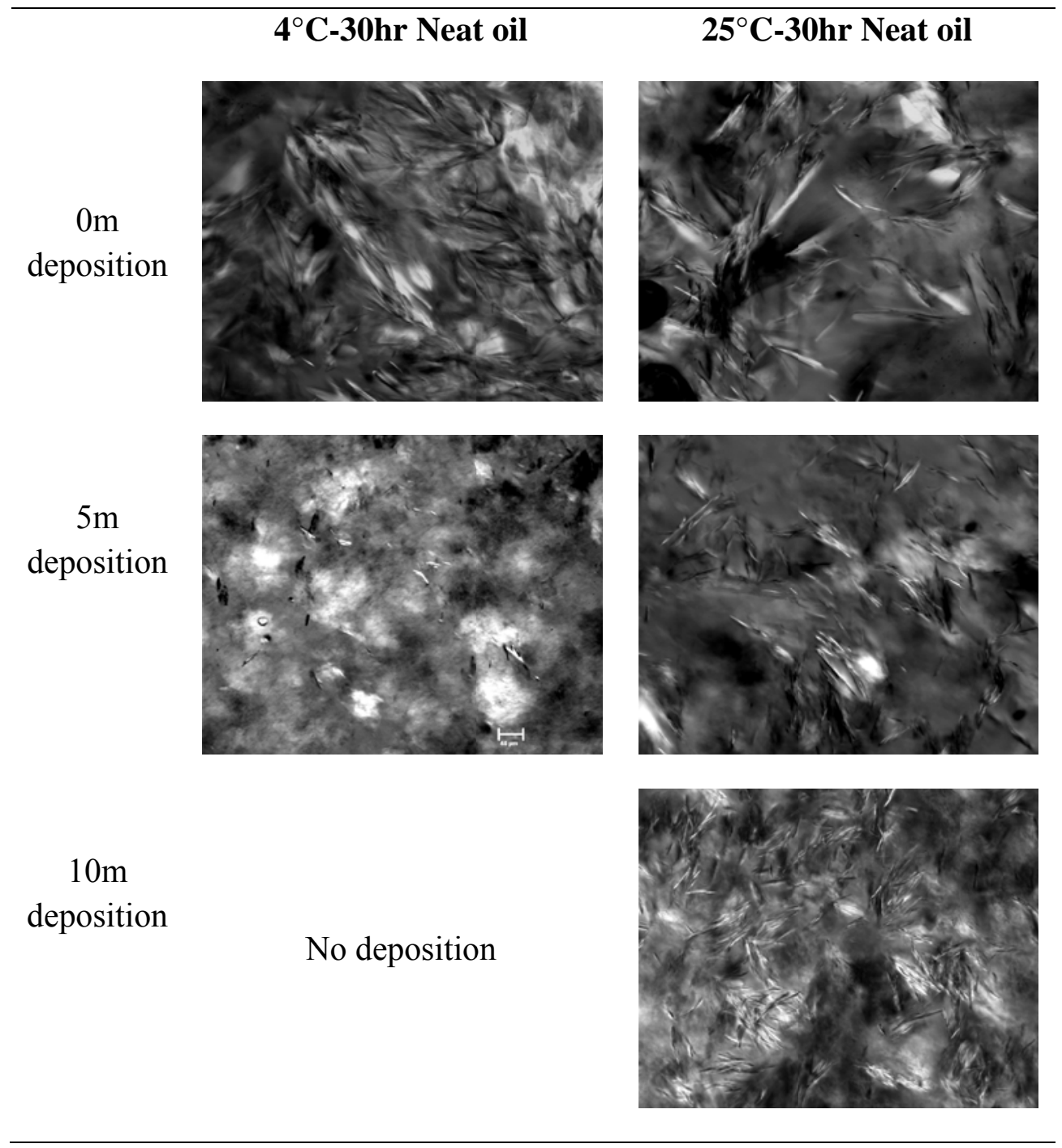




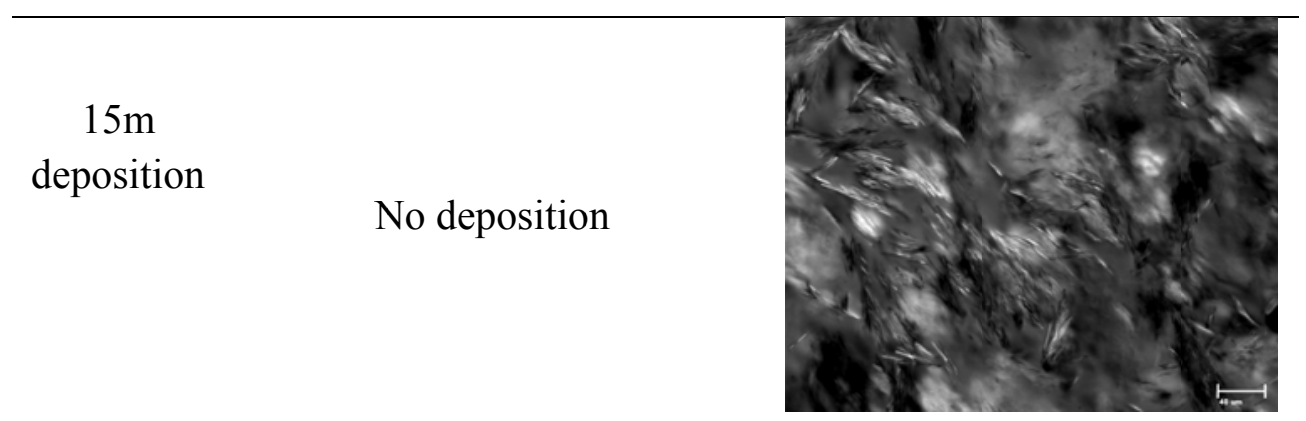

Figure 20: Microstructure of deposited wax from different flowloop sections at $25^{\circ} \mathrm{C}$ and $4{ }^{\circ} \mathrm{C}$. Scale bar represents $40 \mu \mathrm{m}$.

\subsubsection{Wax content of samples collected during the $30 \mathrm{hr}$ flowloop runs}

During all flowloop runs, samples were collected from the outlet valve at specific time intervals and transferred to a $4^{\circ} \mathrm{C}$ incubator for $24 \mathrm{hr}$ to crystallize all of the wax prior to measuring the solid wax content via NMR (Figure 21). For both the $4^{\circ} \mathrm{C}$ and $25^{\circ} \mathrm{C}$ runs, the SWC decreased with time as more wax deposited was on the inner loop wall. Also, after $\sim 16 \mathrm{hr}$, the $25^{\circ} \mathrm{C}$ runs had a lower SWC when compared to the $4^{\circ} \mathrm{C}$ runs, indicating that more wax had diffused onto the flowloop inner wall.

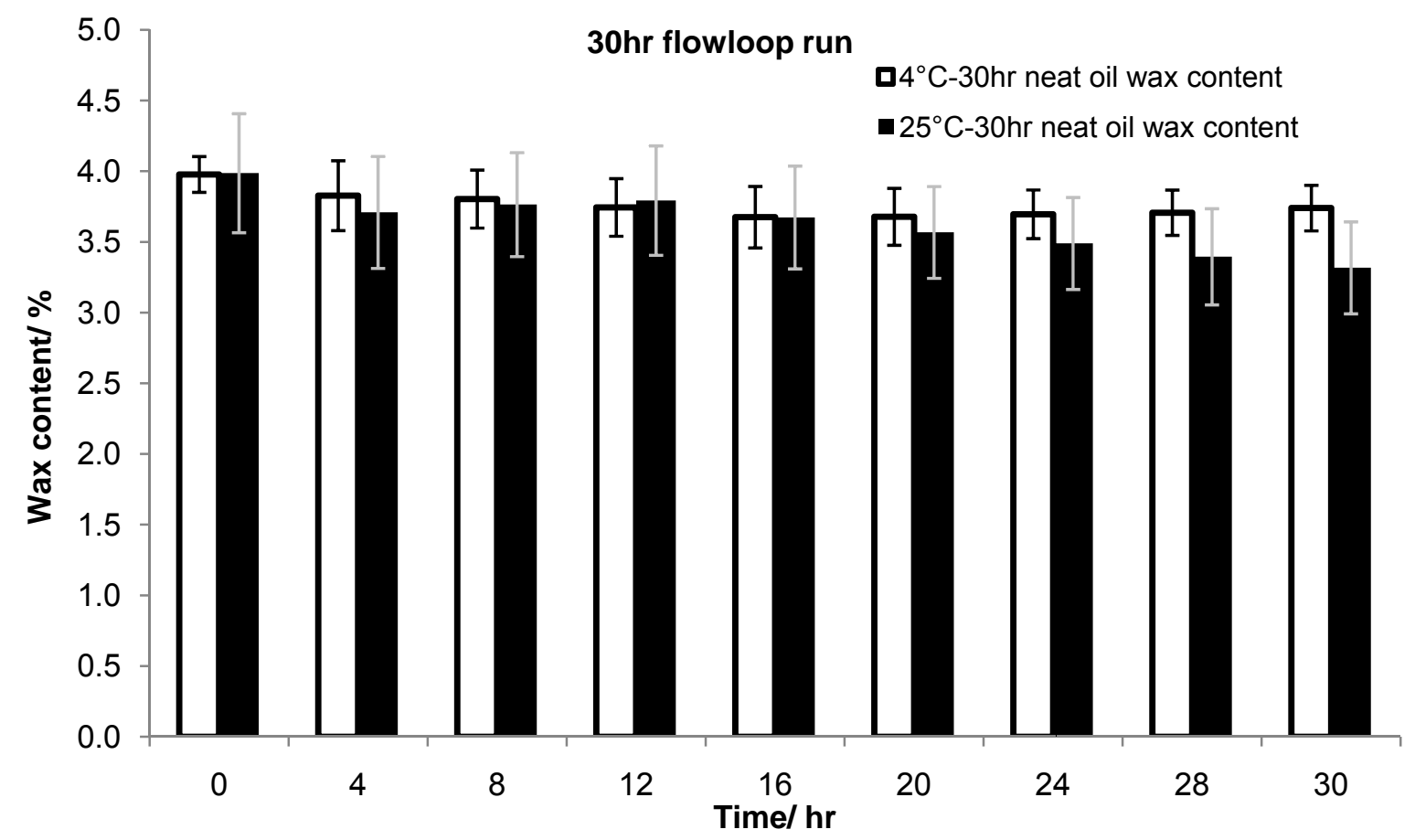

Figure 21: Wax content of samples collected during flowloop runs. All samples were stored at $4^{\circ} \mathrm{C}$ for $24 \mathrm{hr}$ before measuring SWC with NMR. 


\subsection{Conclusion}

The flow behaviour of a wax-oil mixture was characterized under different cooling regimes in a unique, temperature-controlled lab-scale flowloop. Results demonstrated that the following factors significantly impacted wax deposition: the flowloop 'seabed' temperature and the temperature gradient experienced by the flowing fluid.

The flowloop 'seabed' temperature had an obvious effect on wax deposition. Flowloop runs at lower temperatures led to reduce overall deposition on the flowloop inner wall (for runs up to 30 hrs). This was based on the $4^{\circ} \mathrm{C}$ neat oil runs, which only showed deposition at the beginning of the flowloop (mostly in the removable $0 \mathrm{~m}$ section) and on the $25^{\circ} \mathrm{C}$ runs, which showed continued deposition further along the loop length. Temperature also impacted SWC. With the $30 \mathrm{hr}$ runs, the SWC of the neat oil deposit was $\sim 28 \%$ at $4^{\circ} \mathrm{C}$ whereas it was only $13 \%$ with the $25^{\circ} \mathrm{C}$ neat oil runs. The deposit was thus much harder at the lower 'seabed' temperature. The temperature gradient that the flowloop was subjected to also impacted the type of deposition experienced. Running the flowloop at $25^{\circ} \mathrm{C}$ resulted in a much smaller temperature gradient across the flowloop, thus the wax present in the neat oil reached its WAT much more slowly, leading to deposition further along the loop length. At $4^{\circ} \mathrm{C}$, the near flash-cooling experienced by the wax resulted in the rapid formation of a gel in the early portion of the flowloop. The result was that much of the wax was no longer 'available' to be deposited further along the loop. By rapidly reaching this low seabed sea temperature, the wax had already undergone its liquid-solid phase transition, which resulted in minimal subsequent deposition. 


\section{Impact of water cut and the role of continuous phase wax crystals on $\mathrm{W} / \mathrm{O}$ emulsion rheology}

\subsection{Introduction}

Water-in-oil emulsions stabilized by particles such as triglyceride or paraffin wax crystals naturally exist or are an added ingredient in many products including crude oil, butter, ice cream and cosmetic hand creams. From a formulation standpoint, the addition of a dispersed aqueous phase can significantly alter the process ability and/or final properties (e.g., appearance, shelf life, etc.) of a W/O-based product. As well, the volume fraction of the dispersed phase in an emulsion (i.e., the water cut) can have a significant influence on emulsion rheology. There currently remains a dearth of information on the combined contribution of water cut and continuous phase crystals on stability, flow behaviour and rheological properties of colloidstabilized emulsions. The objective of this section was to understand the rheological behaviour of W/O emulsions stabilized by paraffin wax crystals. The study focused on the impact of different water cuts (10-50 wt\%) on emulsions prepared with an oil phase containing $5 \mathrm{wt} \%$ wax and various amount of surfactant (GMO), where all the emulsions had similar average droplet diameter of $\sim 30 \mu \mathrm{m}$.

\subsection{Methodology}

$\mathrm{W} / \mathrm{O}$ emulsions with water cuts $10,20,30,40,50$, and $60 \mathrm{wt} \% \mathrm{~W} / \mathrm{O}$ were studied. To directly compare the rheological behaviour of emulsions with different water cuts, it was crucial to have similar starting droplet size distributions, as consistency in droplet size would remove a key confounding factor responsible for possible differences in rheological behaviour. The following approach was taken to ensure similar droplet sizes for all emulsions. From previous studies in the research group, it was known that a 20\% W/O emulsion (oil phase: $5 \mathrm{wt} \%$ Paraffin wax and 0.05 wt $\%$ GMO) homogenized with the laboratory valve homogenizer yielded an average water droplet diameter of $30 \mu \mathrm{m}$. This composition was used as the basis for all other emulsions wherein the wax content was kept constant ( $5 \mathrm{wt} \%$ ) and the amount of GMO added was changed to reflect the emulsion's water cut (Equation 10) (Paunov, Sandler et al. 2001). To have a similar average droplet size for all emulsions, the right side of the equation, except for volume fraction $(\varphi)$, was deemed constant. Thus, the amount of GMO changed with the water ratio. Emulsion compositions are summarized in Table 6. Equation 10 is used to determine the monolayer droplet 
coverage of surfactant in controlled emulsions. It is also used for surfactants that are not micelles like.

$$
n=\frac{3 \varphi}{r_{00} \cdot a_{s} \cdot N_{A}}
$$

Equation 10

- $\mathrm{n}$ : Molar concentration of the surfactant

- $\varphi$ : Volume fraction (water cut)

- $\mathrm{r}_{00}$ : Number-weighted mean droplet radius

- $a_{s}$ : Surface area

- $\mathrm{N}_{\mathrm{A}}$ : Avagadro's number $=6.0221 \times 10^{23}$

- $\mathrm{MW}_{\mathrm{gmo}}$ : Molecular weight of glycerol monoleate

Table 6: Emulsion composition for all water cuts, assuming a $100 \mathrm{~g}$ mass.

\begin{tabular}{ccccc}
\hline Water Cut \% & Oil Phase \% & Wax (5 wt\% oil) & \multicolumn{2}{c}{ Surfactant (GMO) } \\
10 & 90 & $4.5 \mathrm{~g}$ & $0.025 \%$ & $0.0225 \mathrm{~g}$ \\
20 & 80 & $4.0 \mathrm{~g}$ & $0.050 \%$ & $0.0400 \mathrm{~g}$ \\
30 & 70 & $3.5 \mathrm{~g}$ & $0.075 \%$ & $0.0525 \mathrm{~g}$ \\
40 & 60 & $3.0 \mathrm{~g}$ & $0.100 \%$ & $0.0600 \mathrm{~g}$ \\
50 & 50 & $2.5 \mathrm{~g}$ & $0.125 \%$ & $0.0625 \mathrm{~g}$ \\
60 & 40 & $2.0 \mathrm{~g}$ & $0.150 \%$ & $0.0600 \mathrm{~g}$ \\
\hline
\end{tabular}

Key elements of these emulsions were that they all had to have dispersed aqueous droplets with a mean diameter of $\sim 30 \mu \mathrm{m}$ to remove droplet size as factor responsible for the changes seen in rheology. Also, the resulting emulsions were to only be stabilized by continuous phase wax crystals. Emulsifier usage was controlled so as to only permit formation of the W/O emulsion, but not provide any stabilization. Therefore, the emulsion would completely destabilize and phase separate by heating to the temperature higher than the melting point of the paraffin wax. 


\subsubsection{Emulsion preparation}

Water-in-oil emulsions were produced with a different aqueous phase of $10-60 \mathrm{wt} \%$. The aqueous phase contained $3.5 \mathrm{wt} \% \mathrm{NaCl}$. The presence of salt in the aqueous phase was necessary to prevent the formation of oil droplets in the water phase (hence, double emulsion formation), which was ascribed to charge generation by the intense shearing action of the homogenizer (a previous finding from the Rousseau research group). The oil phase contained different amounts of GMO $(0.025-0.15 \mathrm{wt} \%)$ as emulsifier and $5 \mathrm{wt} \%$ paraffin wax. The oil and aqueous phases were independently heated to $45^{\circ} \mathrm{C}$ and then pre-mixed. Pre-mixing was done by the slow addition of the aqueous phase $(9 \mathrm{ml} / \mathrm{min})$ to the oil phase in a beaker at $45^{\circ} \mathrm{C}$ with a magnetic stirrer at $500 \mathrm{rpm}$ for 15 minutes. The pre-mixed mixture was quickly transferred to a valve homogenizer (APV-1000, APV, Albertslund, Denmark) (Figure 23) preheated to $45^{\circ} \mathrm{C}$ and homogenized at 500 psi for 4 cycles. The final emulsions were quenched-cooled in an ice bath to $4^{\circ} \mathrm{C}$ while stirring at $300 \mathrm{rpm}$ using a top stirrer (overhead impeller). Emulsion stability was assessed via microscopy, differential scanning calorimetry and droplet size analysis. As the resulting emulsions were solely stabilized by wax crystals and GMO was used only to permit formation of $\mathrm{W} / \mathrm{O}$ emulsion, quench cooling to low temperature of $4{ }^{\circ} \mathrm{C}$ was necessary to have the wax stabilize the emulsions. Slow cooling resulted in unstable emulsions that readily phaseseparated (a previous finding from the Rousseau research group). Figure 22 shows a summary of the emulsion preparation approach. 


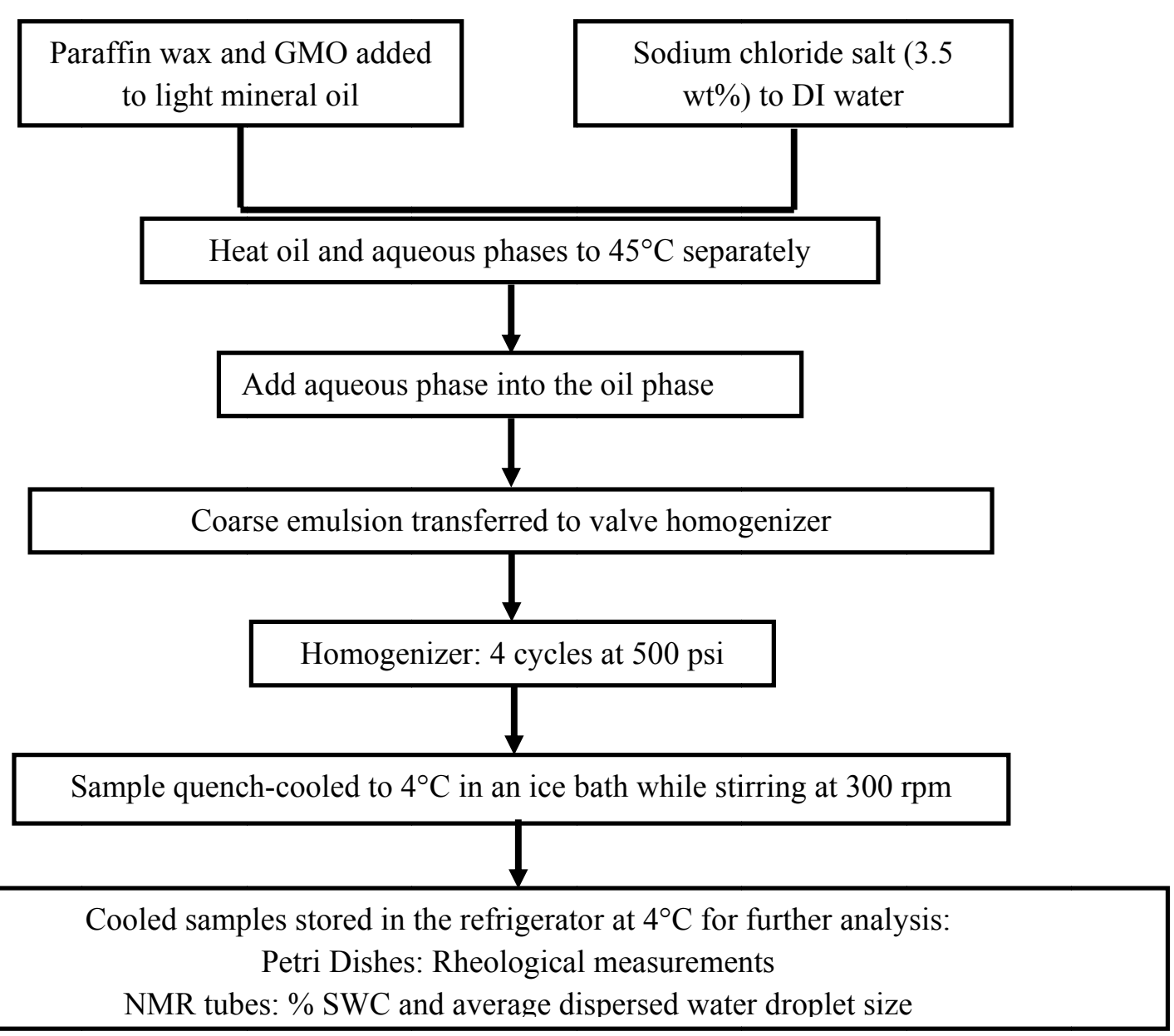

Figure 22: Summary of emulsion preparation.

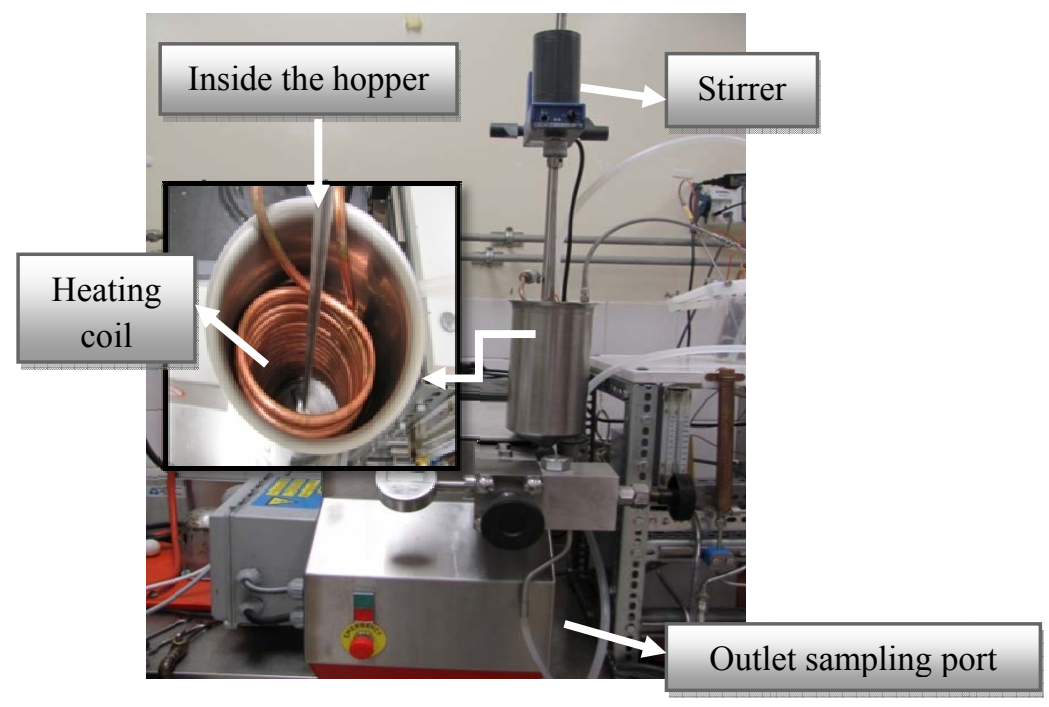

Figure 23: Image of the valve homogenizer used to prepare the $\mathrm{W} / \mathrm{O}$ emulsions with different water cuts. 


\subsubsection{Emulsion storage}

Following preparation, the fresh emulsions were placed in Petri dishes for up to one month to permit rheological characterization of undisturbed emulsions at different time points. During a typical rheological experiment, a sample was transferred from its storage container to the rheometer. In the case where there was structure development over time, it would be broken down as a result of product transfer. By using this approach, it was possible to directly characterize the impact of ageing on emulsion rheology. Samples were characterized at days 0,1 , $2,7,14,21$ and 28 .

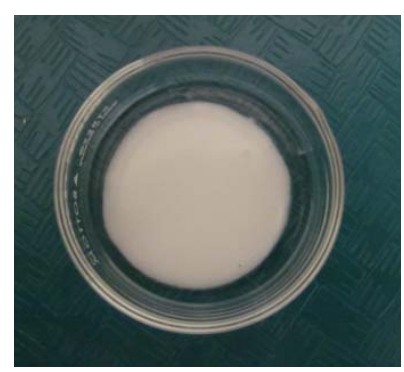

Figure 24: Example of a Petri dish containing an emulsion sample.

\subsubsection{Neat oil mixture (Control)}

To establish the role of the dispersed aqueous phase on emulsion rheology, the corresponding oil phase (mineral oil, wax and surfactant with no added water) of $20 \mathrm{wt} \%$ and $50 \mathrm{wt} \%$ emulsions were prepared in the same manner as the emulsions. The two compositions were: $5 \%$ wax and $0.05 \% \mathrm{GMO}$ in mineral oil (equivalent to the $20 \mathrm{wt} \% \mathrm{~W} / \mathrm{O}$ emulsion) and $5 \%$ wax with $0.125 \%$ in mineral oil (equivalent to the $50 \mathrm{wt} \% \mathrm{~W} / \mathrm{O}$ emulsion).

\subsubsection{Solid wax content}

Aliquots of emulsions were pipetted into NMR tubes (ID $=0.8 \mathrm{~cm}, \mathrm{~L}=20 \mathrm{~cm}$ ) to a height of 6 $\mathrm{cm}$. Samples were stored at $4{ }^{\circ} \mathrm{C}$ to crystallize the wax present and they were monitored for a one month period after day 2. Samples were analyzed using a Bruker Minispec Mq pulsed field gradient nuclear magnetic resonance (pfg-NMR) unit (Bruker Canada, Milton, ON, Canada) with the application software sfe_lfc v2.51.

\subsubsection{Droplet size determination}

The dispersed droplet size distribution of the emulsions was determined at $4{ }^{\circ} \mathrm{C}$ using a Bruker Minispec Mq pulsed field gradient nuclear magnetic resonance (pfg-NMR) unit (Bruker Canada, 
Milton, ON, Canada) that allows unimodal characterization of emulsion droplet size distributions via restricted diffusion measurement. The temperature inside the NMR sample chamber was controlled by an external waterbath pre-set at a specific temperature $\left(1^{\circ} \mathrm{C}\right.$ to achieve $4{ }^{\circ} \mathrm{C}$ in the chamber). The pfg-NMR field gradient strength was calibrated with $\mathrm{CuSO}_{4}$-doped water (diffusion coefficient $=2.3 \times 10-9 \mathrm{~m}^{2} \mathrm{~s}^{-1}$ at $25^{\circ} \mathrm{C}$ ). Emulsion samples (height $=1 \mathrm{~cm}$ ) in glass tubes (ID $=0.8 \mathrm{~cm}, \mathrm{~L}=20 \mathrm{~cm}$ ) were placed in the NMR unit and their droplet size distribution was determined by measuring $\mathrm{d}_{3,3}$ (volume weighted geometric mean diameter) values and the breadth of distribution $\sigma$ (geometric standard deviation). Free water was defined as dispersed water droplets sized above the NMR instrumental limit $(\sim 500 \mu \mathrm{m})$ that had not phase-separated from the emulsion as bulk water. As this technique relies on the molecular movement of water molecules within droplets, it detects size increases in the droplets themselves and not their clustering, thereby differentiating coalescence from flocculation/coagulation.

\subsubsection{Rheology}

The rheology experiments were performed with an Anton PaarPhysica MCR 301 rheometer (Anton Paar, Montreal, QC, Canada). As mentioned before, in order to assess the strength of the emulsions' wax crystal network, it was important to minimize sample handling during rheological measurements, as this would significantly impair crystal network structure. To minimize sample handling, freshly-prepared emulsions (quench cooled with stirring) were transferred to glass Petri dishes on day 0 . These sample Petri dishes were stored at $4{ }^{\circ} \mathrm{C}$ and, when required, transferred to the rheometer for measurement of their rheological behaviour. The rheometer was modified to accommodate the glass Petri dish as its bottom plate. A glass parallel plate geometry (PP-43GL, diameter $43 \mathrm{~mm}$, gap $0.05 \mathrm{~mm}$ ) was used as the top plate to avoid slippage effects at low stress/strain (Visintin, Lapasin et al. 2005). All rheological measurements were performed at a constant temperature of $10^{\circ} \mathrm{C}$ (this temperature was selected given that the time taken to transfer the samples from the storage chamber to the rheometer resulted in a small temperature increase). The temperature was precisely controlled with Peltier baseplate.

Three types of rheology experiments were measured during a one month aging period, including rotational, oscillatory and creep and compliance recovery. For rotational runs, the viscosity of the sample was measured as a function of shear rate. All runs were performed isothermally at $10^{\circ} \mathrm{C}$. The sample was first kept at $10^{\circ} \mathrm{C}$ for one minute to equilibrate, and then sheared from 10 to 
$1000 \mathrm{~s}^{-1}$ linearly while viscosity was measured. The oscillatory measurements were conducted at constant frequency of $1 \mathrm{~Hz}$. There was a $1 \mathrm{~min}$ hold time at $10^{\circ} \mathrm{C}$ prior to the beginning of each run followed by the measurement of storage and loss moduli with log-scale changes in amplitude from $0.01 \%$ to $100 \%$ of the strain. Finally, creep compliance and recovery tests were conducted at a shear stress of $0.3 \mathrm{~Pa}$ (within the linear viscoelastic region). The deformation stress was applied for $319 \mathrm{~s}$ followed by the recovery portion, which was applied with no stress for $636 \mathrm{~s}$. The duration of creep compliance and recovery were chosen such that the slope of the strain against time was constant.

\subsubsection{Microscopy}

Samples were taken from Petri dishes with a glass rod, placed on a viewing slide, covered with a cover slip and observed with an inverted Zeiss Axiovert 200M light microscope (Zeiss Inc., Toronto, ON, Canada). The viewing slides and the cover slips were cooled to the sample temperature prior to sampling. A $10 \mathrm{x}$ and a $20 \mathrm{x}$ objective lens were used to record sample microstructure under DIC (Differential Interference Contrast) and PLM (Polarized Light Microscopy) modes.

\subsubsection{Differential scanning calorimetry}

A DSC (Pyris Diamond model, PerkinElmer Life and Analytical Sciences, Woodbridge, ON, Canada) was used to determine emulsion stability, characterize the wax melting and crystallization behaviour, and determine the WAT. The emulsion samples ( 4-10 mg) were hermetically sealed in aluminum pans and weighed. Samples were cooled from $4{ }^{\circ} \mathrm{C}$ to $-70{ }^{\circ} \mathrm{C}$, re-heated to $70{ }^{\circ} \mathrm{C}$ and then re-crystallized to $-70{ }^{\circ} \mathrm{C}$ at a rate of $2{ }^{\circ} \mathrm{C} / \mathrm{min}$. Crystallization points were determined from the peak temperatures using the DSC data analysis software (Pyris v.7, PerkinElmer Life and Analytical Sciences, Woodbridge, ON, Canada).

\subsubsection{Statistical analyses}

Triplicate analyses were conducted for all the rheological experiments, droplet size and solid wax content measurements. Analyses of variance (ANOVA) was performed using OriginPro 8 SR3 (Northampton, MA, USA) and statistical differences were considered significant at $\mathrm{p}=0.05$. 


\subsection{Results and discussion}

\subsubsection{Water droplet size evolution with time for emulsions with different water cuts}

Emulsion stability was monitored by measuring the water droplet size over a one month period for emulsions with water cuts of 20-60 wt $\%$. The $\mathrm{W} / \mathrm{O}$ emulsions with a $10 \mathrm{wt} \%$ water cut $\mathrm{W} / \mathrm{O}$ did not yield droplets measureable via pulsed NMR, due to their small population, which was lower than the detection limit of the NMR, and so were monitored with light microscopy instead (Figure 25). For the emulsions with water cuts of 20-50 wt \%, an average droplet size of $30 \mu \mathrm{m}$ was obtained with 50th and 97.5th values of $8.4 \pm 1.8$ and $111.5 \pm 19.5$ respectively for up to 21 days (Figure 26) $(\mathrm{P}>0.05)$. The emulsion with a water cut of $50 \mathrm{wt} \%$ had 97.5 th percentile of $<200 \mu \mathrm{m}$ on day 28 while the average droplet size remained at $\sim 30 \mu \mathrm{m}$. This suggested some coalescence was happening after 1 month (Figure 26C). The average droplet size of the emulsion with a $60 \mathrm{wt} \%$ water cut was $30 \mu \mathrm{m}$, but its $2.5^{\text {th }}$ and $97.5^{\text {th }}$ percentile values did not match that of the other emulsions (Figure 27), and had larger $2.5^{\text {th }}$ and smaller $97.5^{\text {th }}$ percentile values than the other emulsions. Therefore, the droplet distributions of $60 \% \mathrm{~W} / \mathrm{O}$ emulsion was different with the $95 \%$ of the droplets were between 20 to $40 \mu \mathrm{m}$. As well, this emulsion also began to phase-separate soon after its preparation. As a result, only emulsions with water cuts of 10-50 $\mathrm{wt} \%$ were characterized for their rheological behaviour. Microstructurally, though the droplet sizes for the 10-50 $\mathrm{wt} \%$ emulsions were similar, there were significant differences in droplet packing density. With an increase in water cut, there was a corresponding increase in the droplet packing density, along with a corresponding decrease in wax crystal population (Figure 28). In all instances, wax crystals were either present in the continuous phase or adsorbed to the oilwater interface.

The pulsed NMR was also used to characterize the free water content of the emulsions. Over the one month experimental time frame, the emulsions with water cuts of 20-40 wt\% did not show any significant changes in free water content, confirming their stability (Figure 29). The free water content of the emulsion with a $50 \mathrm{wt} \%$ water cut increased from $\sim 0.25 \%$ to $0.4 \%$, indicative of slow destabilization $(\mathrm{P}<0.05)$. 

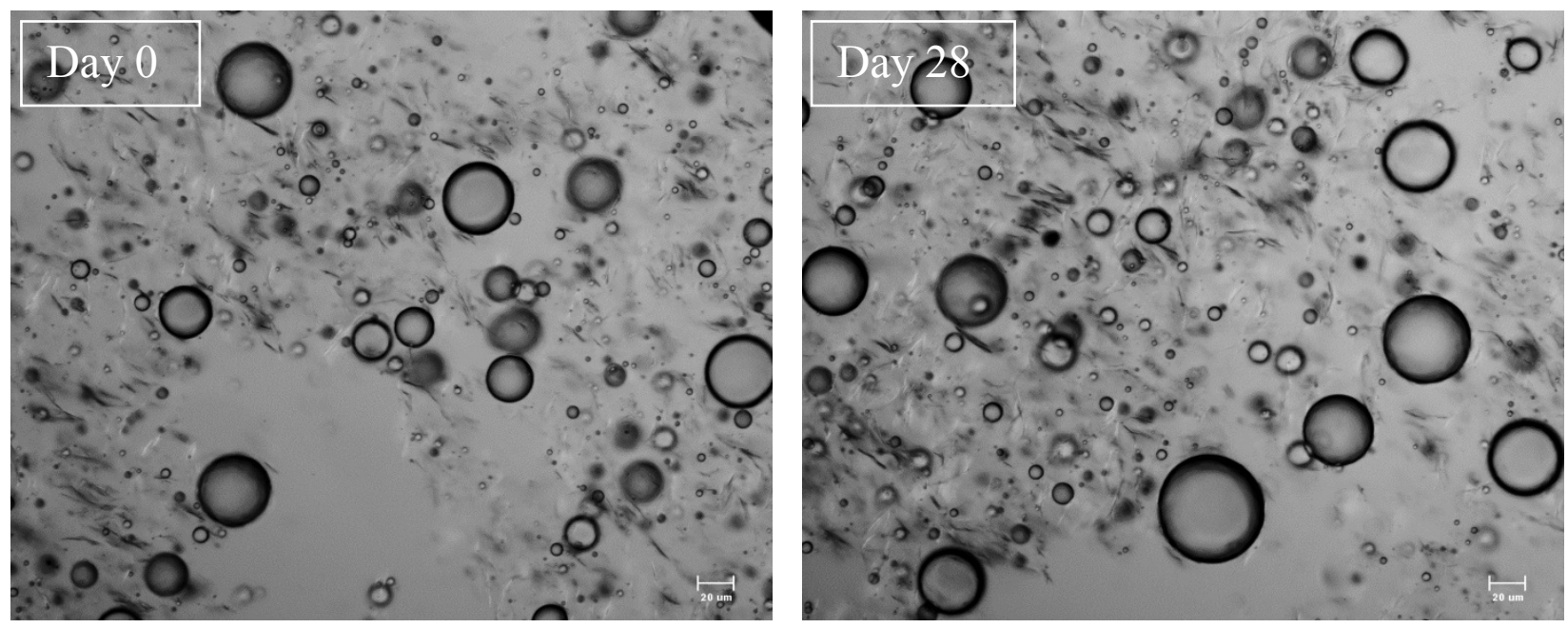

Figure 25: Microstructure of a 10\% W/O emulsion. The scale bar represents $20 \mu \mathrm{m}$.
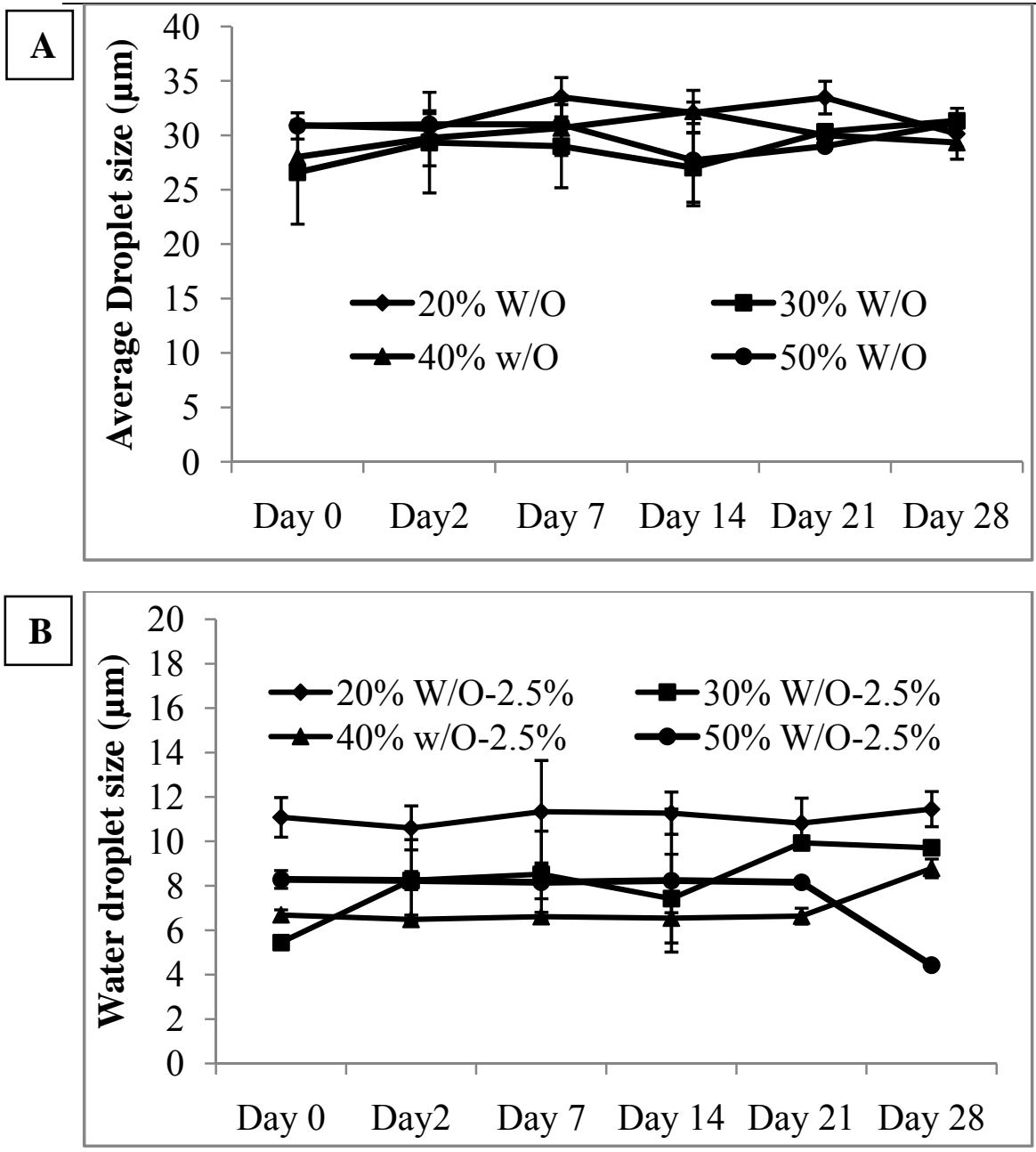


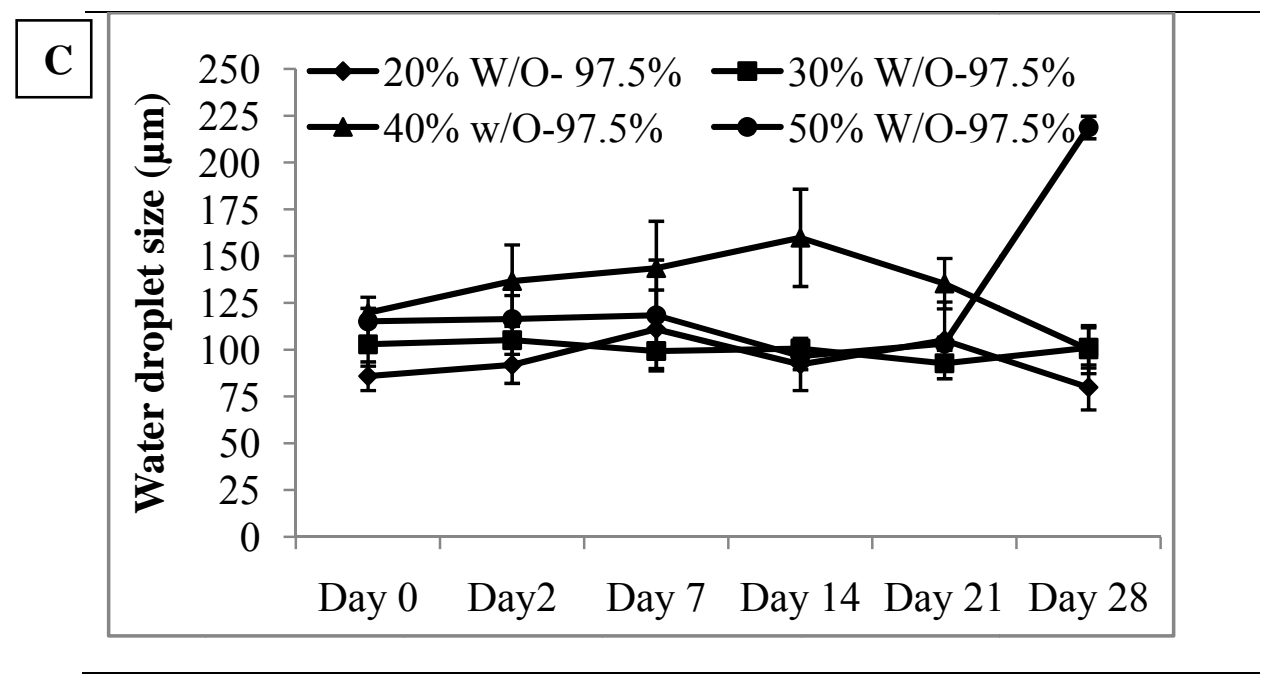

Figure 26: Droplet size distribution of the 20-50 wt $\% \mathrm{~W} / \mathrm{O}$ emulsions; A: $2.5^{\text {th }}$ percentile droplet size; B: $50^{\text {th }}$ percentile droplet size and C: $97.5^{\text {th }}$ percentile droplet size. A \& B (P>0.05), C $(\mathrm{P}<0.05)$, $\mathrm{C}$ without $50 \mathrm{wt} \%$ emulsion on day $28(\mathrm{P}>0.05)$.

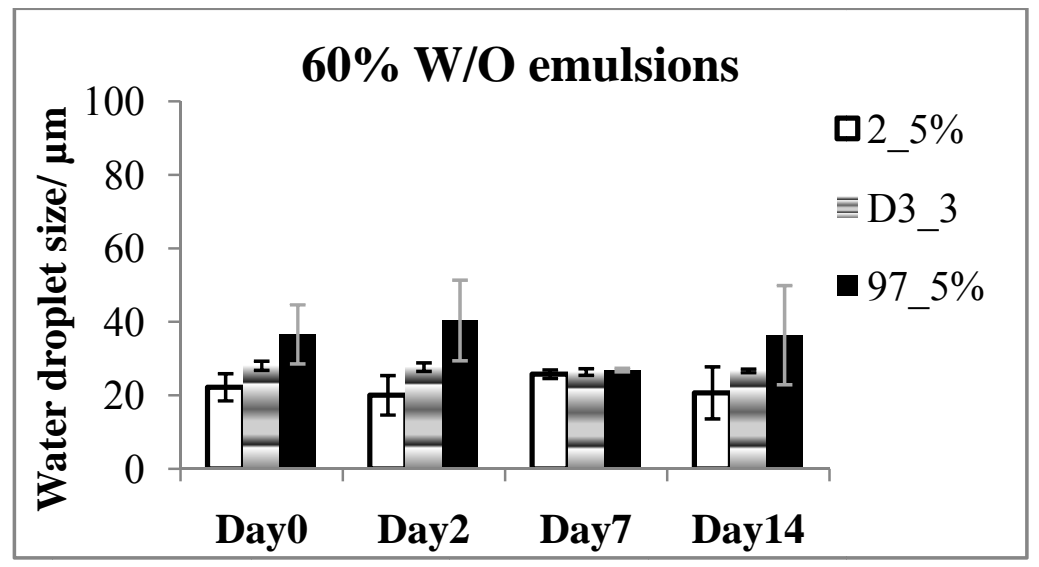

Figure 27: Droplet size distribution of the $60 \mathrm{wt} \% \mathrm{~W} / \mathrm{O}$ emulsion with time.
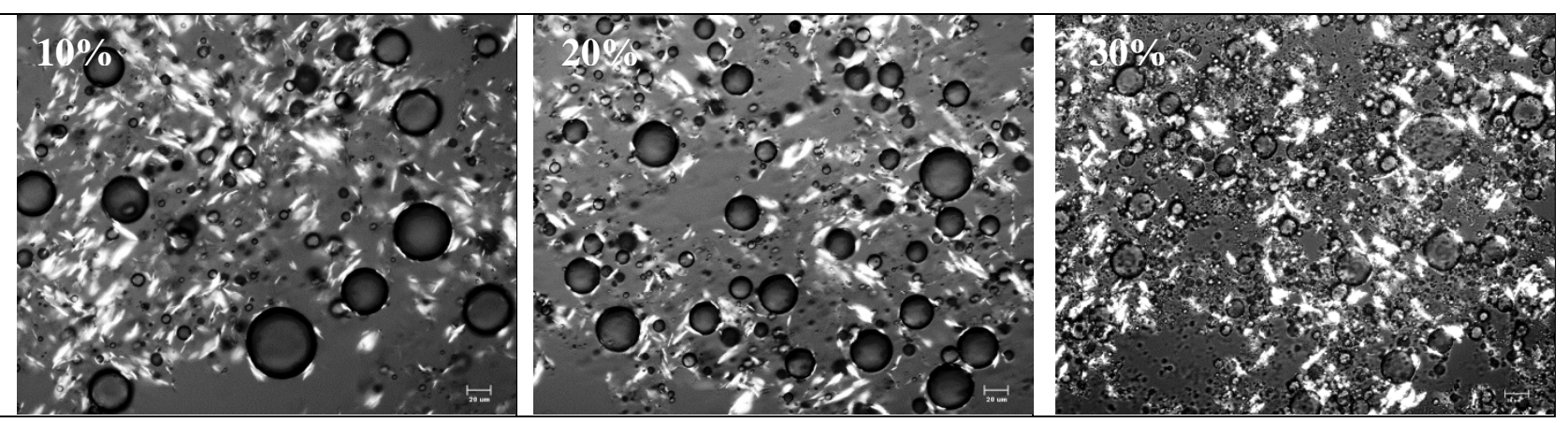


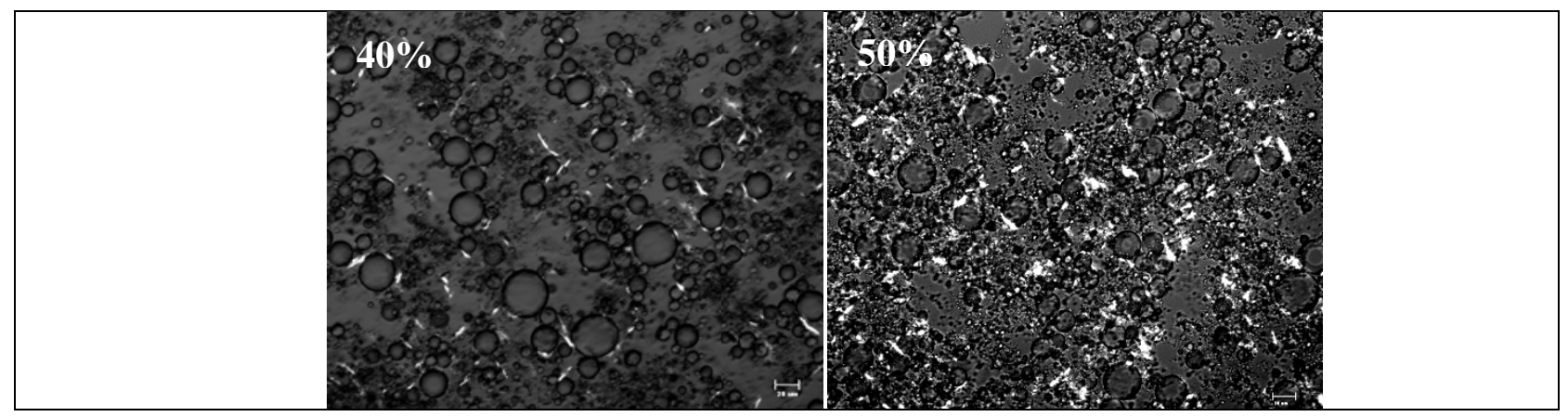

Figure 28: Microstructure of the 10-50wt $\% \mathrm{~W} / \mathrm{O}$ emulsions on day 28 . The scale bar represents $20 \mu \mathrm{m}$.

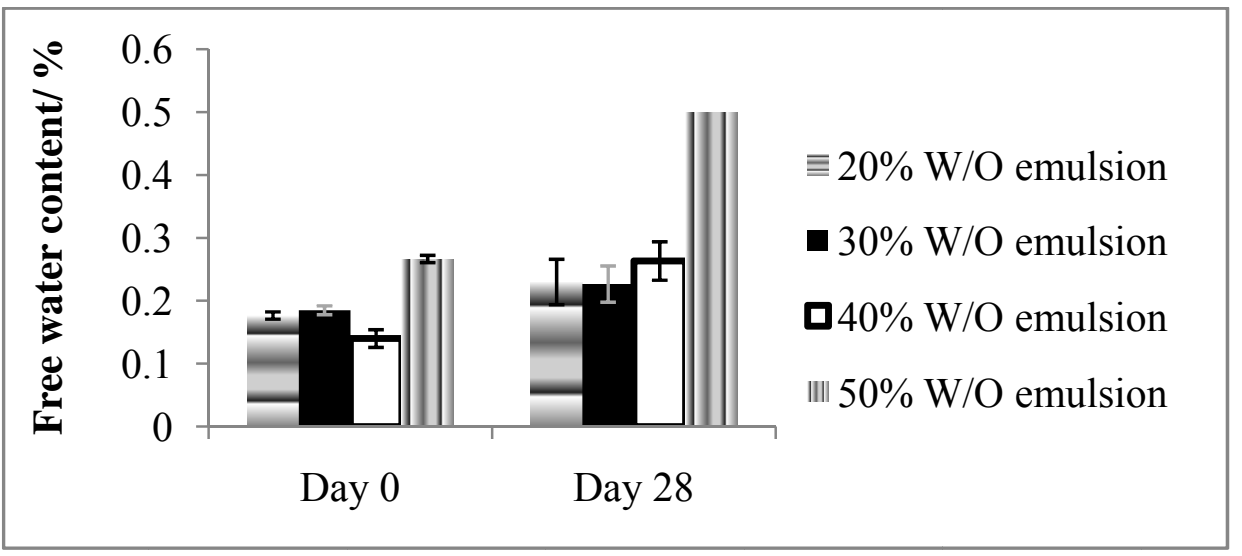

Figure 29: Free water content of the 20- $50 \mathrm{wt} \% \mathrm{~W} / \mathrm{O}$ emulsions.

\subsubsection{Differential scanning calorimetry}

Emulsion stability was also measured via a differential scanning calorimeter (DSC). Aliquots of fresh emulsion ( 4 -10 mg) were hermetically sealed in an aluminum pan and temperaturecycled in a DSC. The samples were cooled from $4^{\circ} \mathrm{C}$ to $-70^{\circ} \mathrm{C}$ and heated to $70^{\circ} \mathrm{C}$, followed by a second cooling cycle to $-70^{\circ} \mathrm{C}$, all at a rate of $2^{\circ} \mathrm{C} / \mathrm{min}$. Before start of each cycle, the samples were held at $70^{\circ} \mathrm{C}$ for one minute. The DSC cooling and heating curves for the $20 \% \mathrm{~W} / \mathrm{O}$ emulsion (Figure 30) showed an exothermic peak at $-41^{\circ} \mathrm{C}$ due to the crystallization of narrowlysized water droplets (P Avibin, 2009, Dalmazzone and Clausse 2001). On heating, there were two endothermic peaks at $-22^{\circ} \mathrm{C}$ and $-3{ }^{\circ} \mathrm{C}$, ascribed to the melting of concentrated and dilute salt solutions, respectively (Figure 31- comparison of pure DI water and 3.5\% $\mathrm{NaCl}$ water solution). Separation of the salt solution into two phases during cooling was also observed with DSC temperature-cycling of a salt solution. The small peak at $\sim 30^{\circ} \mathrm{C}$ was due to the melting of wax crystals. During the second cooling cycle, wax crystallized at $\sim 30^{\circ} \mathrm{C}$. The sharp peak at $-22^{\circ} \mathrm{C}$ 
resulted from crystallization of demulsified water. Several small irregular peaks at $\sim-30^{\circ} \mathrm{C}$ were due to the crystallization of the concentrated salt solution and/or presence of large regions of aqueous phase that hadn't completely phase-separated from the emulsion. The presence of a small peak at $-41^{\circ} \mathrm{C}$ during the second cooling cycle indicated that a fraction of the aqueous phase droplets was still emulsified.

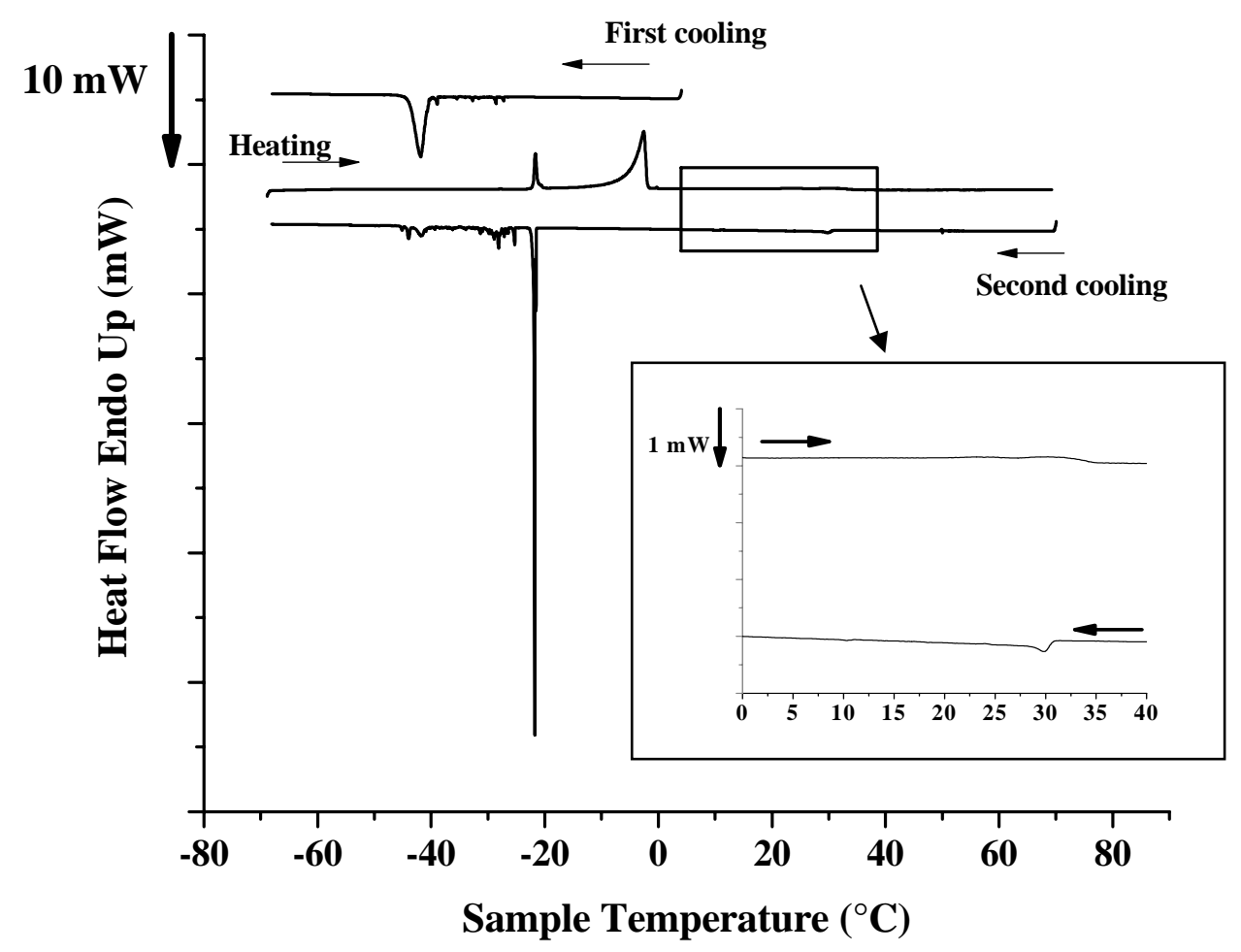

Figure 30: DSC thermograms of a temperature-cycled wax-stabilized $20 \mathrm{wt} \% \mathrm{~W} / \mathrm{O}$ emulsion. Samples were cooled from $4^{\circ} \mathrm{C}$ to $-70^{\circ} \mathrm{C}$ and heated to $70^{\circ} \mathrm{C}$ followed by a second cooling cycle to $-70^{\circ} \mathrm{C}$ at a rate of $2^{\circ} \mathrm{C} / \mathrm{min}$. The inset shows a magnified view of the wax crystallization and melting region. 

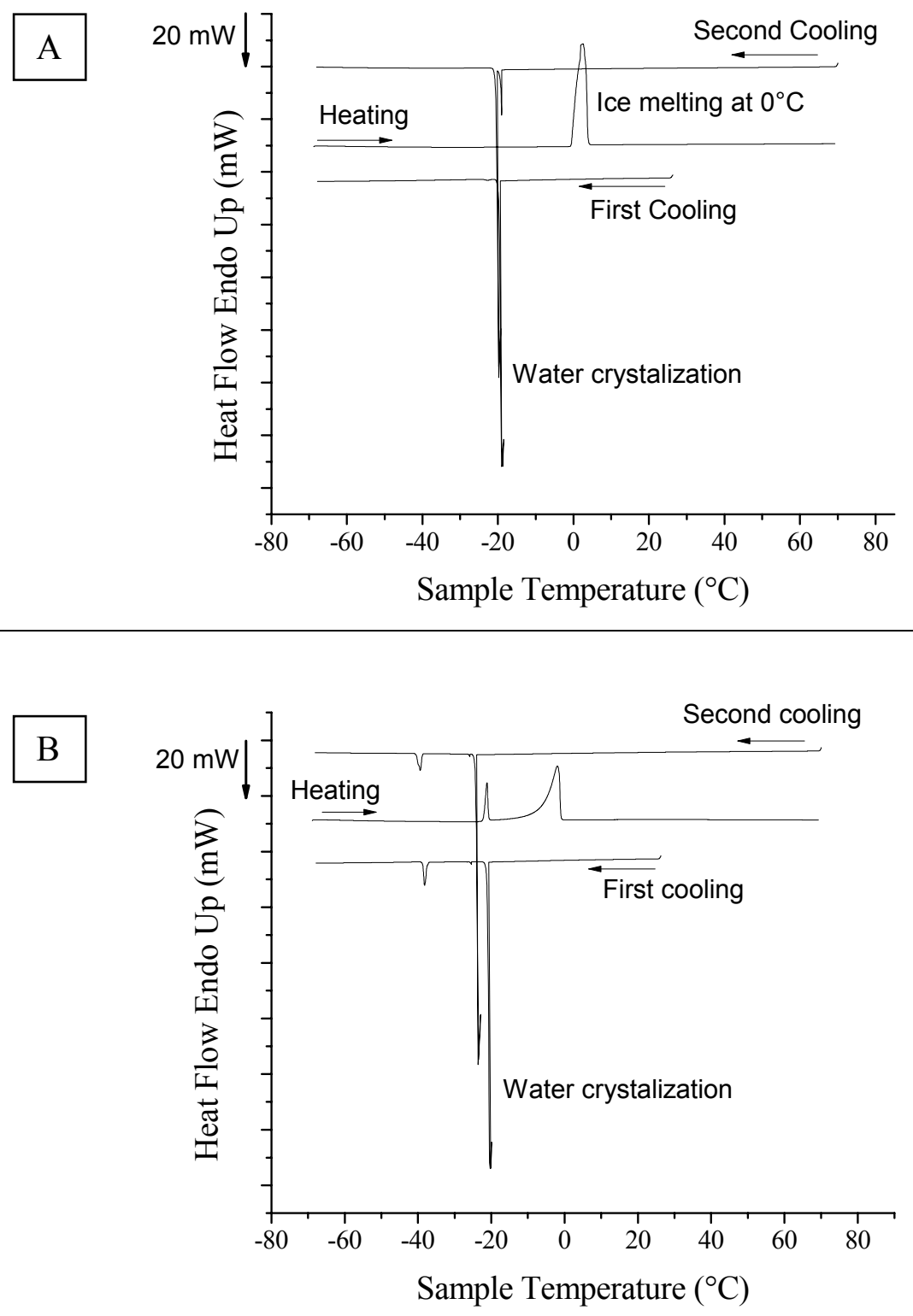

Figure 31: DSC thermograms of pure DI water (A) and 3.5\% $\mathrm{NaCl}$ water solution (B). Heating and cooling rate was $0.5^{\circ} \mathrm{C} /$ minutes.

When the emulsions were stored at $70{ }^{\circ} \mathrm{C}$ for $24 \mathrm{hrs}$, they destabilized and phase-separated as the wax crystals melted, leaving the clear continuous oil-wax mixture as a supernatant (Figure 32). This confirmed that the wax crystals within the emulsions were the sole source of stabilization.

Long-term emulsion stability was monitored by examining the DSC cooling curves $\left(4^{\circ} \mathrm{C}\right.$ to $70^{\circ} \mathrm{C}$ ) of all emulsions for a one month period (Figure 33). The exothermic peak at $-41^{\circ} \mathrm{C}$, which 
was due to crystallization of narrowly-sized water droplets, indicated that the emulsions remained stable during the month-long storage period.

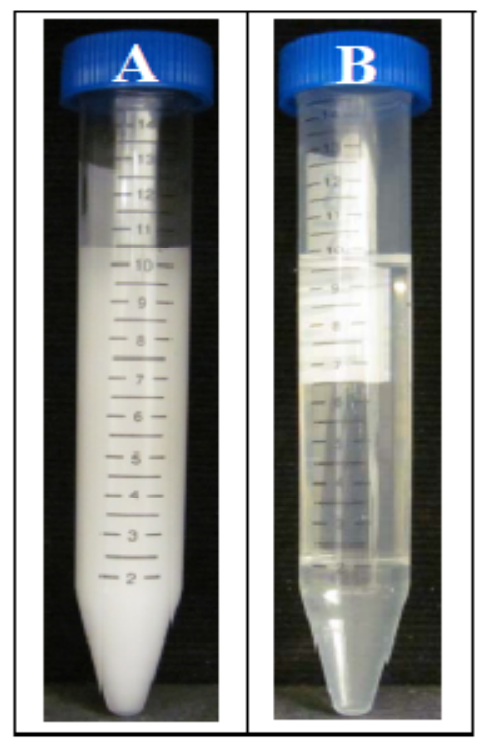

Figure 32: Temperature dependence of wax-stabilized emulsion sedimentation: (A) cooled to $4^{\circ} \mathrm{C}$ with stirring under quench-cooling, (B) held at $70^{\circ} \mathrm{C}$ for $24 \mathrm{hrs}$.

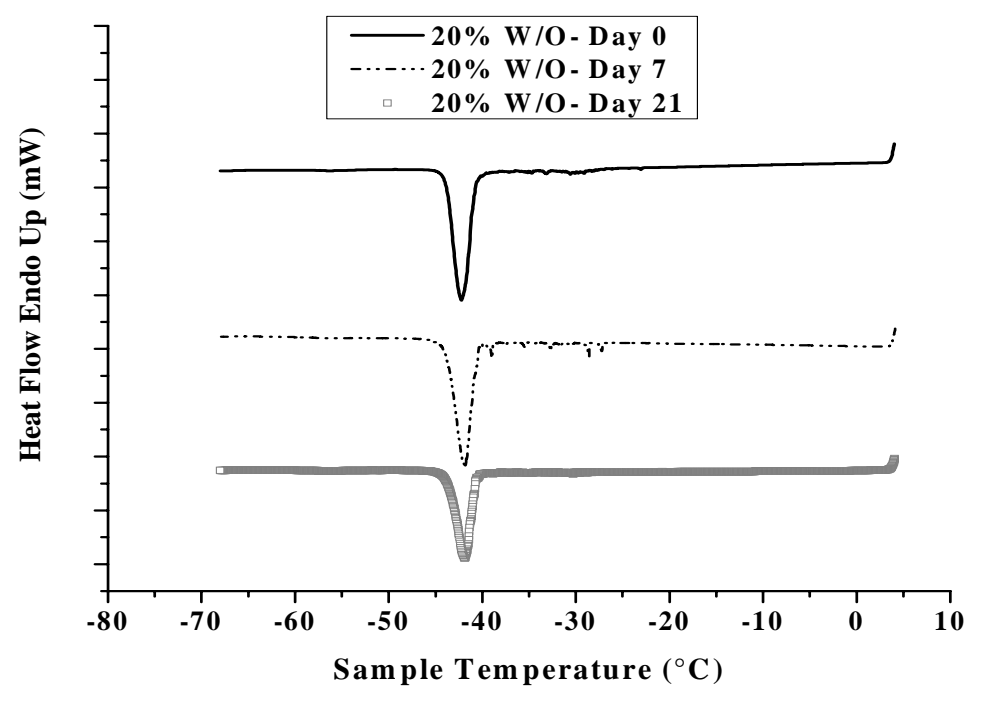

Figure 33: The thermogram of a $20 \% \mathrm{~W} / \mathrm{O}$ emulsion, showing the stability of emulsion from day 0 to day 21 . The peak at $-41^{\circ} \mathrm{C}$ represents droplet crystallization in the emulsion. All emulsions demonstrated this crystallization behaviour.

In the previous section, it was mentioned that the $60 \% \mathrm{~W} / \mathrm{O}$ emulsion was not considered for further analysis as its $2.5^{\text {th }}$ and $97.5^{\text {th }}$ percentile values did not match that of the other emulsions. 
This was confirmed by DSC (Figure 34). During the first cooling curve $\left(4^{\circ} \mathrm{C}\right.$ to $\left.-70^{\circ} \mathrm{C}\right)$, a deemulsified water crystallization (bulk water) peak at around $-20^{\circ} \mathrm{C}$ was visible and the peak associated with dispersed water droplets was small, demonstrating phase separation. These same peaks were also visible in the second cooling curve $\left(70^{\circ} \mathrm{C}\right.$ to $\left.-70^{\circ} \mathrm{C}\right)$.

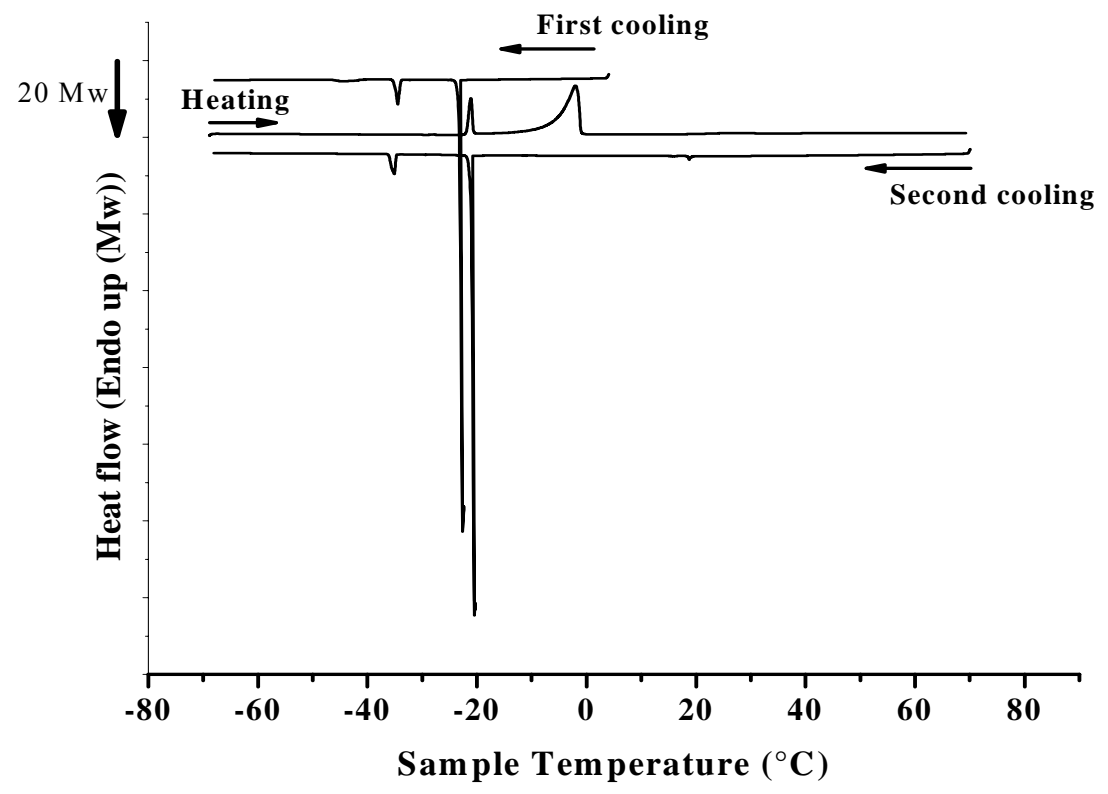

Figure 34: Temperature-cycled thermograms of a $60 \mathrm{wt} \% \mathrm{~W} / \mathrm{O}$ emulsion. The large peaks in the first and second cooling curves represent bulk water.

\subsubsection{Wax content of emulsion and neat oil samples}

The solid wax content (SWC) of all emulsions was measured starting on day 2 and for up to one month using pulsed NMR (Figure 35). As the water cut increased, the amount of solid wax expectedly decreased, as per the original compositions (Table 6). There were very small increases in \% SWC over the one month period $(\mathrm{P}<0.05)$. For the neat oil samples (Figure 36), the $\%$ SWC of the samples also slightly increased over time $(\mathrm{P}<0.05)$. These results demonstrated that ageing promoted wax crystallization.

As seen with the emulsion droplet size results, the $50 \% \mathrm{~W} / \mathrm{O}$ emulsions started to demonstrate droplet coalescence by the end of day 28 whereas the other emulsions were still stable. This may have been due to the low amount of solid wax content in this emulsion, where the amount of wax was insufficient to fully stabilize the higher dispersed phase content present. 


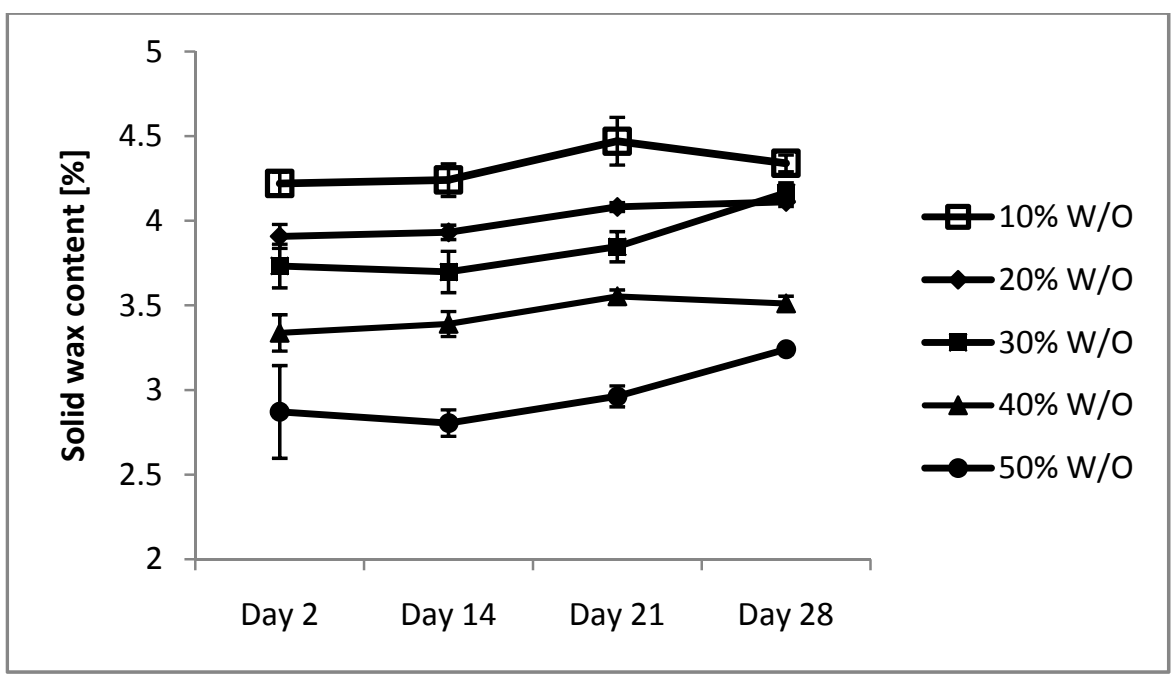

Figure 35: Wax content of emulsions with different water cuts. All the samples were stored at $4^{\circ} \mathrm{C}$ before measuring the \% SWC using pulsed NMR $(\mathrm{P}<0.05)$.

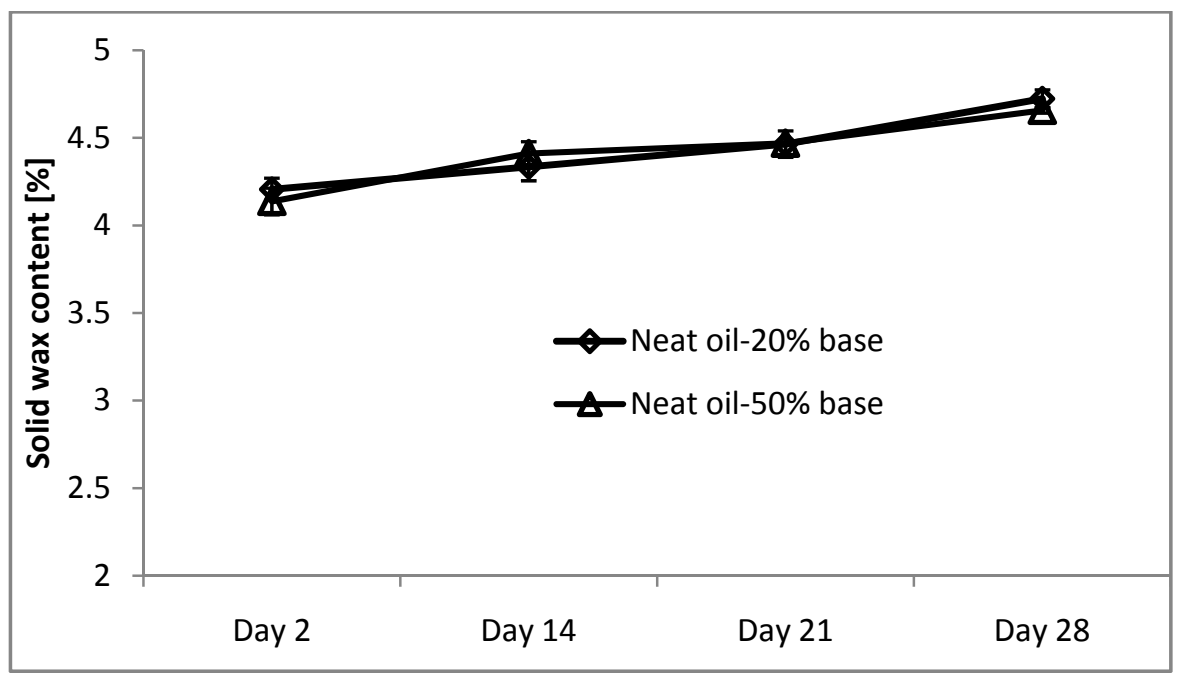

Figure 36: Solid wax content of neat oil samples $(\mathrm{P}<0.05)$.

\subsubsection{Effect of storage time on emulsion viscosity}

Emulsion samples kept in Petri dishes were transferred to the rheometer preset at $10^{\circ} \mathrm{C}$ and tested for viscosity as a function of shear rate (Figure 37 and Figure 38). Figure 37represents the flow curve of individual emulsions over a one-month period. Overall, the viscosity of all the emulsions increased with time at lower shear rates, suggesting that the presence of wax crystals appeared responsible for the observed increase in viscosity. This was more significant for the emulsions with water cuts of $10-30 \mathrm{wt} \%$ as these emulsions contained more wax than the emulsions with higher water cuts (40-50 wt\%) (Table 6). For example, from day 0 to 28 , the low 
shear viscosity of the $10 \% \mathrm{~W} / \mathrm{O}$ emulsion increased 4.3 times whereas for the $50 \% \mathrm{~W} / \mathrm{O}$ emulsion, there was an increase of 1.8 times. This slight increase in viscosity strongly hinted at the dispersed phase remaining stable over time; otherwise, a decrease in viscosity would have been observed (Pal 1996). The application of shear broke down the wax crystal network structure above shear rates of $\sim 200 \mathrm{~s}^{-1}$, at which point all emulsions had relatively similar viscosities.
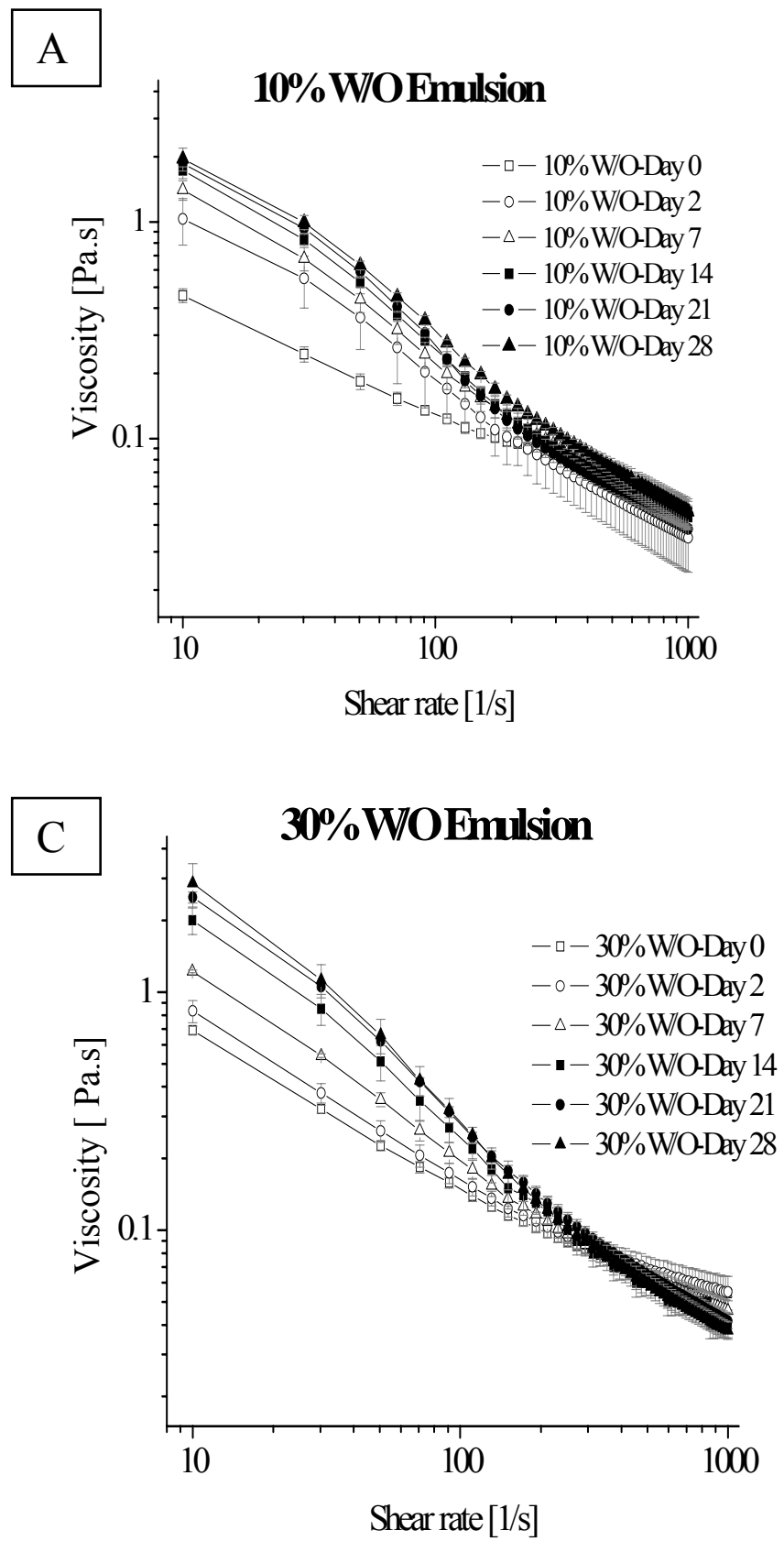
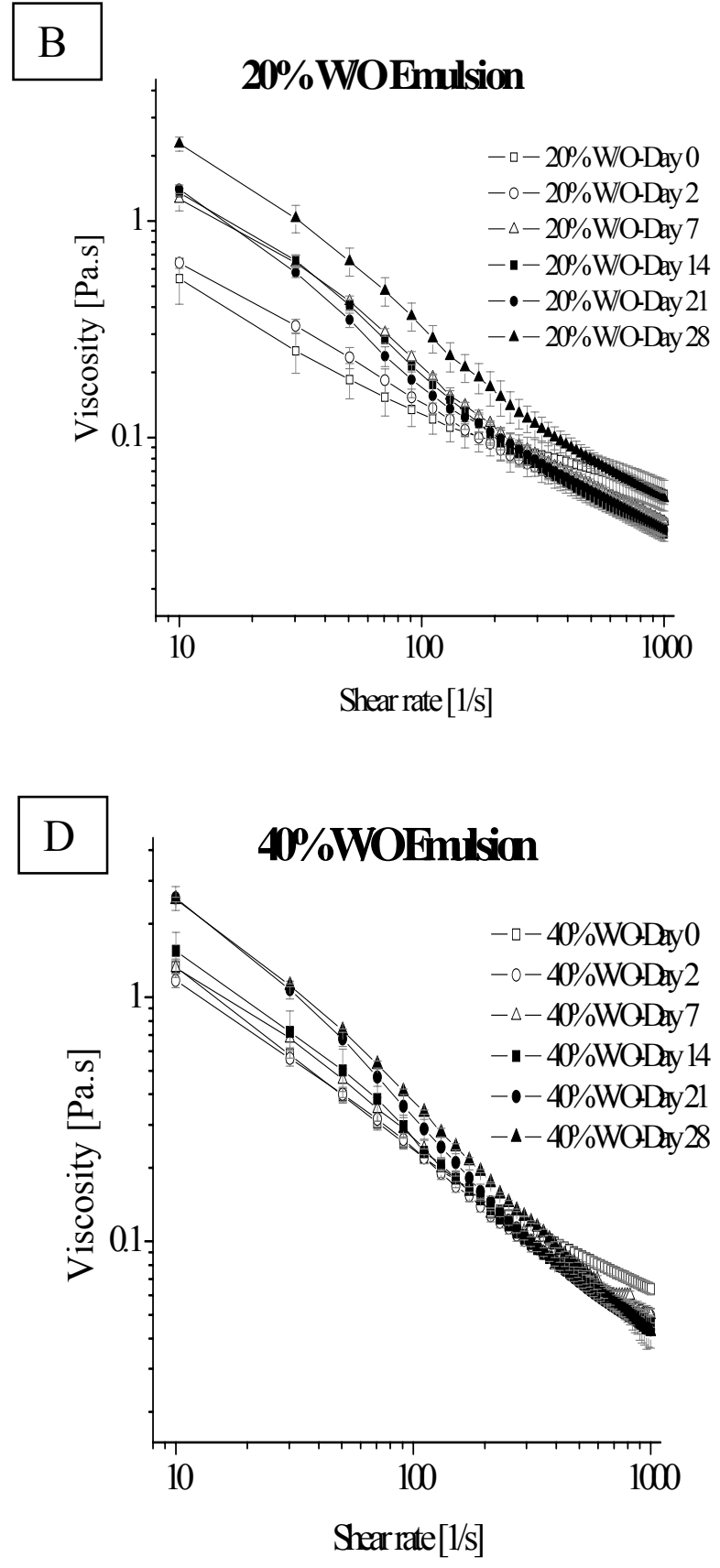


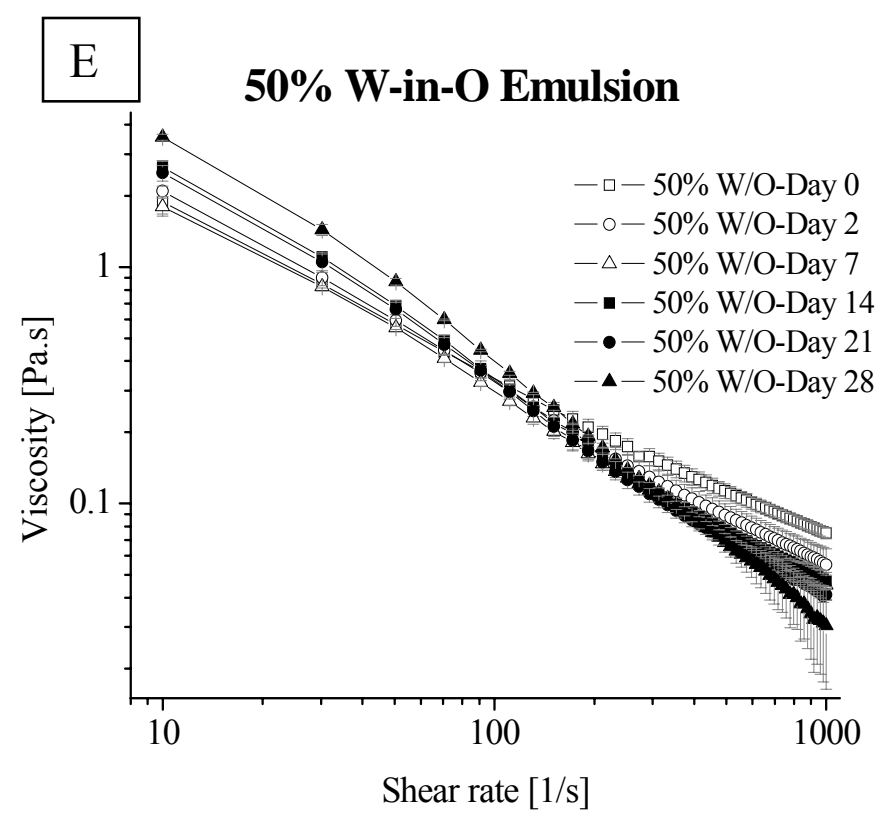

Figure 37: Viscosity of wax-stabilized emulsions as a function of shear rate and storage time (in days). Samples were held at constant temperature of $10^{\circ} \mathrm{C}$ during measurements. A to E: $10 \mathrm{wt} \%$ to $50 \mathrm{wt} \% \mathrm{~W} / \mathrm{O}$ emulsions.

\subsubsection{Effect of water cut on emulsion viscosity}

In this section, the same viscosity and shear rate results as above are shown, but based on water cut instead. For fresh samples (day 0) (Figure 38A), the flow curves displayed an increase in viscosity with increasing water cut. On day 2 , the lower water cut emulsions (with their correspondingly higher paraffin wax content) saw a greater increase in viscosity compared to the emulsions with higher water cuts. For example, the $10 \% \mathrm{~W} / \mathrm{O}$ emulsion had a similar viscosity to the $40 \% \mathrm{~W} / \mathrm{O}$ emulsion at low shear rate (Figure 38B). This was due to the formation of a strong wax crystal networks in the former that made the emulsion more rigid. As shown in Figure 38C$\mathrm{F}$, emulsion viscosity at lower water cuts (10-30 wt $\%)$ gradually increased at low shear rates whereas there was a very small increase for the emulsions with higher water cuts. Therefore, with the aged samples, the viscosity of the emulsions with lower water cuts overlapped that of the emulsions with higher water cuts (40 and $50 \mathrm{wt} \%$ ) as a result of wax crystal network formation. As well, for the day 0 samples, the viscosity of the emulsions with higher water cuts decreased more significantly compared to those with lower water cuts. For example, on day 0 the viscosity (at $10 \mathrm{~s}^{-1}$ shear rate) of the $50 \% \mathrm{~W} / \mathrm{O}$ emulsion decreases 25 times following the application of shear whereas the viscosity of $10 \% \mathrm{~W} / \mathrm{O}$ emulsion decreased 10 times. The likely cause of this behaviour was that with the higher water cut emulsions, there was a much higher 
possibility of droplet deformation due to greater collisions caused by the applied shear. Such deformation would cause the droplets to slide over one another, making the emulsion less resistant to the applied shear resulting in a higher drop in viscosity (Abivin, Henaut et al. 2009).
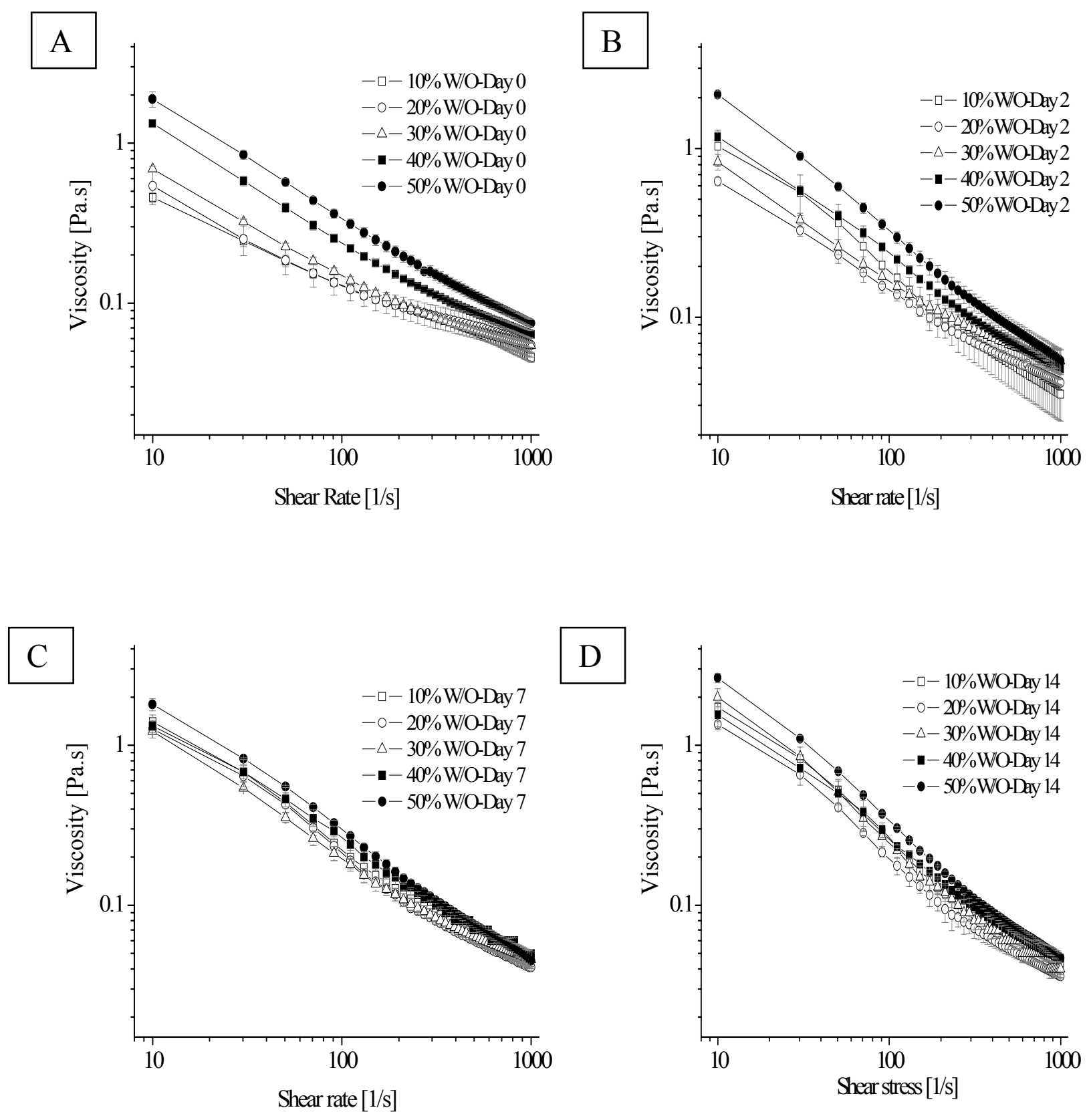

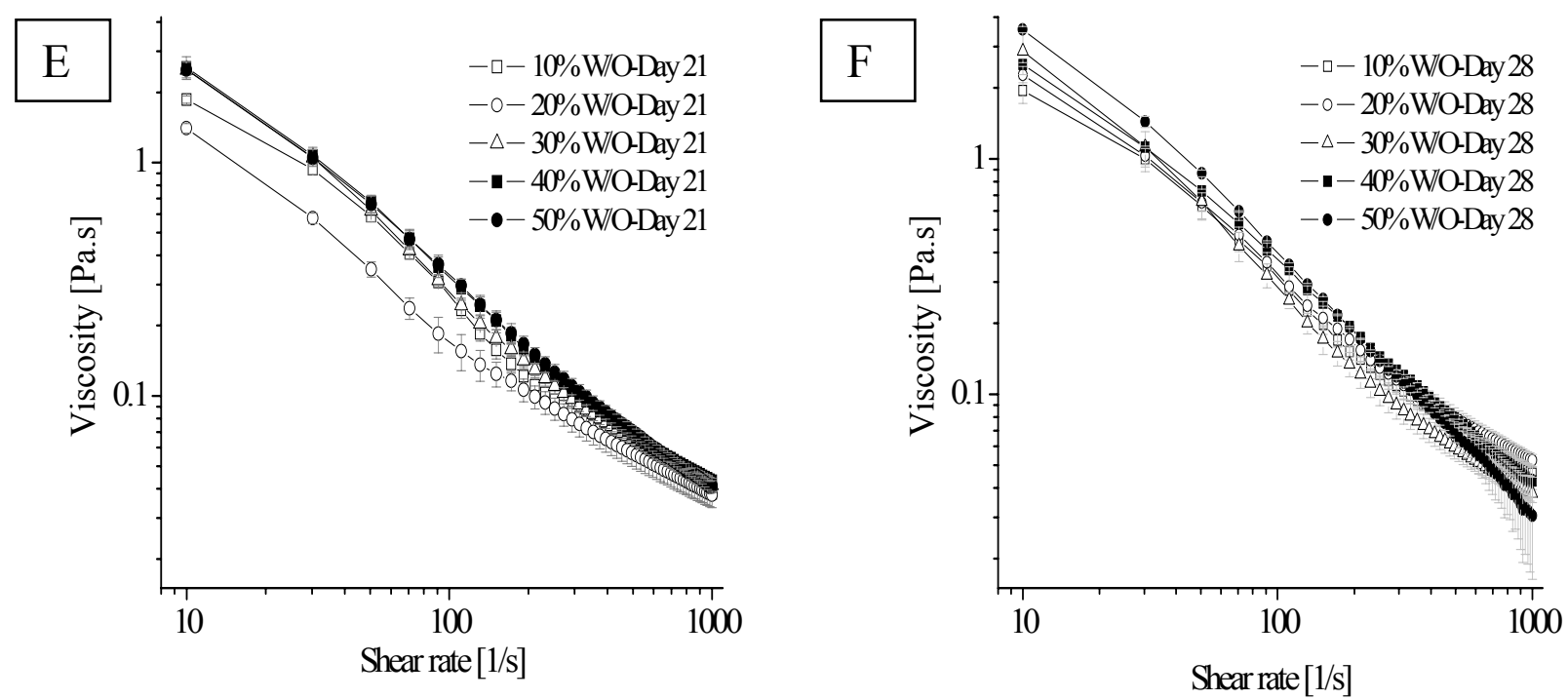

Figure 38: Viscosity of wax-stabilized emulsions as a function of shear rate, water cut and storage time (in days). Samples were held at constant temperature of $10^{\circ} \mathrm{C}$ during measurements. A to F: day 0 to day 28 .

The flow curve data were fitted to Herschel-Bulkley model to quantify the yield stress of the respective emulsions $\left(\mathrm{R}^{2} \sim 0.97\right.$ - average of all the fittings) (Herschel and Bulkley 1926). Herschel-Bulkley model is used for the fluids that have yield stress:

$\tau=\tau_{\mathrm{HB}}+\mathrm{k} \gamma^{\cdot \mathrm{n}}$ Equation 11

where ' $\mathrm{n}$ ' is the shear rate index, ' $\mathrm{K}$ ' is the consistency factor and ' $\sigma_{\mathrm{HB}}$ ' is the Herschel-Bulkley yield stress. The emulsion initial yield stress increased with water cut (Figure 39), with more prominent increases at higher water cuts (Visintin, Thomas et al. 2008). The increase in yield stress within the same water cut supported the notion that the SWC also contributed to the mechanical strength of the emulsions (Paso, Silset et al. 2009) (Figure 39). With time, all emulsions demonstrating higher yield stresses (Figure 40), demonstrating the role of wax crystal network formation over time (i.e., the $\mathrm{SWC} \%$ increased with time). Rather surprisingly, however, the increase in yield stress was rather similar for all emulsions, in spite of the gradually lower SWC with increasing water cut. This strongly suggested that there was significant interaction between the dispersed droplets and continuous phase crystals. For example, with the 
lowest SWC, the $50 \mathrm{wt} \%$ emulsion saw its yield stress increase 3 -fold, similar to the $20 \mathrm{wt} \%$ emulsion.

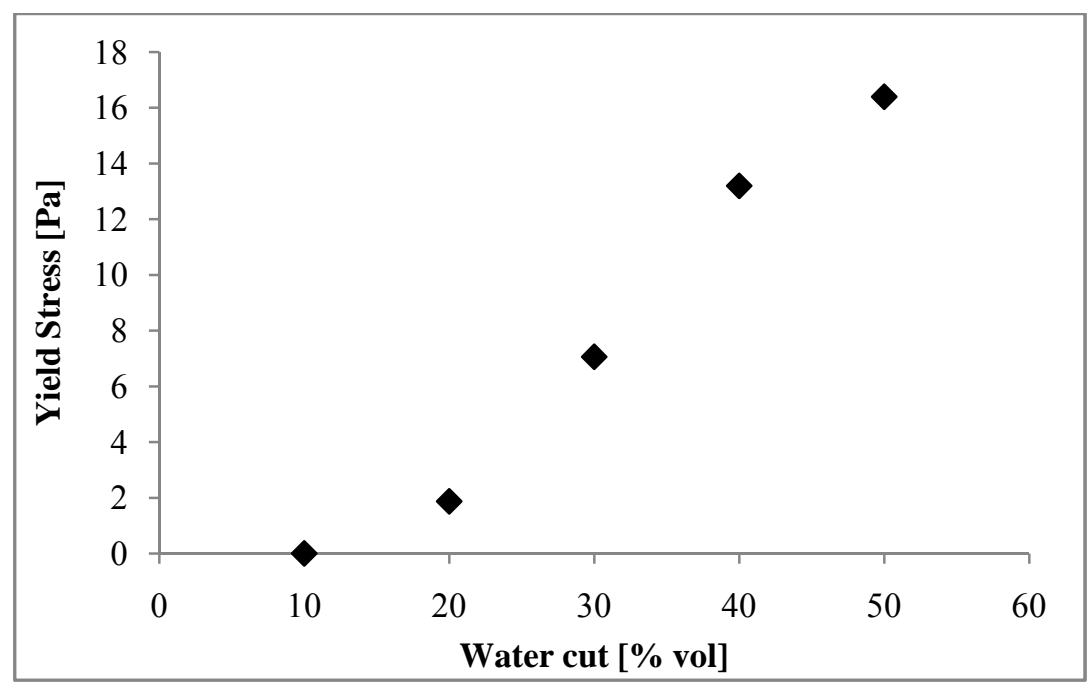

Figure 39: Herschel-Bulkley yield stress of model W/O emulsions as a function of water cut, at $10^{\circ} \mathrm{C}$ and Day 0 .

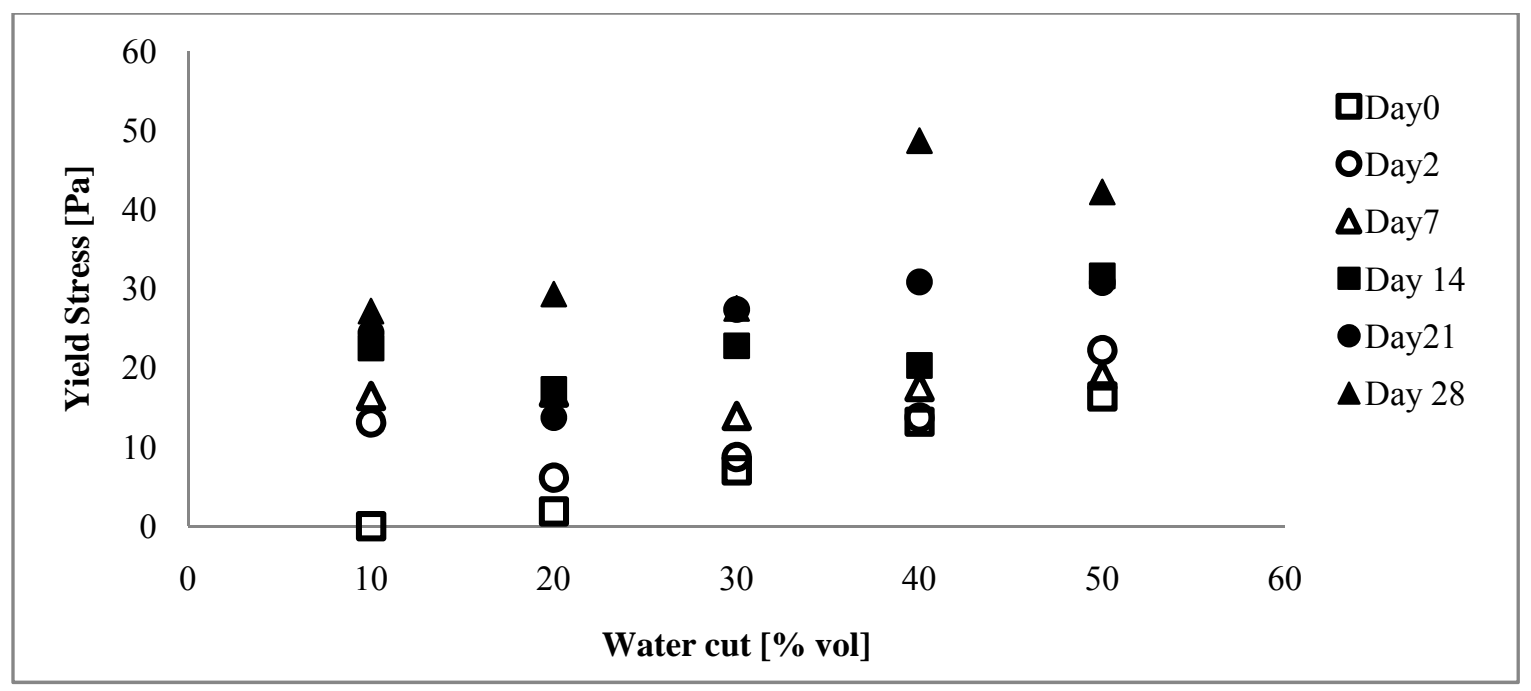

Figure 40: Herschel-Bulkley yield stress of W/O emulsions with different water cuts and at different time points.

\subsubsection{Comparison of emulsion and neat oil samples}

To characterize the effect of a dispersed aqueous phase on the model emulsions, the same rheological experiments were carried out using only the oil phase corresponding to emulsion with $20 \%$ and $50 \%$ water cuts. Figure 41 and Figure 42 delineate the effect of a dispersed aqueous phase on the viscosity of these emulsions over a one month period. On day 0 , the 
emulsions had higher viscosity compared to its corresponding oil phase with both the $20 \%$ and $50 \%$ water cuts $(\mathrm{P}<0.05)$ (Krieger and Dougherty 1959). With the $50 \mathrm{wt} \%$ water cut, the difference between the emulsion and neat oil was more significant than when compared to the 20 wt $\%$ water cut. The viscosity of the $50 \% \mathrm{~W} / \mathrm{O}$ emulsion was 5 times that of the corresponding oil phase whereas with the $20 \mathrm{wt} \%$ water cut, emulsion viscosity was only 1.2 times higher at low shear rates. After day 2, the oil fraction of the $20 \mathrm{wt} \%$ emulsion had a higher viscosity when compared to the emulsion (Figure 41). Thus, for aged samples, the wax crystal network began to significantly contribute to viscosity. With the $50 \mathrm{wt} \%$ system, the oil phase viscosity increased as well but only approached the emulsion's viscosity after one month. Hence, the combined presence of a larger water cut with less wax resulted in an emulsion with a lower viscosity, but only after prolonged storage. Overall, the neat oil showed a higher viscosity after extended storage, likely due to the formation of more developed wax crystals in the oil phase for neat oil compared to the emulsion, where there was less growth of wax crystals due to the presence of dispersed aqueous droplets. 

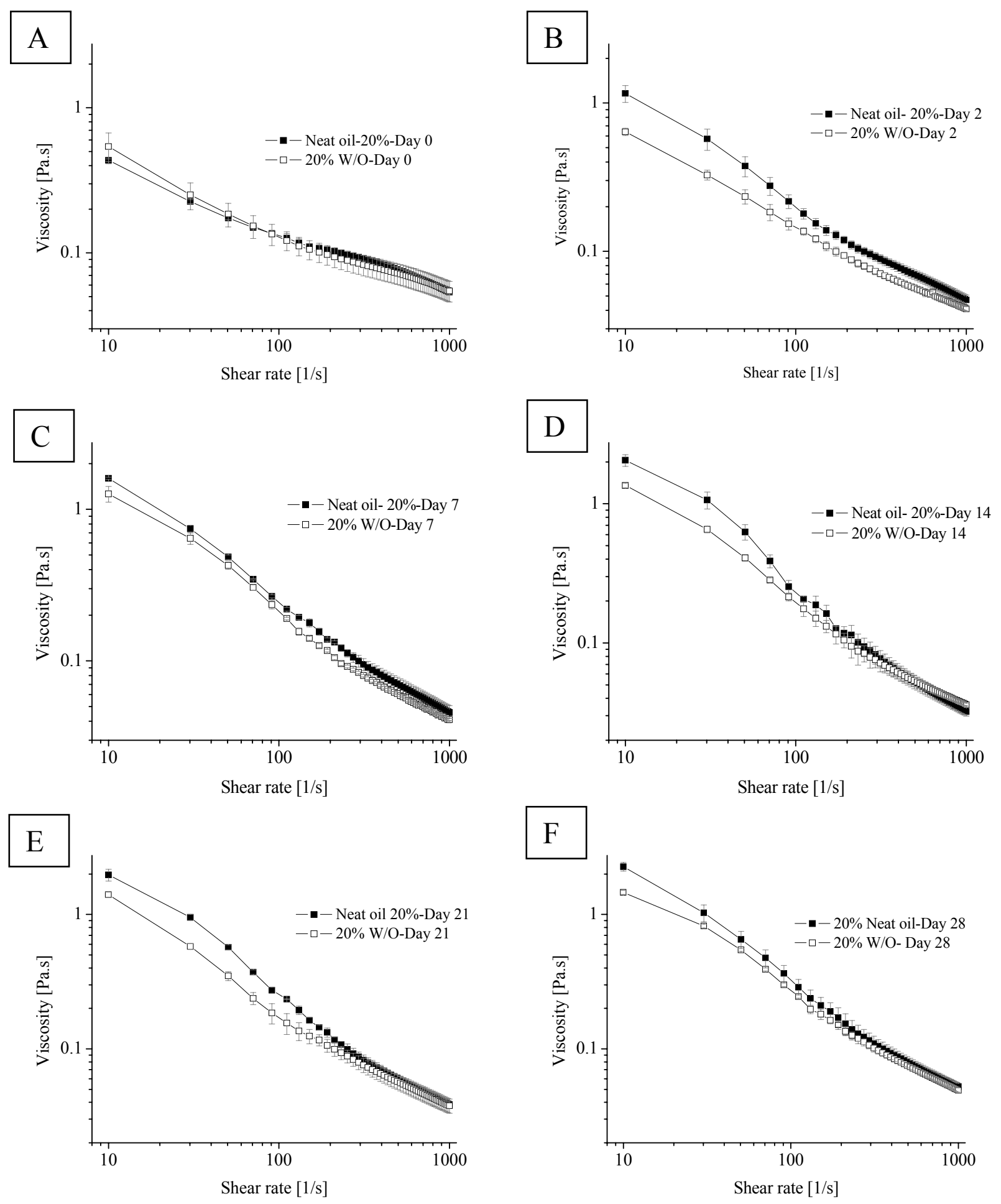

Figure 41: Comparison of flow curves for neat oil ( $5 \mathrm{wt} \%$ paraffin wax and $0.05 \mathrm{wt} \% \mathrm{GMO}$ in light mineral oil) and the corresponding $20 \mathrm{wt} \% \mathrm{~W} / \mathrm{O}$ emulsion. 

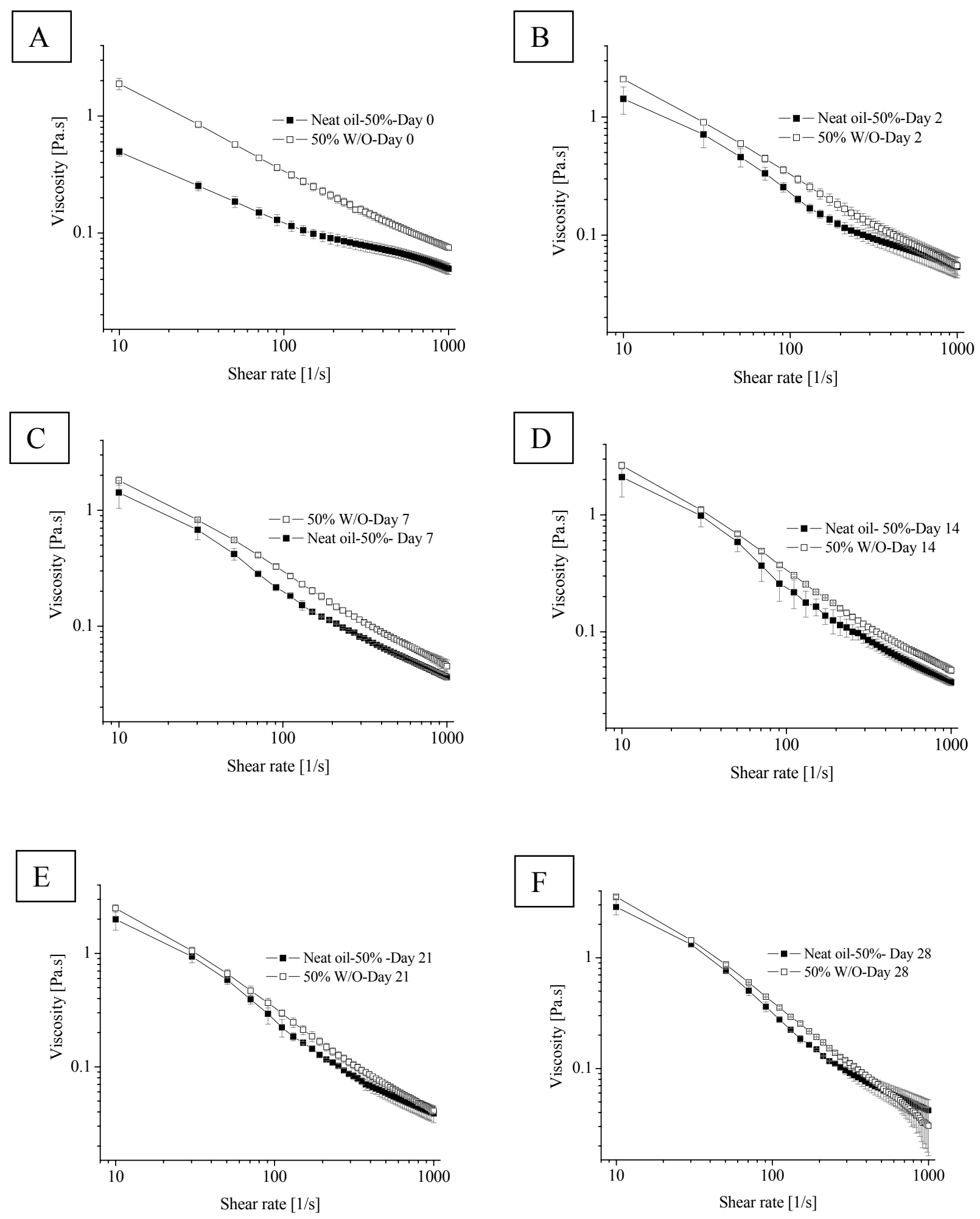

Figure 42: Comparison of flow curves for neat oil ( $5 \mathrm{wt} \%$ paraffin wax and $0.125 \mathrm{wt} \%$ GMO in light mineral oil) and the corresponding $50 \mathrm{wt} \% \mathrm{~W} / \mathrm{O}$ emulsion. 


\subsubsection{Shear-thinning behaviour}

From the emulsion and neat oil flow curves, it can be concluded that all samples were nonNewtonian fluid, given their shear-thinning behaviour. Other than this shear thinning behaviour, the emulsions and neat oil samples also behaved as viscoplastic fluids [i.e., fluids that exhibit a measurable yield stress $\left(\tau_{0}\right)$ ] (Figure 43Figure 43). Thus, before the fluid could flow or deform, $\tau_{0}$ had to be exceeded. As per Figure 43Figure 43, the flow curves for the 10-50 wt $\%$ emulsions did not pass through the origin ( $x=0, y=0)$, demonstrating that an applied stress had to exceed the value of the yield stress for the fluid to flow. The shear stress as a function of shear rate for other days during a one month period followed the same pattern of viscosity results as a function of shear rate (sections 5.3.4 -5.3.6), i.e., the $\tau_{0}$ values increased with an increase in water cut.
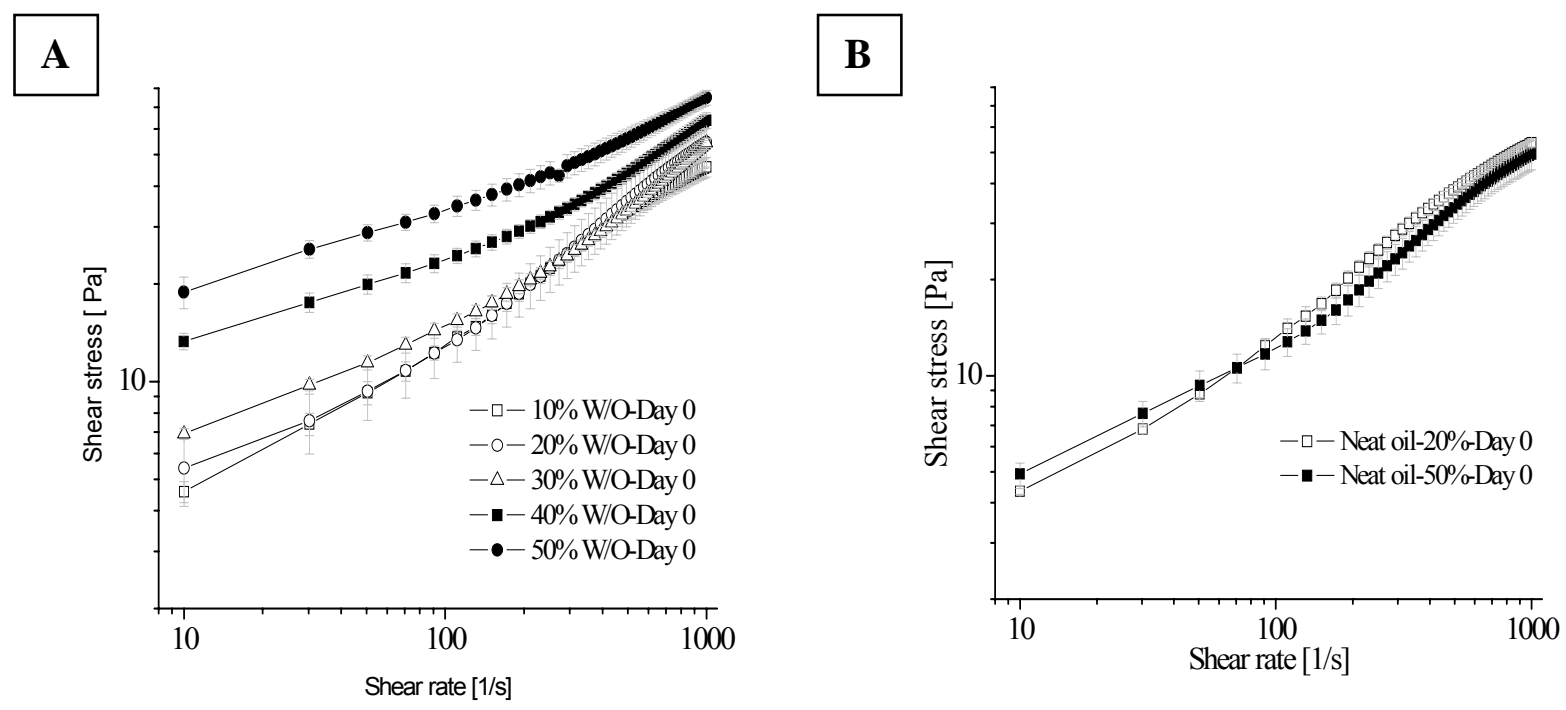

Figure 43: Flow curve of $10-50 \mathrm{wt} \% \mathrm{~W} / \mathrm{O}$ emulsions $[\mathrm{A}]$ and neat oil samples [B] on day 0 (Shear stress versus shear rate).

\subsubsection{Viscosity of fresh and aged emulsions}

From the flow curves shown in Figure 37, the viscosity of the fresh emulsions (days 0 and 2) started to increase when compared to aged samples (days 21 and 28) at shear rate $>200 \mathrm{~s}^{-1}$ for all emulsions. Inverted microscopy was used to observe the microstructure of samples before and after applying shear for both fresh and aged samples. $20 \mathrm{wt} \%$ water cut emulsion is used as an example in here. In the fresh unsheared samples, the dispersed aqueous phase in the continuous oil was surrounded by wax crystals in both the continuous phase and at the interface (Figure 44), suggesting the presence of both interfacial and bulk network wax crystallization. In the aged 
samples (Figure 45), the number and size of wax crystals had increased. Clearly visible were adsorbed crystals that stabilized the dispersed phase via Pickering stabilization as well as network stabilization, where crystals contributed to hindering droplet movement by enmeshing them within a crystalline matrix. Interestingly, after shear, the fresh samples had a very different microstructure when compared to un-sheared samples. After shear, there were more water droplets present, with many smaller droplets flocculated in-between larger droplets, suggesting that the viscosity increase at higher shear rates was due to droplet distortion and flocculation. As has been noted by others, emulsions with flocculated droplets will have higher viscosities compared to similar emulsions with well-dispersed droplets, suggesting that the flocs increased emulsion viscosity (Liu and Masliyah 1996; McClements 2004). For the aged samples, there were no significant differences in microstructure before and after the application of shear. After shearing, the only changes observed were the breakage of some of the wax crystals and an increase in the diameter of the water droplets (Figure 45). Therefore, the formation of a strong wax crystal network limited the movement of droplets in the aged samples whereas in the fresh samples, post-shear coalescence occurred as the wax crystal network had yet to sufficiently age and strengthen and hinder droplet-droplet contact. 


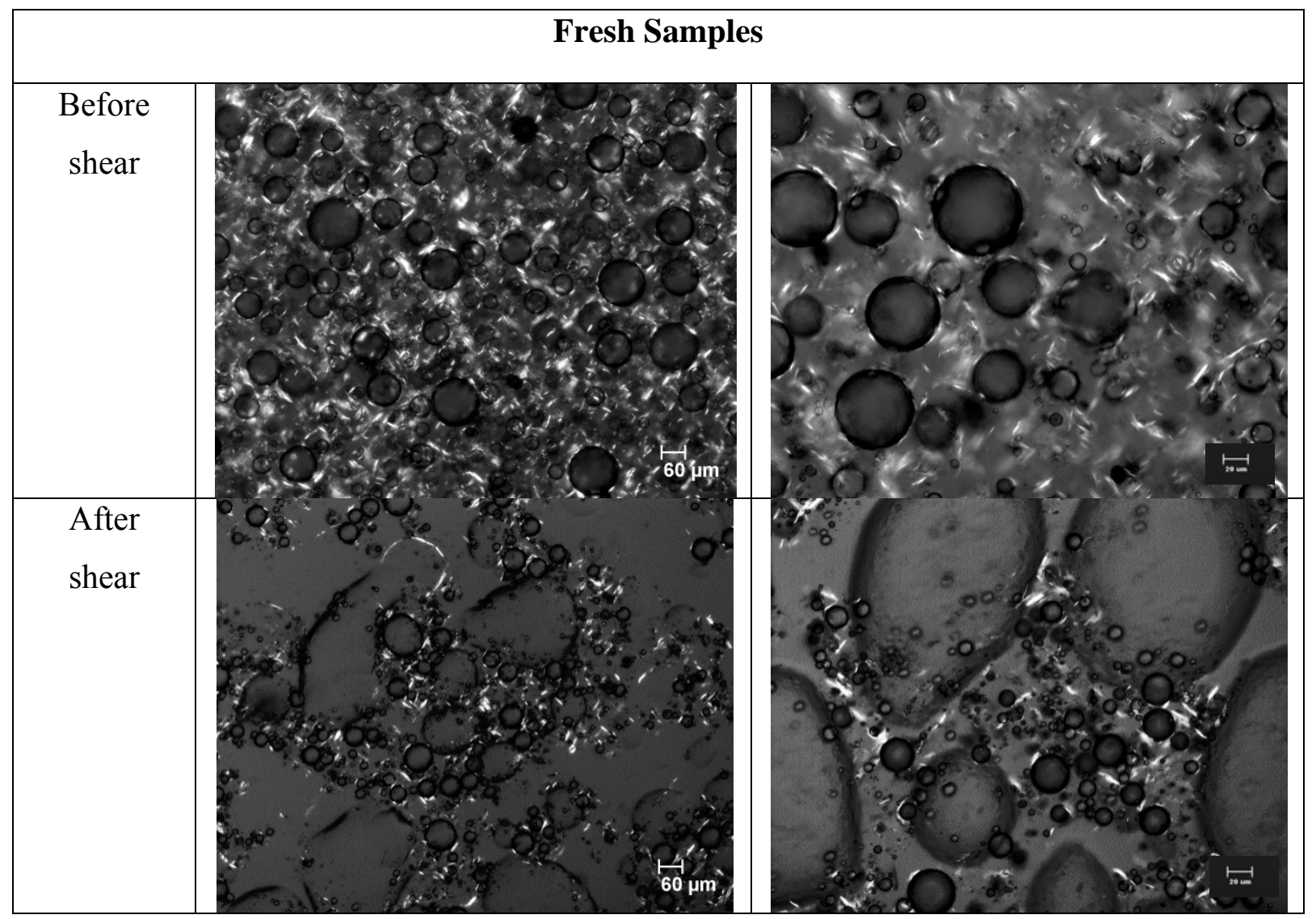

Figure 44: Microstructure of a freshly-made $20 \% \mathrm{~W} / \mathrm{O}$ emulsion before and after the application of shear at $1000 \mathrm{~s}^{-1}$. The scale bars on left column represent $60 \mu \mathrm{m}$ and on right column, $20 \mu \mathrm{m}$.

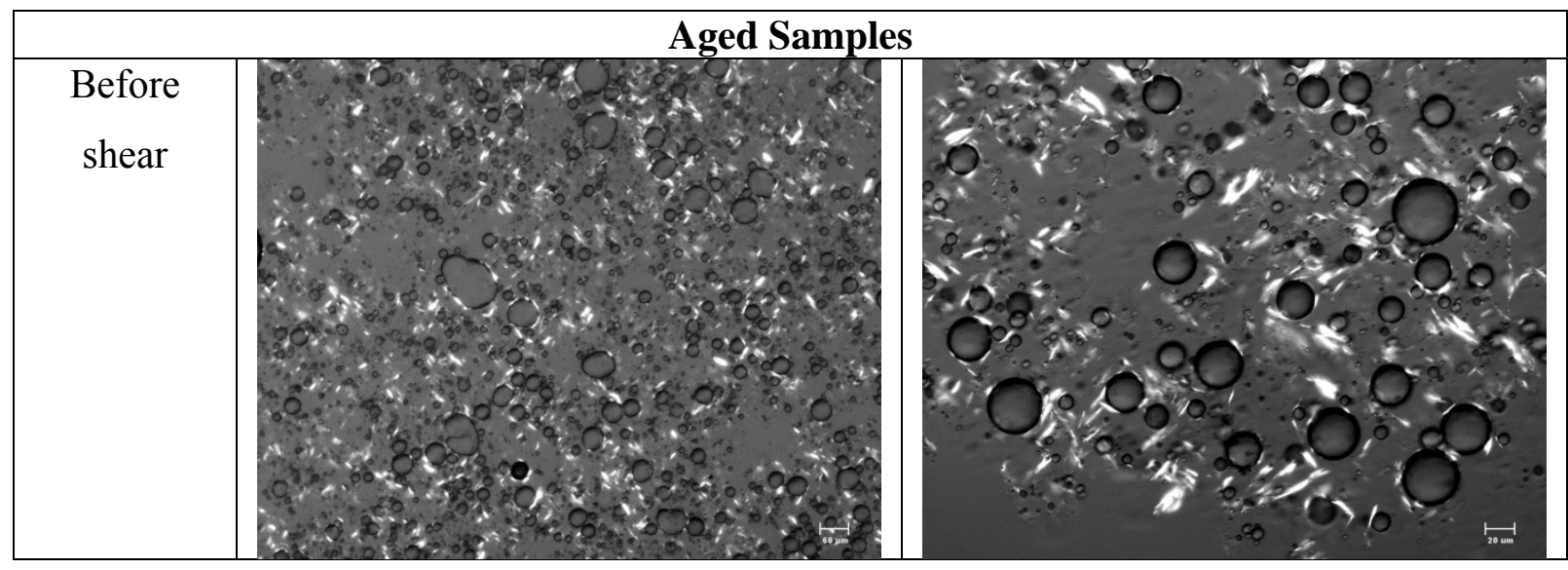




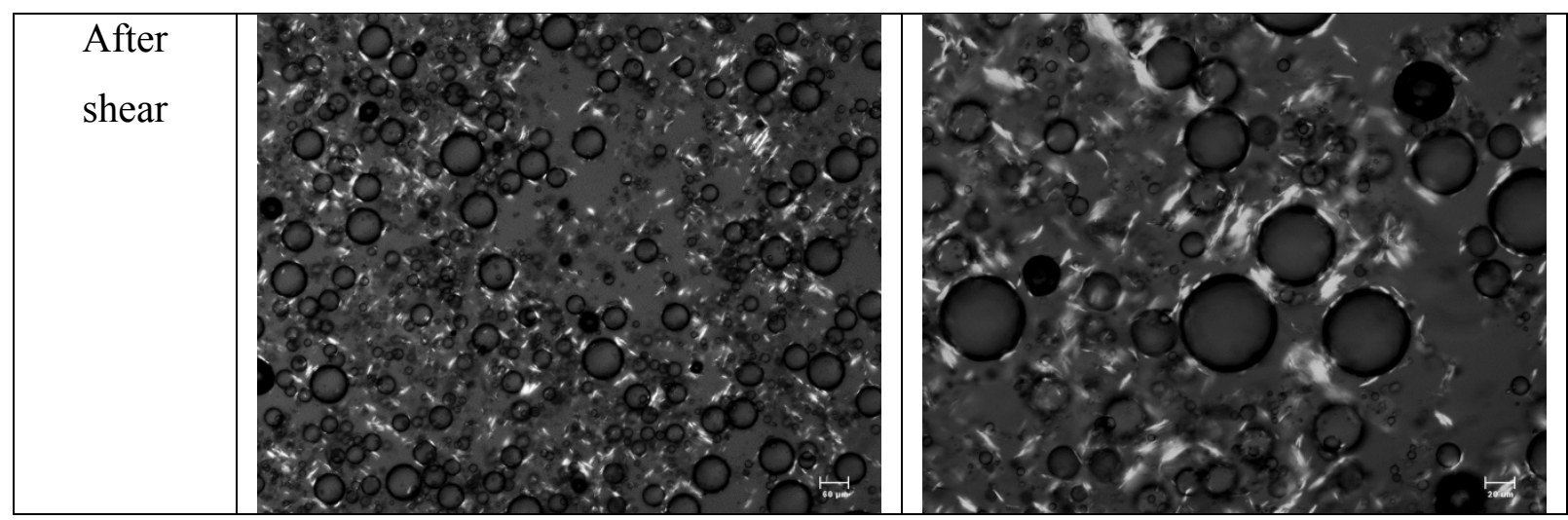

Figure 45: Microstructure of an aged 20\% W/O emulsion (day 28) before and after the application of shear at $1000 \mathrm{~s}^{-1}$. The scale bars on left column represent $60 \mu \mathrm{m}$ and on right column, $20 \mu \mathrm{m}$.

\subsubsection{Effect of storage time on creep compliance and recovery}

In creep experiments, a constant shear stress is applied over a specific time and then released. The resulting deformation or strain following by the extent of the recovery is recorded as a function of time (Briceno 2000; Morrison 2001). These types of experiments are applicable to elastic and viscoelastic samples. Elastic samples have very short-term deformation and when the stress is removed, elastic solid recover their original configuration completely (Briceno 2000; Morrison 2001). A viscoelastic sample will show a different behaviour. Upon the application of a stress, it will deform until it reaches a steady rate of strain. After the stress is removed, it will only partially recover its original configuration. Most of the energy in viscoelastic creep experiments is lost through viscous dissipation or flow (Briceno 2000; Morrison 2001).

The material function used to describe the creep experiments is called creep compliance $\left(\mathrm{J}\left(\mathrm{t}, \tau_{0}\right)\right.$, which is the sample deformation $\gamma(\mathrm{t})$ (strain) at the prescribed stress $\tau_{0}$ (constant) (Figure 46) (Briceno 2000; Morrison 2001).

$J\left(t, \tau_{0}\right)=\frac{\gamma(t)}{-\tau_{0}}$

Equation 12

The creep recovery function is defined as the strain recovered $\left(\gamma_{\mathrm{r}(\mathrm{t})}\right)$ after stress removal divided by the constant stress $\tau_{0}$.

$\mathrm{J}_{\mathrm{r}}\left(\mathrm{t}, \tau_{0}\right)=\frac{\gamma_{\mathrm{r}(\mathrm{t})}}{-\tau_{0}}$

Equation 13

There are different features related to the creep compliance curve (Figure 46). Initially, a stress is applied and the creep compliance is measured. Following removal of the stress (dotted line in 
Figure 46), the recovery of the material is measured until a plateau value is reached [i.e, the strain (deformation) becomes linear with time]. This is when the flow reaches a steady state and the slope of $J\left(t, \tau_{0}\right)$ is the steady state shear rate divided by the corresponding $\tau_{0}$. This ratio is the inverse of the steady shear viscosity $\left(\frac{1}{\eta(\gamma \infty)}\right)$. InFigure 46, the steady-state compliance is obtained by extrapolating the linear portion of $\mathrm{J}\left(\mathrm{t}, \tau_{0}\right)$ back to time zero, as follows:

$\mathrm{J}_{\mathrm{s}}\left(\tau_{0}\right)=\left.\mathrm{J}\left(\mathrm{t}, \tau_{0}\right)\right|_{\text {Steady state }-} \frac{\mathrm{t}}{\eta(\gamma \infty)}$

Equation 14

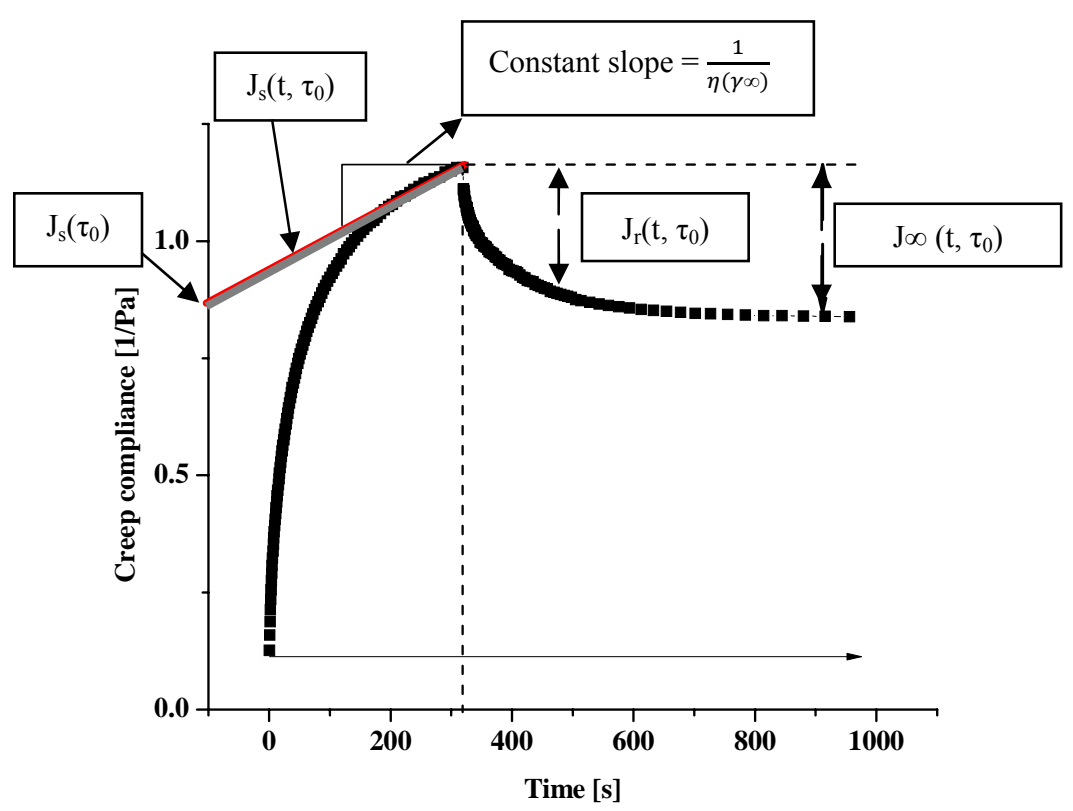

Figure 46: Typical creep and compliance recovery curve with various material functions(adapted from (Briceno 2000; Morrison 2001)).

Creep and recovery compliance tests were conducted on the emulsions stored on Petri dishes at a shear stress of $0.3 \mathrm{~Pa}$ (Figure 47 and Figure 48), which was within the linear viscoelastic range for all samples. The deformation stress was applied for 319 s. A similar creep compliance and recovery pattern was seen for all other emulsions(Figure 47A-E), whereby there was gradually less and less deformation with increasing water cut and time. The difference in creep compliance between days 0 and 28 was much higher for $10 \% \mathrm{~W} / \mathrm{O}$ emulsions compared to $50 \mathrm{wt} \% \mathrm{~W} / \mathrm{O}$ emulsions. For example, in Figure 47B, the day 0 and 2 samples showed similar large deformation behaviour ( $220 \%$ deformation). After day 7 , a significant reduction in deformation was observed ( $114 \%$ deformation) which dropped to $\sim 35 \%$ deformation after day 28 . Analogous 
to the viscosity results, the creep and recovery compliance results indicated the continued growth of the wax crystals and associated changes in network strength with storage time. The postdeformation recovery of the emulsions portion in Figure 47B (after $636 \mathrm{~s}$ ) indicated that the 'young' samples (day 0 and 2) failed to significantly recover their structure. The aged samples (days 7-28), however, recovered much more of their deformed structure, indicating a more elastic behaviour than in the samples stored for up to 2 days. These results were in line with the flow curve results and showed the combined effect of wax crystal network formation and water cut on emulsion structure.
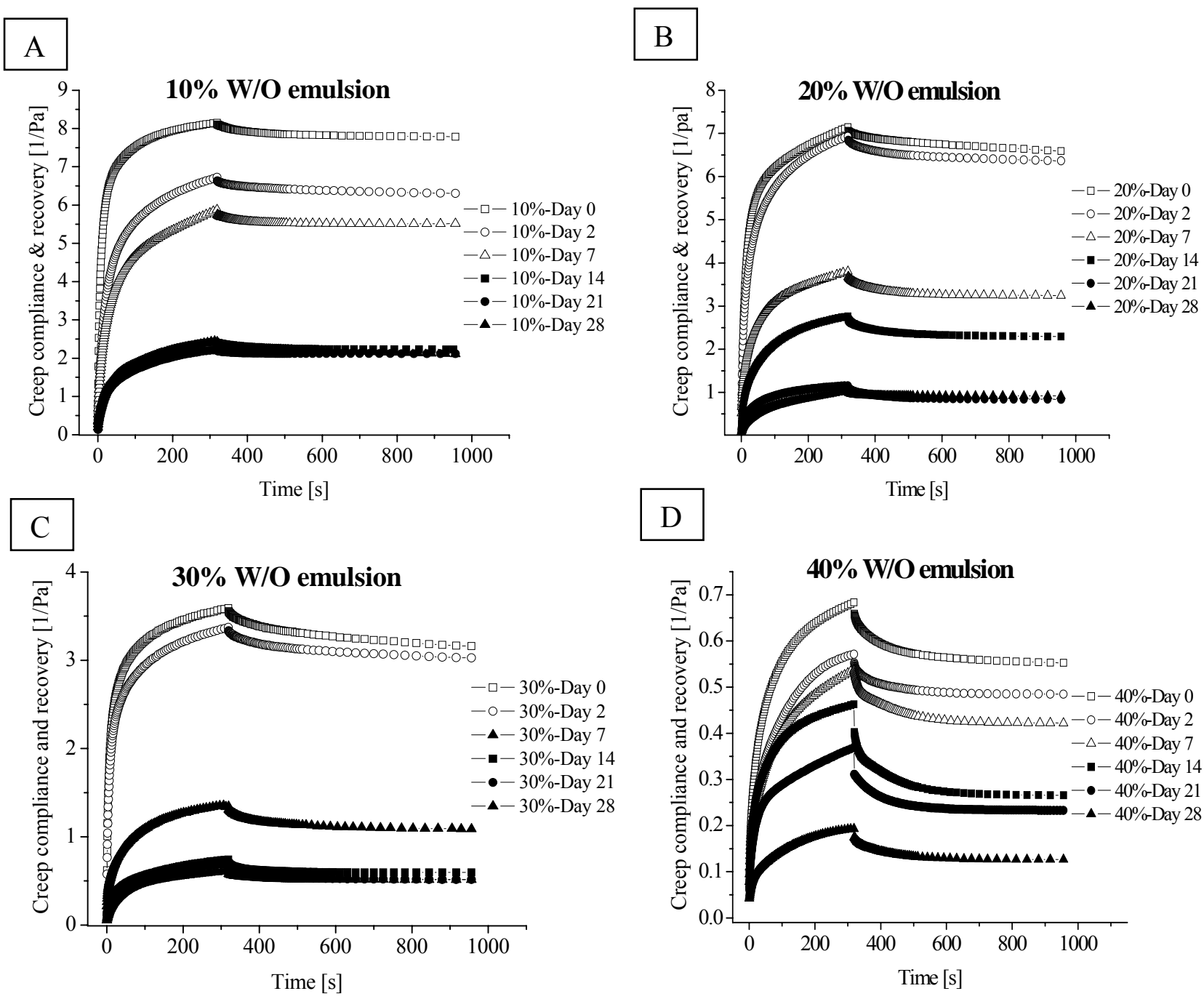


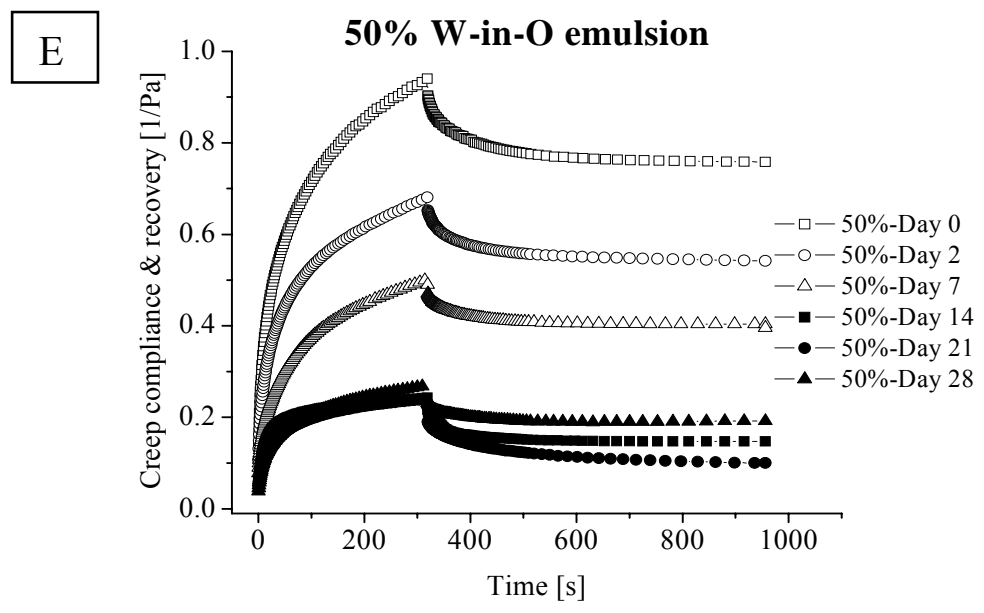

Figure 47: Creep compliance and recovery of wax-stabilized emulsions as a function storage time (in days). Samples were held at constant temperature of $10^{\circ} \mathrm{C}$ during measurements. A to E: $10 \% \mathrm{~W} / \mathrm{O}$ emulsions to $50 \% \mathrm{~W} / \mathrm{O}$ emulsions.

\subsubsection{Effect of water cut on creep compliance and recovery}

In Figure 48, the creep compliance experimental results are presented based on emulsion age. Figure 48A (day 0) confirmed that with a higher $\mathrm{wt} \%$ of dispersed phase, there was a higher material rigidity. For example, the $10 \% \mathrm{~W} / \mathrm{O}$ emulsion at day 0 demonstrated significant deformation ( $245 \%$ deformation) whereas the $50 \% \mathrm{~W} / \mathrm{O}$ emulsion underwent much less deformation ( $28 \%$ deformation). With ageing, the creep compliance and sample deformation decreased at all water cuts, though they still followed the same pattern as on day 0 . Therefore, even though the lower water cut emulsions had higher wax contents, the dispersed aqueous phase was still dominant over the wax crystal networks. This is further discussed in section 5.3.12. The same observation also applied to the post-deformation recovery of the emulsions portion (after $636 \mathrm{~s}$ ). The 'young' samples (days 0 and 2) failed to recover their structure whereas the aged samples (days 7-28) recovered much more of their deformed structure, indicating a more elastic behaviour than in the samples stored for up to 2 days. 

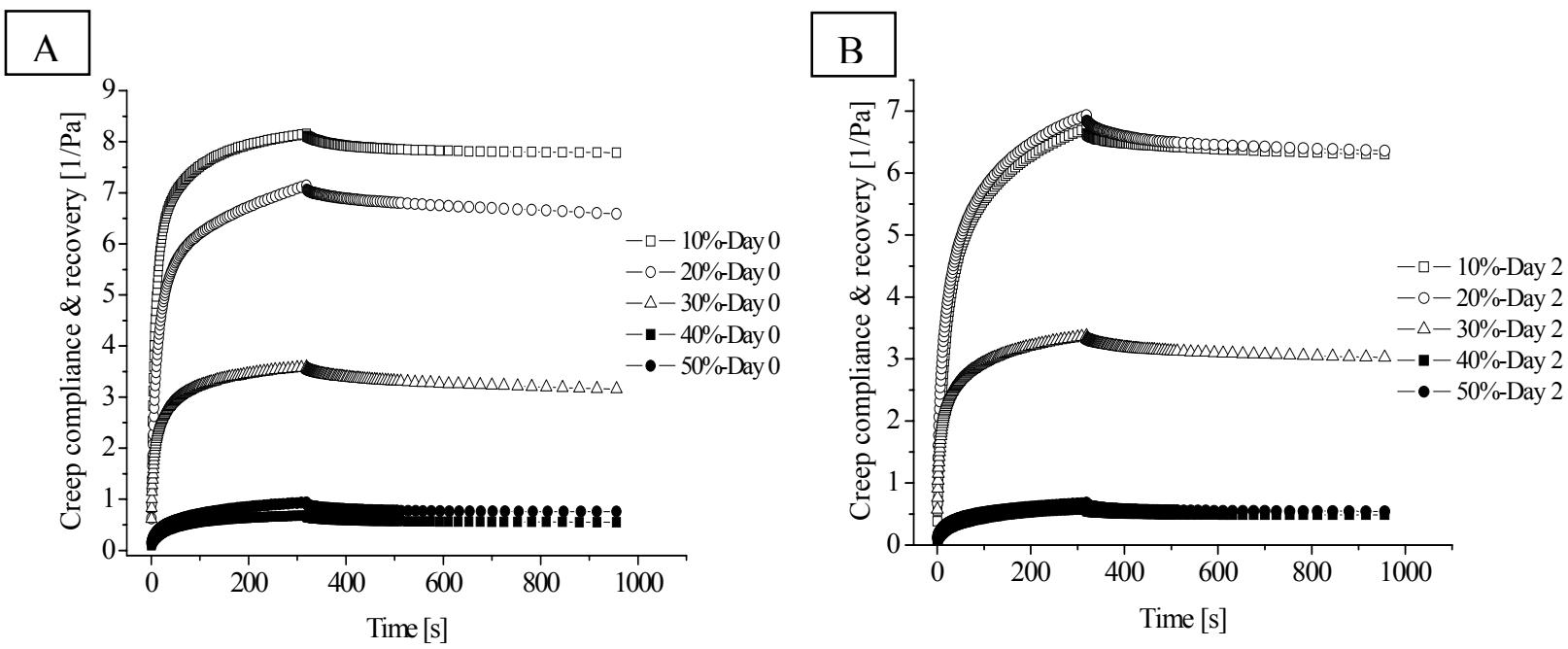

\section{C}

\section{D}
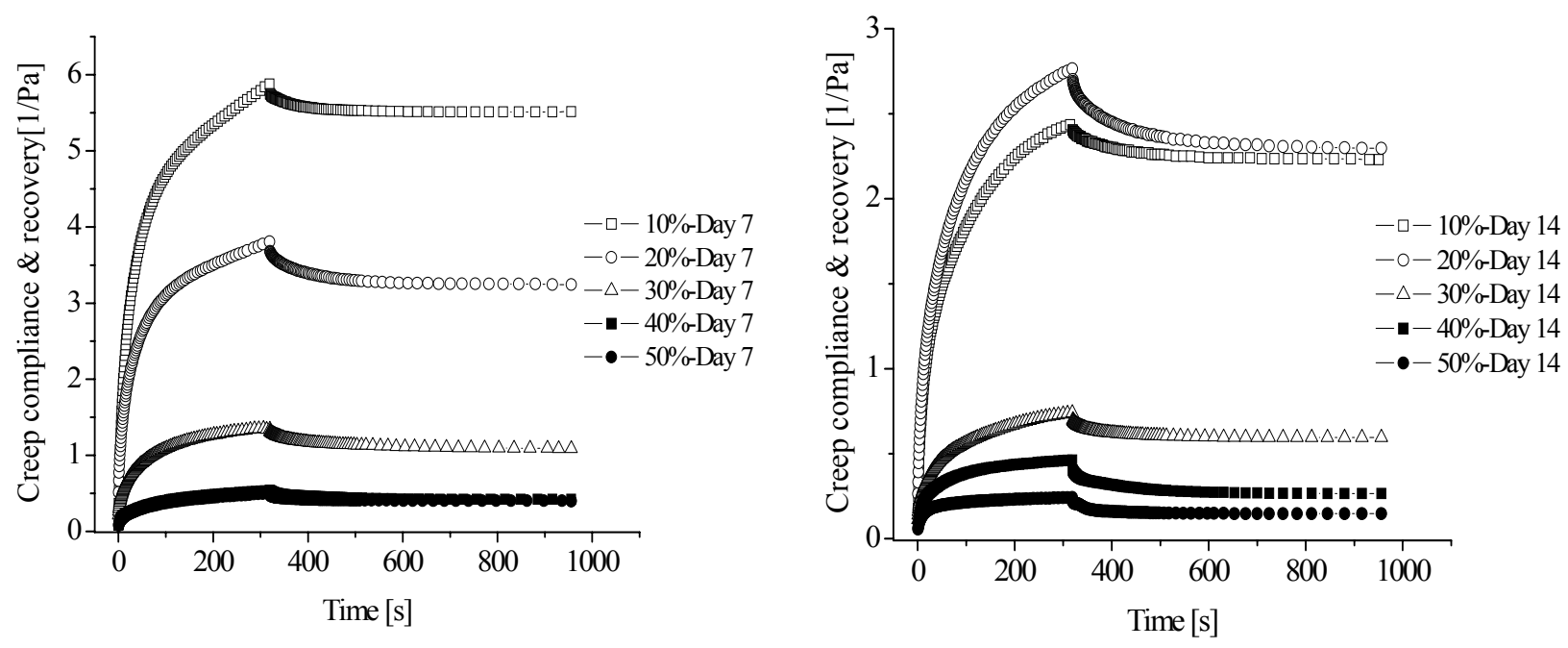

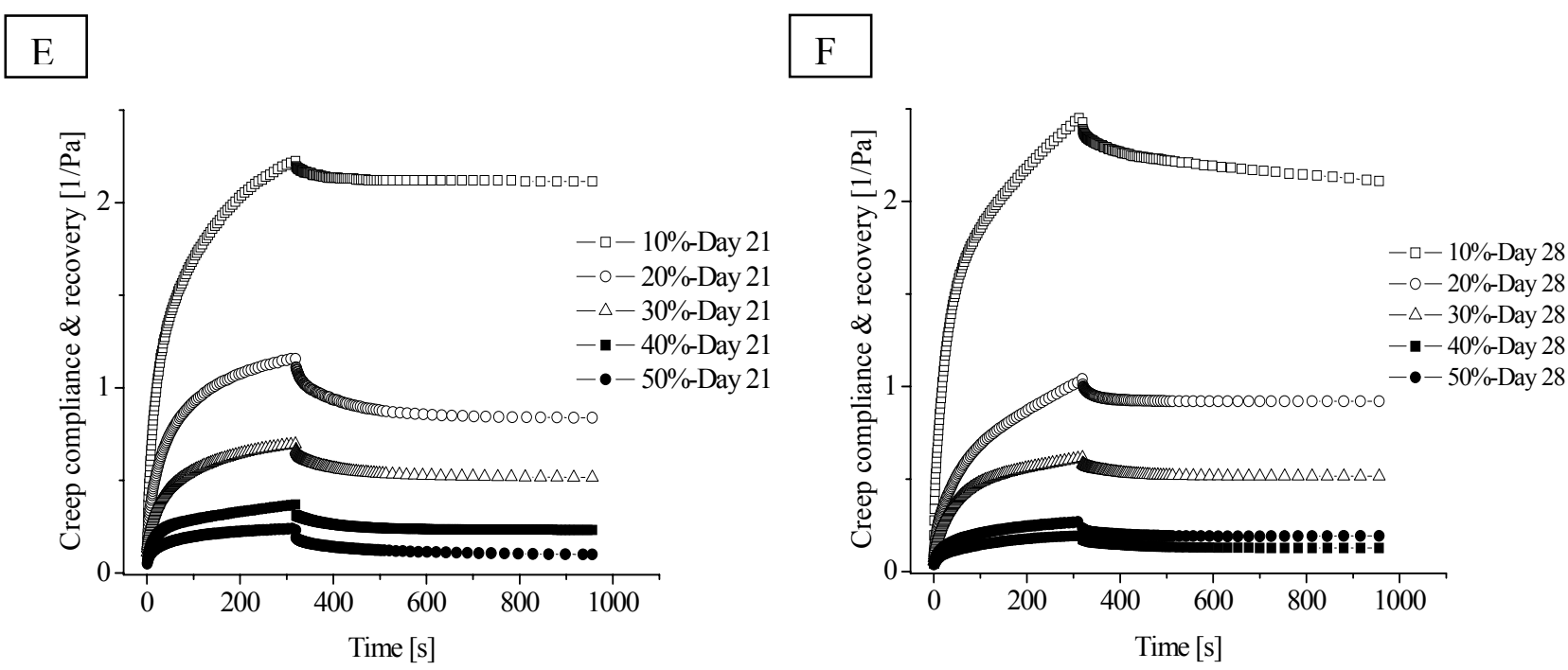

Figure 48: Creep compliance and recovery of wax-stabilized emulsions as a function of water cut and storage time (in days). Samples were held at constant temperature of $10^{\circ} \mathrm{C}$ during measurements. A to F: day 0 to day 28.

\subsubsection{Viscoelastic properties of emulsion samples}

Oscillatory rheology was conducted at a constant frequency of $1 \mathrm{~Hz}$. A one-minute hold time at $10^{\circ} \mathrm{C}$ was set at the beginning of the run followed by the measurement of the storage and loss moduli with log-scale amplitude changes from $0.01 \%$ to $100 \%$. When the storage and loss modulus were equal, the corresponding shear stress was deemed the flow point of the emulsion. Figure 49 shows the yield points for emulsions with different water cuts over a one month period. On day 0 , the lower water cut emulsions were less rigid when compared to higher water cut emulsions. The 50\% W/O emulsion has no yield value as the storage and loss moduli did not intersect (Figure 54), suggesting that this emulsion was more rigid. Furthermore, the $40 \% \mathrm{~W} / \mathrm{O}$ emulsion only showed a yield point on day 0 (Figure 53) and the $30 \% \mathrm{~W} / \mathrm{O}$ emulsion demonstrated yield point values for days 0, 2, 7 and 14 only (Figure 52). The 10\% and 20\% W/O emulsions showed yield values for all days (Figure 50 and Figure 51). Thus, it can be concluded that even though the lower water cut samples $(10 \%$ and $20 \%)$ were significantly strengthened with the formation of stronger wax crystal networks (given their increase in $\mathrm{G}^{\prime}$ ), they were not as elastic as the higher water contents. Therefore, the water cut dominated over the wax crystal network in terms of viscoelastic properties. Figure 50 through Figure 54show the loss and storage moduli for $10 \% \mathrm{~W} / \mathrm{O}$ through $50 \% \mathrm{~W} / \mathrm{O}$ emulsions, respectively. 


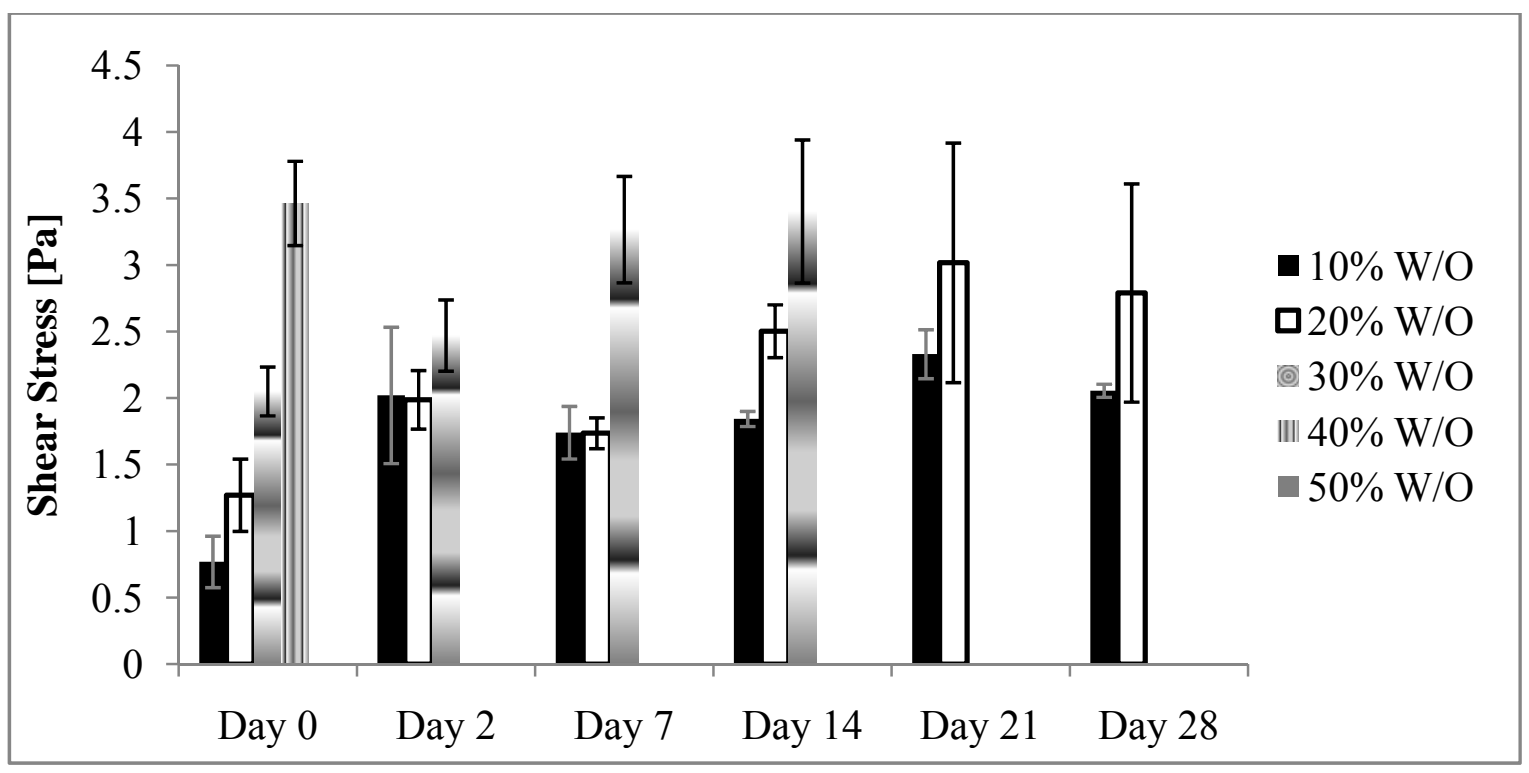

Figure 49: Yield point or flow point of all the water cut emulsions.

10\% W/O Emulsion
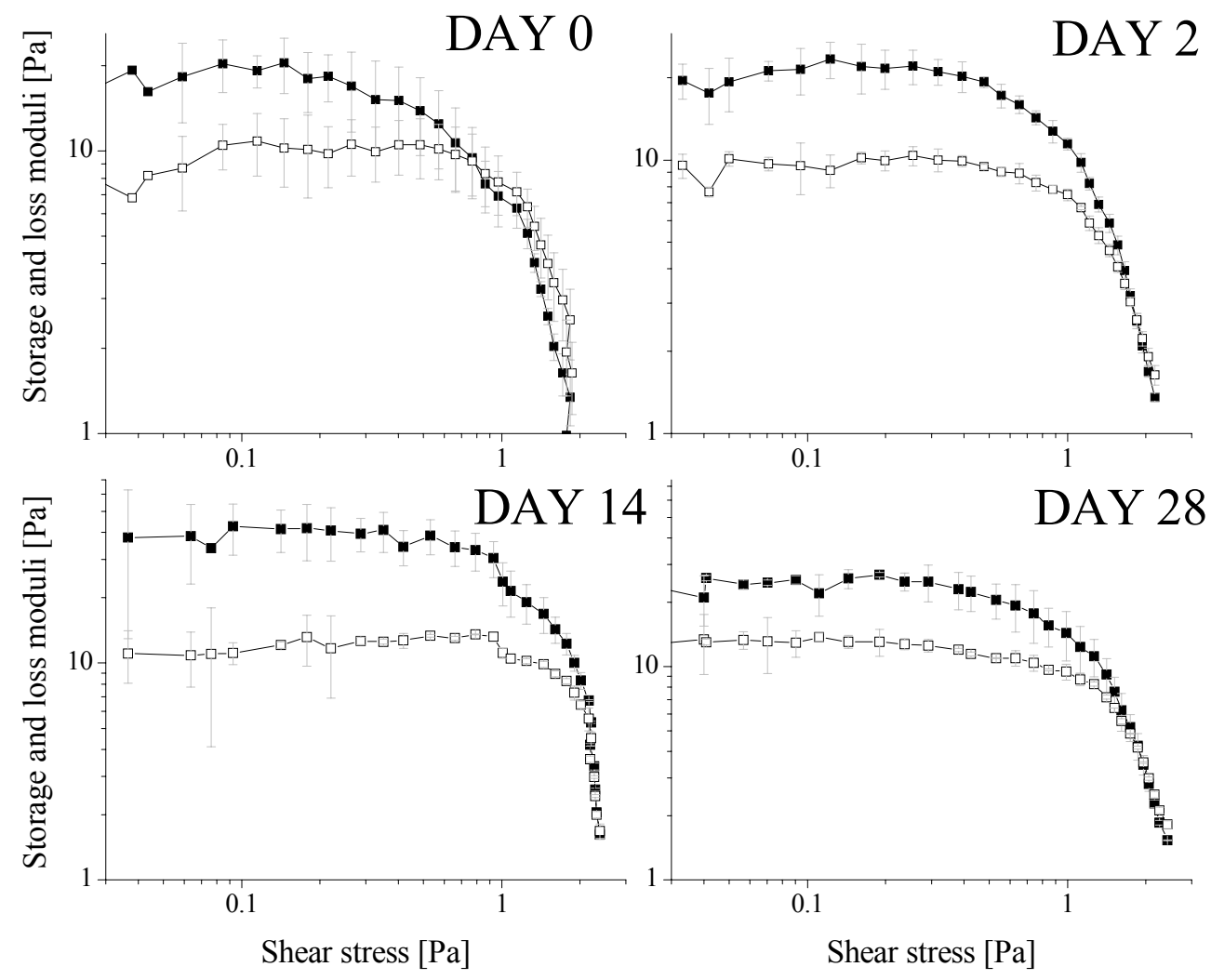

Figure 50: Storage and loss modulus of a 10\% W/O emulsion on days 0, 2, 14 and 28. 


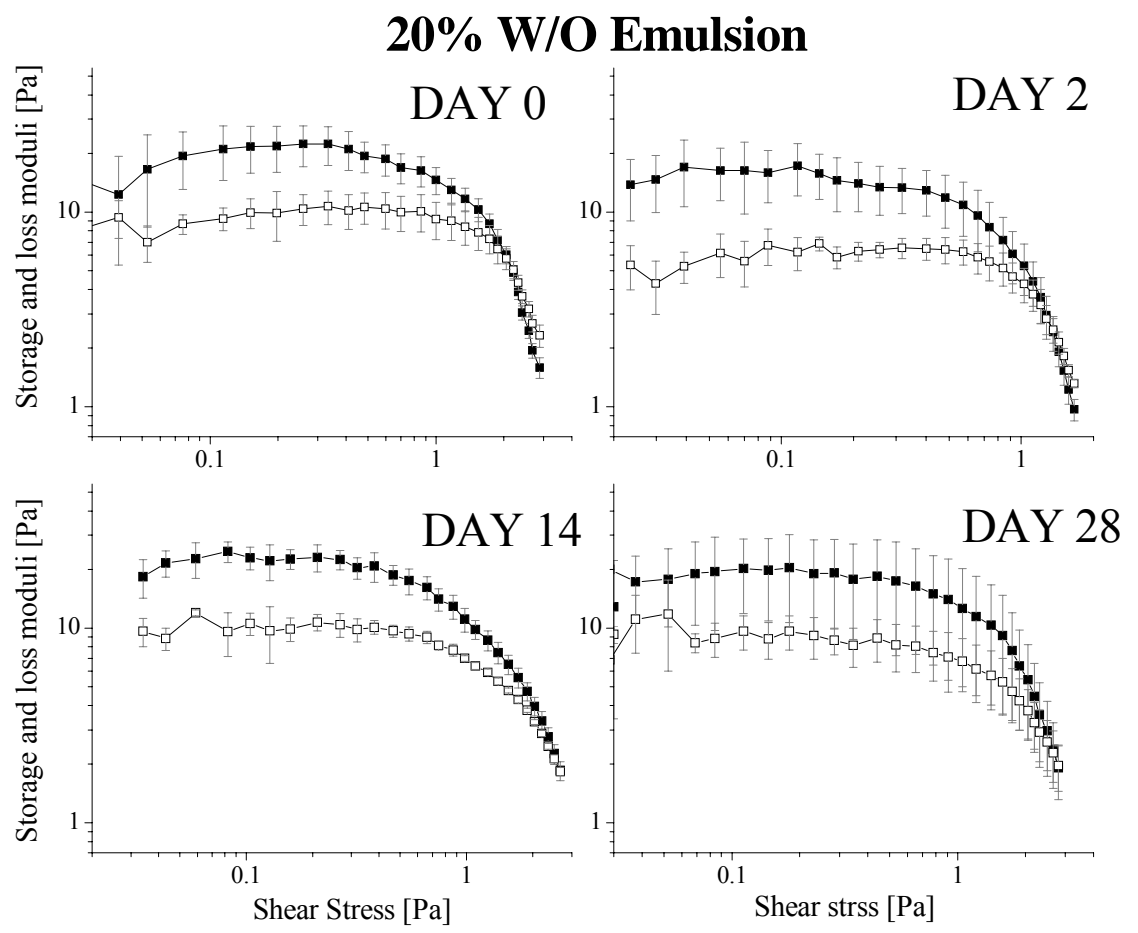

Figure 51: Storage and loss modulus of a $20 \% \mathrm{~W} / \mathrm{O}$ emulsion on days $0,2,14$ and 28

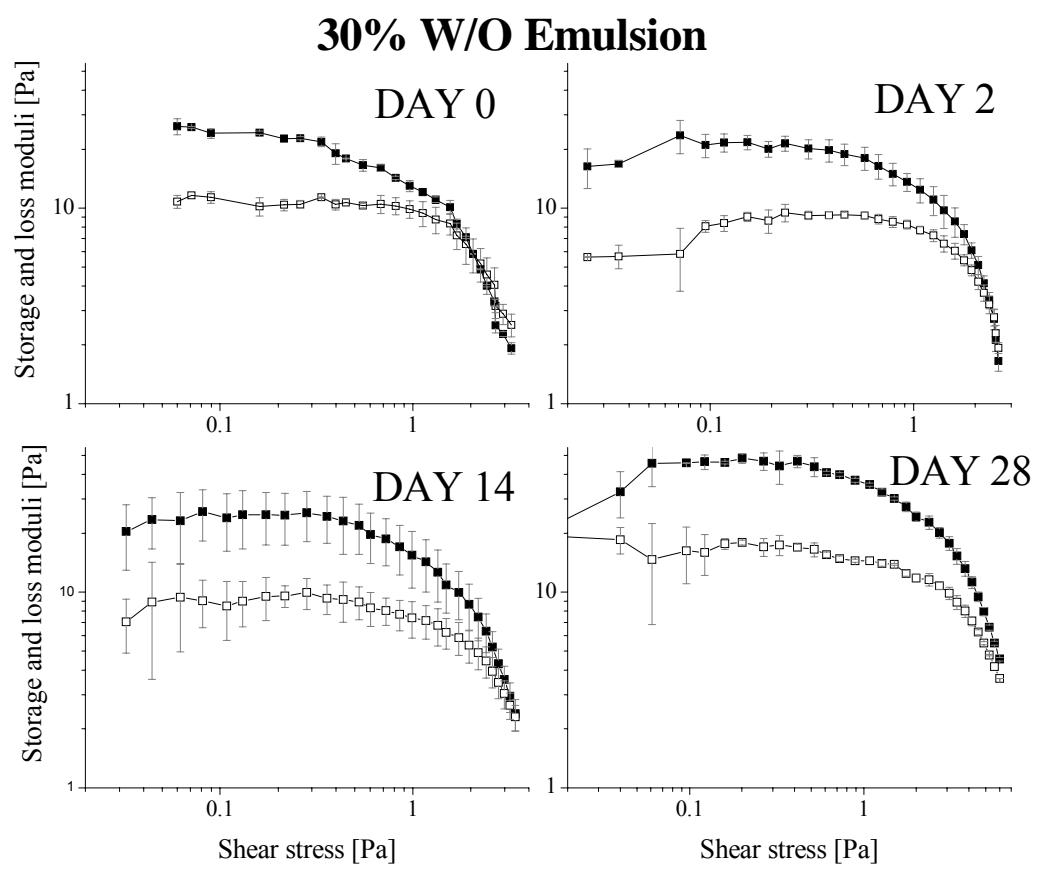

Figure 52: Storage and loss modulus of a 30\% W/O emulsion on days $0,2,14$ and 28 


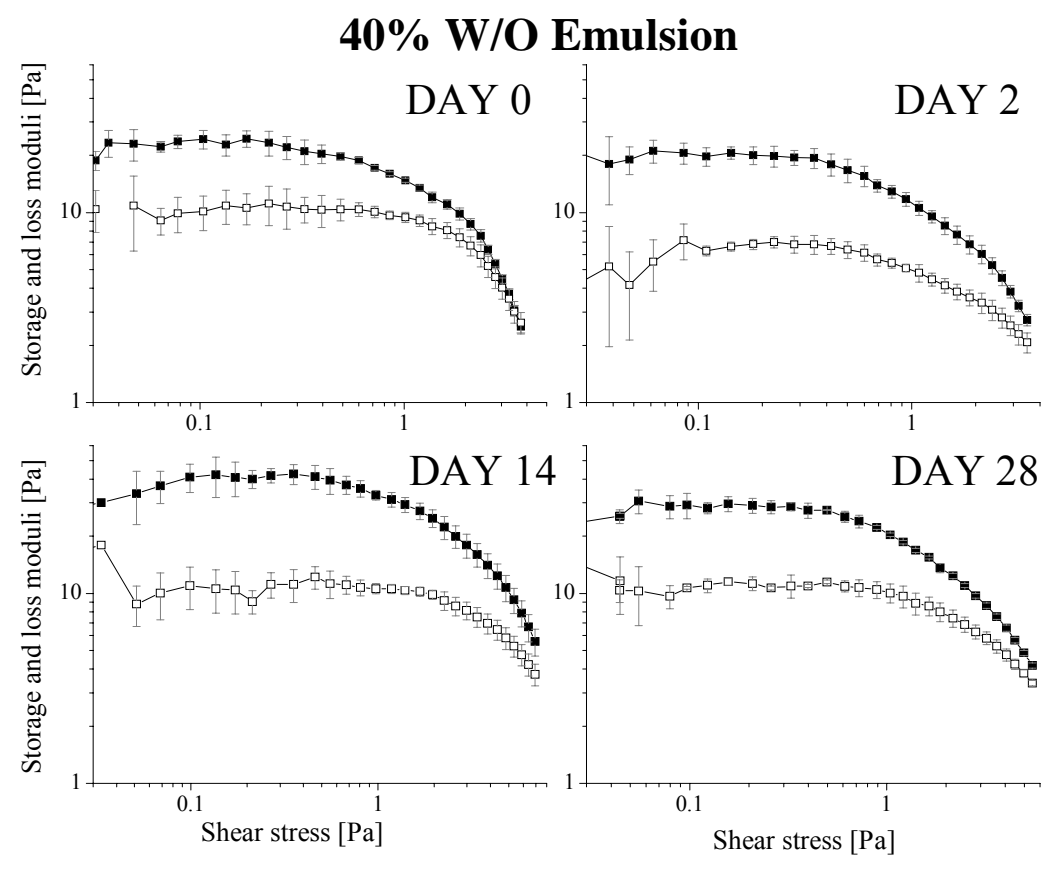

Figure 53: Storage and loss modulus of a 40\% W/O emulsion on days $0,2,14$ and 28

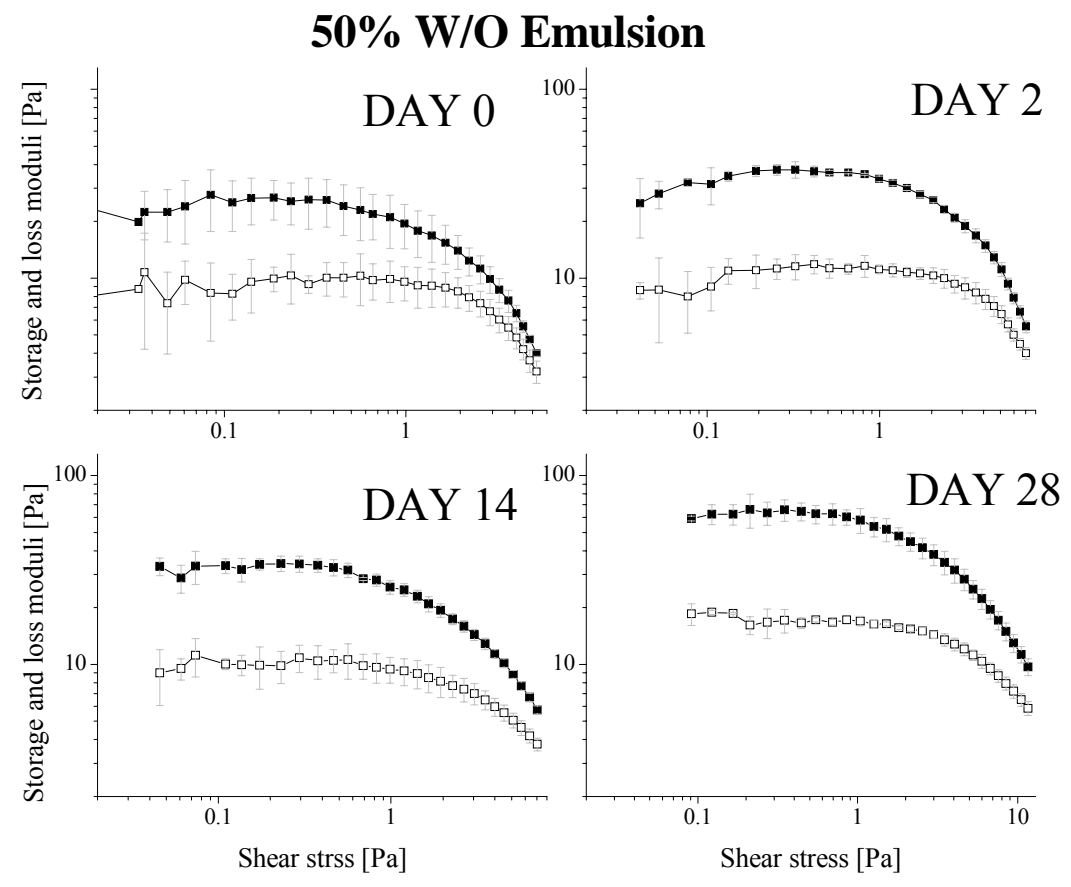

Figure 54: Storage and loss modulus of a 50\% W/O emulsion on days 0, 2, 14 and 28. 
The storage and loss moduli ratio is called damping factor or loss factor ( $\tan \delta$ ) (Figure 15). When loss modulus is equal to storage modulus, the damping factor is equal to one, which indicates that a material has equal contributions to its viscoelasticity from its viscous and elastic components. If the damping factor is bigger than one, the sample is viscous and less than one, the sample is elastic. The damping factors for 10-50\% W/O emulsions are shown in Figure 55 for the day 0 and 28 samples. On day 0 , the damping factors for $50 \% \mathrm{~W} / \mathrm{O}$ emulsion were $<1$, indicating it was more elastic than viscous. For $10-40 \% \mathrm{~W} / \mathrm{O}$ emulsions, the damping factors increased as a function of shear rate from $<1$ to $>1$. Therefore, beyond a certain applied strain, these samples went from demonstrating initially more elastic behaviour to more viscous behaviour. On day 28 , the $30-50 \% \mathrm{~W} / \mathrm{O}$ emulsions all had $\tan \delta$ values $<1$ showing that even after applied stress, the sample were more elastic and did not flow. On the other hand, the tan $\delta$ values of the 10-20\% $\mathrm{W} / \mathrm{O}$ emulsions started at $<1$ at low strain and increased to $>1$ with higher applied strains. These results were in agreement with the previous yield stress results. Moreover, if Figure 55 A and B are compared, it is visible that over a one-month period, the viscous portion of the samples decreased for $10-40 \% \mathrm{~W} / \mathrm{O}$ emulsions, indicating the samples became more rigid over time.

$\tan \delta=\frac{\mathbf{G}^{\prime}}{\mathbf{G}^{\prime \prime}}$

Equation 15
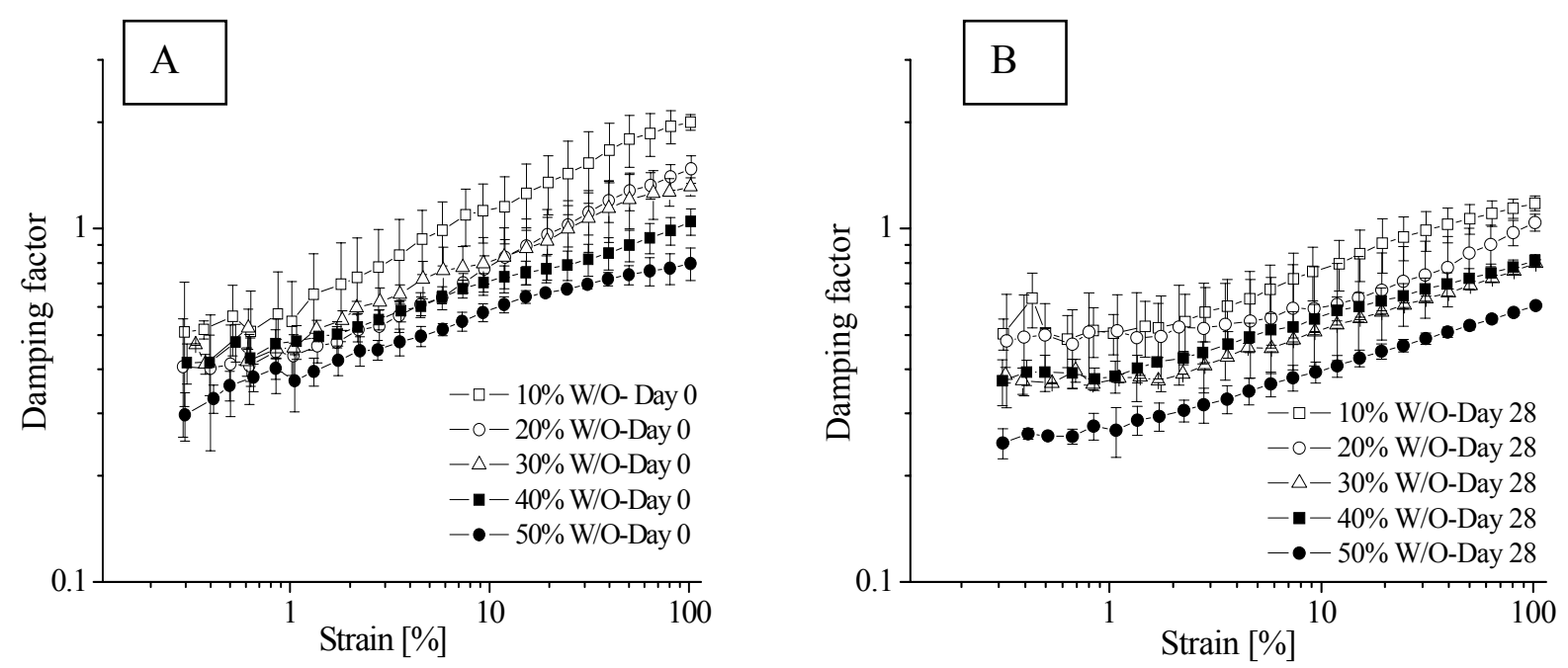

Figure 55: Damping factor as a function of strain for $10-50 \% \mathrm{~W} / \mathrm{O}$ emulsions on days 0 and 28. 


\subsubsection{Contribution of SWC, water cut and surfactant (GMO) on emulsion viscosity}

Figure $56 \mathrm{~A}$ shows the viscosity ( period. With an increase in water cut, the day 0 viscosity of the emulsions increased. With time, the viscosity also increased for all water cuts. Figure 56 B-F relates the viscosity of each water cut as a function of $\% \mathrm{SWC}$. As discussed earlier, emulsion viscosity increased with an increase in \%SWC. In addition, from the original compositions used, the amount of surfactant (GMO) decreased by increase of water cut. It is worthwhile examining which of these independent variables (\%SWC, water cut or GMO) had a greater contribution to the increase in emulsion viscosity. According to the method called the contribution of explanatory variable (Tryfos 1998), the extent to which these independent variables as well as the combined effect of water cut and SWC impacted viscosity may be examined as follows (Tryfos 1998):

1. Consider a full model that contains $\% \mathrm{SWC} \%$ water cut (WC), amount of GMO (GMO), and the combined SWC and water cut (SWC $\times$ WC) effect (where $b_{0}, b_{1}, b_{2}, b_{3}$ and $b_{4}$ are variable coefficients)

Viscosity $=b_{0}+b_{1} \times S W C+b_{2} \times W C+b_{3} \times G M O+b_{4} \times(S W C \times W C)$

Equation 16

2. Regression of this model provides an R-square of:

$$
\mathrm{R}_{\text {Full model }}^{2}=0.608
$$

3. To assess the independent contribution of each variables, partial regression was conducted as follows (where $\mathrm{c}-\mathrm{f}$ are variable coefficients):

$$
\begin{array}{ll}
\text { Viscosity }=\mathrm{c}_{0}+\mathrm{c}_{1} \times \mathrm{SWC}+\mathrm{c}_{2} \times \mathrm{GMO}+\mathrm{c}_{3} \times(\mathrm{SWC} \times \mathrm{WC}) & \text { Equation } 17 \\
\text { Viscosity }=\mathrm{d}_{0}+\mathrm{d}_{1} \times \mathrm{WC}+\mathrm{d}_{2} \times \mathrm{GMO}+\mathrm{d}_{3} \times(\mathrm{SWC} \times \mathrm{WC}) & \text { Equation } 18 \\
\text { Viscosity }=\mathrm{e}_{0}+\mathrm{e}_{1} \times \mathrm{SWC}+\mathrm{e}_{2} \times \mathrm{WC}+\mathrm{e}_{3} \times \mathrm{GMO} & \text { Equation } 19 \\
\text { Viscosity }=\mathrm{f}_{0}+\mathrm{f}_{1} \times \mathrm{SWC}+\mathrm{f}_{2} \times \mathrm{WC}+\mathrm{f}_{3} \times(\mathrm{SWC} \times \mathrm{WC}) & \text { Equation } 20
\end{array}
$$

4. The corresponding R-square values were:

$$
\begin{gathered}
\mathrm{R}_{\mathrm{P}-\mathrm{SWC}}^{2}=0.366 \\
\mathrm{R}_{\mathrm{P}-\mathrm{WC}}^{2}=0.394 \\
\mathrm{R}_{\mathrm{P}-\mathrm{GMO}}^{2}=0.605 \\
\mathrm{R}_{\mathrm{P}-\mathrm{SWC} \text { x WC }}^{2}=0.511
\end{gathered}
$$


5. The contribution metric for each variable was calculated as follows:

$\mathrm{Q}_{\mathrm{SWC}}=\frac{\mathrm{R}_{\mathrm{Fullmodel}}^{2}-\mathrm{R}_{\mathrm{P}-\mathrm{SWC}}^{2}}{1-\mathrm{R}_{\mathrm{P}-\mathrm{SWC}}^{2}}=\frac{0.608-0366}{1-0.366}=0.352$

Equation 21

$\mathrm{Q}_{\mathrm{WC}}=\frac{\mathrm{R}_{\mathrm{Fullmodel}}^{2}-\mathrm{R}_{\mathrm{P}-\mathrm{WC}}^{2}}{1-\mathrm{R}_{\mathrm{P}-\mathrm{WC}}^{2}}=\frac{0.608-0.394}{1-0.394}=0.381$

Equation 22

$\mathrm{Q}_{\mathrm{GMO}}=\frac{\mathrm{R}_{\mathrm{Fullmodel}}^{2}-\mathrm{R}_{\mathrm{P}-\mathrm{GMO}}^{2}}{1-\mathrm{R}_{\mathrm{P}-\mathrm{GMO}}^{2}}=\frac{0.608-0.605}{1-0.605}=0.00623$

Equation 23

$\mathrm{Q}_{\mathrm{SWC} \text { X WC }}=\frac{\mathrm{R}_{\text {Fullmodel }}^{2}-\mathrm{R}_{\mathrm{P}-\mathrm{SWC} \text { x WC }}^{2}}{1-\mathrm{R}_{\mathrm{P}-\mathrm{SWC} \text { X WC }}^{2}}=\frac{0.608-0.511}{1-0.511}=0.197$

Equation 24

From these $\mathrm{Q}$ values, it was concluded that $\% \mathrm{SWC}$ had a $35.2 \%$ contribution, the $\% \mathrm{WC}$ had a $38.1 \%$ contribution, the GMO had a $0.623 \%$ contribution and the combine SWC and water cut had a $19.7 \%$ contribution towards viscosity. Based on these results, the WC has the greatest effect on emulsion viscosity while GMO had the least effect on emulsion viscosity. The total contribution of all variables based on the sum of the calculated Qs was 93.6\%. Therefore, there were other variables (factors) that contributed to the increase in viscosity, and the value of $\mathrm{R}^{2}$ for the full model is another indicator for other missed explanatory variables. Other factors that could have contributed to the viscosity are the size of wax crystals in the fresh and aged emulsions, and the effect of Pickering versus network stabilizations.

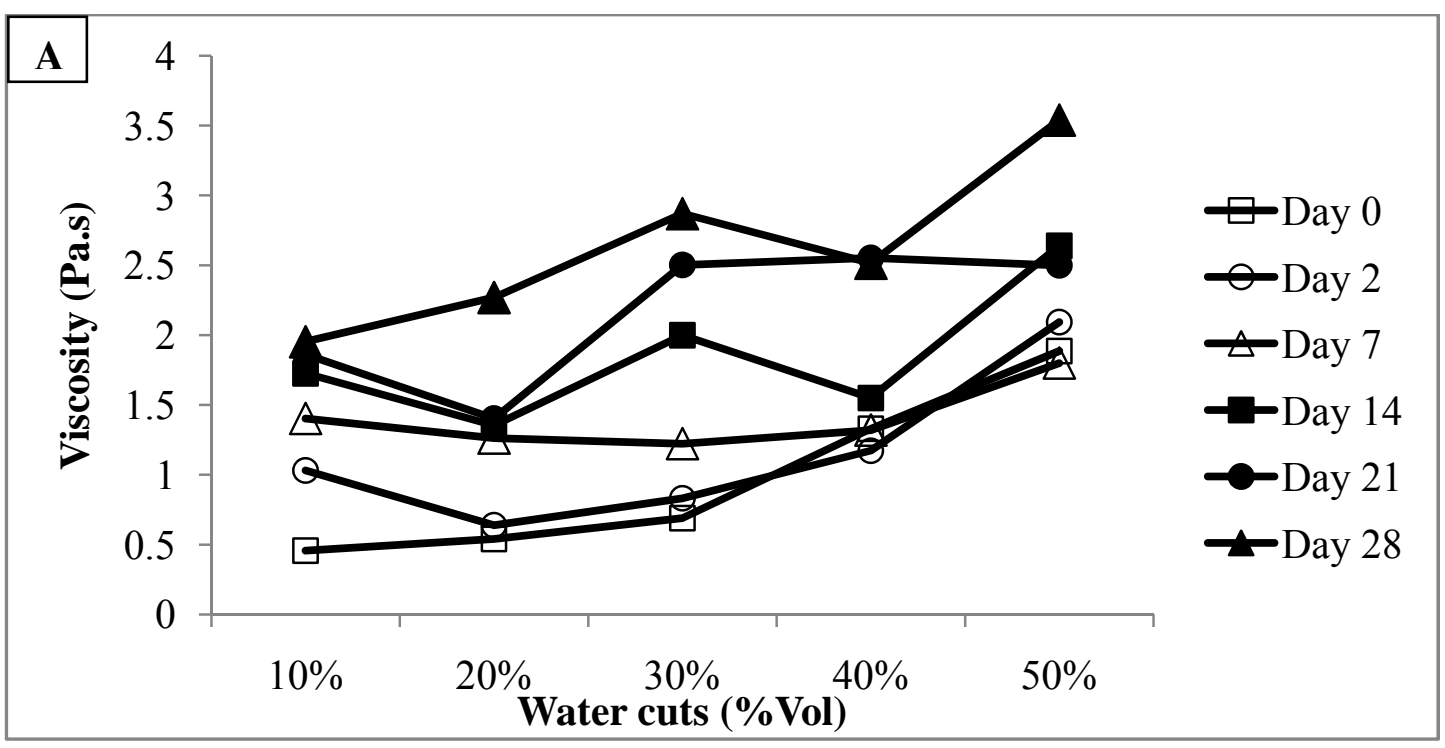



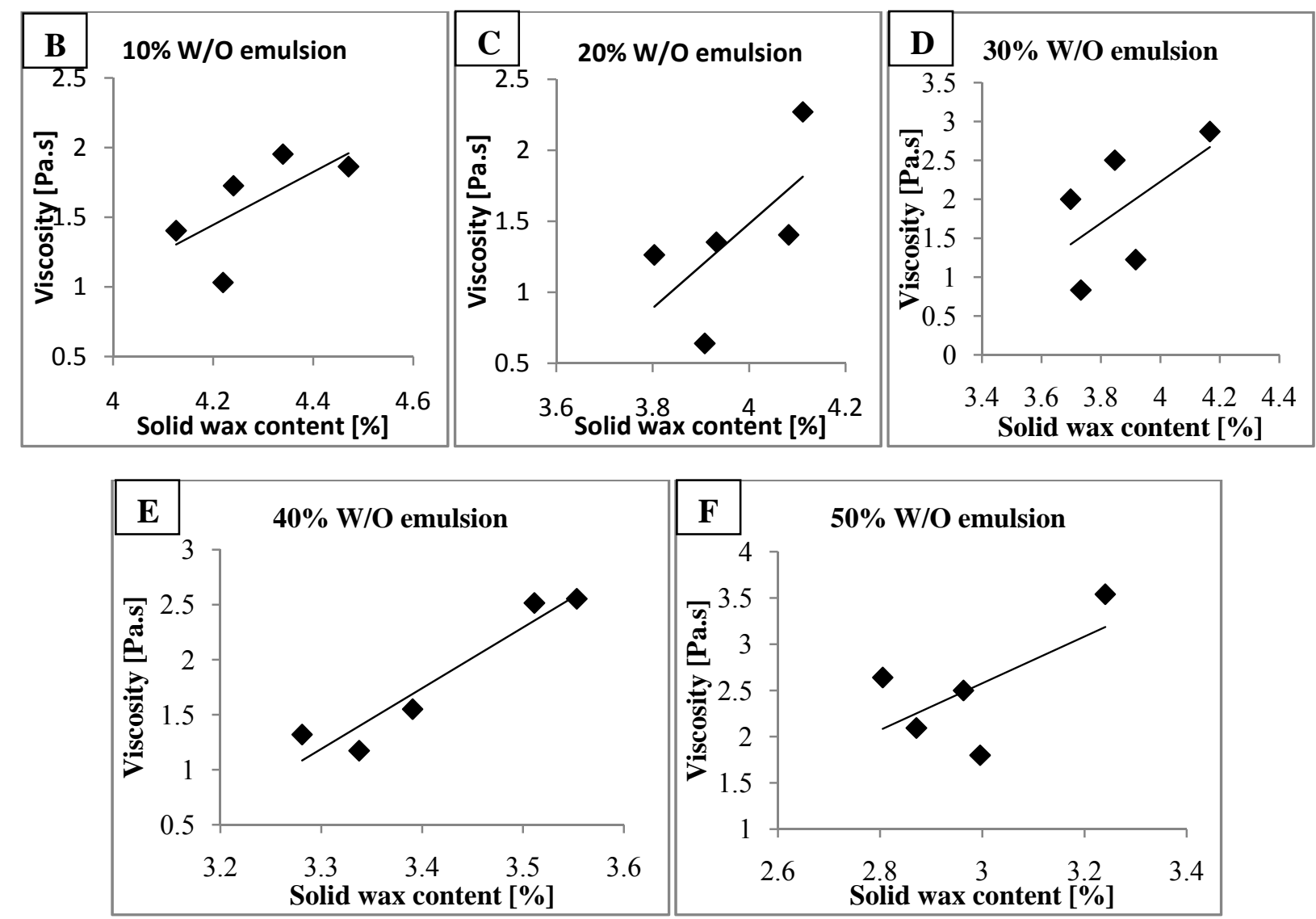

Figure 56: A: Emulsion viscosity as a function of water cut over a one month period. B-F: Emulsion viscosity as a function of SWC over a one month period.

\subsection{Conclusion}

The impact of water cut and \% SWC on W/O emulsions was ascertained. With increasing water cut (from 10 to $50 \%$ ), the initial amount of wax in the system decreased (based on the original compositions used). However, over time, the SWC of the emulsions at all water cuts increased slowly as more wax solidified (e.g., $\mathrm{SWC}_{\text {Day } 0}^{50 \% \mathrm{~W} / 0}$ was 2.871 and $\mathrm{SWC}_{\text {Day } 28}^{50 \% \mathrm{~W} / \mathrm{O}}$ was 3.241). Stable emulsions were obtained for all water cuts with an average droplet size of $30 \mu \mathrm{m}$, except for the $50 \% \mathrm{~W} / \mathrm{O}$ emulsion which started to destabilize after 21 days.

All emulsions and neat oil samples showed shear-thinning fluid behaviour due to the presence of the dispersed aqueous phase and continuous phase wax crystals. Emulsion with a higher water cut (40 and $50 \mathrm{wt} \%$ ) had a higher low-shear viscosity and were more rigid (higher $\mathrm{G}^{\prime}$ ) for both fresh and aged samples. From the creep compliance and recovery results, the higher water cut emulsions (40 and $50 \mathrm{wt} \%$ ) deformed less and recovered more. Therefore, it was concluded that 
the higher water cut emulsions were more rigid and showed more elastic behaviour for both fresh and aged samples when compared to lower water cut emulsions $(10-30 \mathrm{wt} \%)$. In addition, as a result of wax crystal network formation at all water cuts (increased \% SWC), viscosity and $\mathrm{G}^{\prime}$ increased over time. This was further proven with microscopy, where the fresh samples destabilized after shearing as a result of weak wax crystal networks whereas the aged samples retained their structure and integrity due to existence of stronger wax crystal network. These results suggested that dispersed phase fraction (water cut) dominates over solid wax content in terms of sample viscosity.

The rheology of the neat oil (oil phase only) confirmed that the dispersed aqueous phase played a significant role on a model emulsion properties, with all emulsions having a higher viscosity when compared to neat oil (on day 0). However, with ageing, the neat oil viscosity either surpassed or approached that of the corresponding emulsion (for the $20 \% \mathrm{~W} / \mathrm{O}$ and $50 \% \mathrm{~W} / \mathrm{O}$ emulsions, respectively. 


\section{Conclusion and recommendations}

The objective of this study was to characterize the flow and rheological behaviour of model waxstabilized water-in-oil emulsions consisting of light mineral oil, paraffin wax ( $5 \mathrm{wt} \%$ of the oil phase) and the surfactant glycerol monooleate as the oil phase and water as the dispersed aqueous phase. An in-house laboratory-scale benchtop flowloop system was developed and used to explore the flow behaviour of the emulsions' oil phase (oil, paraffin wax and surfactant). Flowloop runs at lower temperatures led to reduce overall deposition on the flowloop inner wall (for runs up to $30 \mathrm{hrs}$ ). This was based on the $4^{\circ} \mathrm{C}$ neat oil runs, which only showed deposition at the beginning of the flowloop (mostly in the removable $0 \mathrm{~m}$ section) and on the $25^{\circ} \mathrm{C}$ runs, which showed continued deposition further along the loop length. Temperature also impacted solid wax content (SWC). With the $30 \mathrm{hr}$ runs, the SWC of the neat oil deposit was $\sim 28 \%$ at $4{ }^{\circ} \mathrm{C}$ whereas it was only $13 \%$ with the $25^{\circ} \mathrm{C}$ neat oil runs. The deposit was thus much harder at the lower 'seabed' temperature. The temperature gradient that the flowloop was subjected to also impacted the type of deposition experienced. Running the flowloop at $25^{\circ} \mathrm{C}$ resulted in a much smaller temperature gradient across the flowloop, thus the wax present in the neat oil reached its WAT much more slowly, leading to deposition further along the loop length. At $4^{\circ} \mathrm{C}$, the near flashcooling experienced by the wax resulted in the rapid formation of a gel in the early portion of the flowloop. The result was that much of the wax was no longer 'available' to be deposited further along the loop. By rapidly reaching this low seabed sea temperature, the wax had already undergone its liquid-solid phase transition, which resulted in minimal subsequent deposition.

In the second portion of this thesis, the rheological properties of emulsions with different water cuts $(10-50 \mathrm{wt} \%)$ were studied, with rotational viscometry, oscillatory rheology and creep compliance and recovery. All emulsions were prepared via high pressure valve homogenization and consisted of the same average droplet size $(\sim 30 \mu \mathrm{m})$. Rheological characterization was performed on emulsions aged up to 28 days. Results showed that the freshly-prepared and aged emulsions with a higher water cut (40 and $50 \mathrm{wt} \%$ ) had a higher viscosity and were more rigid (higher storage modulus) when compared to those with a lower water cut. With ageing, however, the viscosity and storage modulus of the lower water cut emulsions significantly increased (e.g. for $10 \mathrm{wt} \% \mathrm{~W} / \mathrm{O}$, from day 0 to day 28 , there was 4.3 times increase) whereas only slight increases were seen with the higher water cut emulsions (e.g. for $50 \mathrm{wt} \% \mathrm{~W} / \mathrm{O}$, from day 0 to day 28, there was 1.8 times increase). The large increases seen were due to the development of a 
more pronounced wax crystal network in the low water cut systems. With comparing the effect of water cut and the role of continuous phase, it was concluded that the dispersed phase (water cut) dominated over solid wax content in terms of viscosity.

For possible future studies, it is recommended that emulsion stability be characterized for longer periods of time, which would make the results more relevant to other applications in the cosmetics, petroleum, pharmaceutical and food industries. For example, in the development of lower-fat tablespreads, product stability may be compromised with less solid in the continuous phase. What would the impact of this be on the long-term stability of the emulsion is unknown, but highly relevant to shelf life. Another possible area of enquiry would be to characterize W/O emulsions with the same amount of wax, but different water cuts. This would provide further evidence of the driving force behind crystal-stabilized W/O emulsions. 


\section{References}

Abivin, P., I. Henaut, et al. (2009). "Dispersed systems in heavy crude oils." Oil and Gas Science and Technology 64(5): 557-570.

Ahn, S., K. S. Wang, et al. (2005). Paraffin crystal and deposition control by emulsification. 2005 SPE, Society of Petroleum Engineers. Houston, Texas, USA, Society of Petroleum Engineers Inc.

Awad, T. and K. Sato (2002). "Acceleration of crystallisation of palm kernel oil in oil-in-water emulsion by hydrophobic emulsifier additives." Colloids and Surfaces B-Biointerfaces 25(1): 45-53.

Barnes , H. A., J (1999). Non-Newt. Fluid Mech. 81: 133.

Becher, P. (1965). Emulsions: theory and practice. New York, Monograph series (American Chemical Society). Reinhold Pub- lishing.

Becher, P. (1985). Encyclopedia of Emulsion Technology. Encyclopedia of Emulsion Technology. B. P. New York, Marcel Dekker. 2.

Bern, P. A., V. R. Withers, et al. (1980). Wax Deposition in Crude Oil Pipelines. Proceedings of the European Offshore Petroleum Conference, London, England, Oct 21-24.exhibit paper EUR 206.

Binks, B. P. (2002). "Particles as surfactants - similarities and differences." Current Opinion in Colloid and Interface Science 7: 21-41.

Binks, B. P., J. H. Clint, et al. (2005). "Naturally occurring spore particles at planar fluid interfaces and in emulsions." Langmuir 21(18): 8161-8167.

Binks, B. P. and A. Rocher (2009). "Effects of temperature on water-in-oil emulsions stabilised solely by wax microparticles." Journal of Colloid and Interface Science 335: 94-104.

Binks, B. P. and J. A. Rodrigues (2005). "Inversion of emulsions stabilized solely by ionizable nanoparticles." Angewandte Chemie-International Edition 44(3): 441-444.

Briceno, M. I. (2000). Pharmaceutical emulsions and suspensions. New york. Basel, Marcel Dekker, Inc.

Burger, E. D., T. K. Perkins, et al. (1981). "Studies of wax deposition in the Trans Alaska Pipeline." J. Pet. Technol. 33(6): 1075-1086.

Chhabra, R. P. Richardson, J. F. (2008)."Non-Newtonian flow and applied rheologyEngineering Applications." ( $2^{\text {nd }}$ Edition). Knovel Corporation.

Darling, D. F. (1982). "Recent advances in the destabilization of dairy emulsions." Journal of Dairy Research 49(4): 695-712. 
Dickinson, E. (1992). "Structure and composition of adsorbed protein layers and the relationship to emulsion stability." Journal of the Chemical Society-Faraday Transactions 88(20): 2973-2983.

Dickinson, E. (2010). "Food emulsions and foams: Stabilization by particles." Current Opinion in Colloid \& Interface Science 15(1-2): 40-49.

Dickinson, E. (2011). "Food colloids research: Historical perspective and outlook." Advances in Colloid and Interface Science 165(1): 7-13.

Dirand, M., V. Chevallier, et al. (1998). "Multicomponent paraffin waxes and petroleum solid deposits: Structural and thermodynamic state." Fuel Processing Technology 12: 1253.

Dorset, D. L. and R. G. Snyder (1990). "Chain length and the cosolubility of n-paraffins in the solid state. " Macromolecules 23: 623.

Evdokimov, I. N., Y. O. Efimov, et al. (2008). "Morphological transformation of native petroleum emulsions. I. Viscosity studies." Langmuir 24(14): 7124-7131.

Fredrick, E., P. Walstra, et al. (2010). "Factors governing partial coalescence in oil-in-water emulsions." Advances in Colloid and Interface Science 153(1-2): 30-42.

Friberg, S. (1997). Emulsion Stability. New York, Marcel Dekker.

Ghosh, S., T. Tran, et al. "Comparison of Pickering and Network Stabilization in Water-in-Oil Emulsions." Langmuir 27(11): 6589-6597.

Herschel, H. and R. Bulkley (1926). Proc. Am. Soc. Test. Mater. 16: 621.

Hodge, S. M. and D. Rousseau (2005). "Continuous-phase fat crystals strongly influence waterin-oil emulsion stability." Journal of the American Oil Chemists Society 82(3): 159-164.

Horozov, B. P. B. a. T. S., Ed. (2006). Colloidal Particles at liquid interfaces Cambridge, University Press.

Hoteit, H., R. Banki, et al. (2008). "Wax deposition and aging in flowlines from irreversible thermodynamics." Energy \& Fuels 22(4): 2693-2706.

Hunter, T. N., R. J. Pugh, et al. (2008). "The role of particles in stabilising foams and emulsions." Advances in Colloid and Interface Science 137(2): 57-81.

Innings, F. F., L; Tragardh, C (2011). "Theoretical and experimental analyses of drop deformation and break-up in a scale model of a high-pressure homogenizer " Food Engineering 103(1): 21-28. 
Johansson, D., B. Bergenstahl, et al. (1995). "Wetting of fat crystals by triglyceride oil and water. 1. The effect of additives." Journal of the American Oil Chemists Society 72(8): 921-931.

Kabalnov, A. S. and E. D. Shchukin (1992). "Ostwald ripening theory- applications to fluorocarbon emulsion stability." Advances in Colloid and Interface Science 38: 69-97.

Krieger, I. M. and T. J. Dougherty (1959). "A mechanism for non-newtonian flow in suspensions of rigid spheres." Transactions of the society of rheology 3: 137-152.

Kulkarni, S. M., R. B. Maxcy, et al. (1974). "Evaluation of soil deposition and removal processes:An interpretive review I." Our industry today.

Lee, H. S., P. Singh, et al. (2008). "Waxy oil gel breaking mechanisms: adhesive versus cohesive failure." Energy \& Fuels 22: 480-487.

Levine, S., B. D. Bowen, et al. (1989). "Stabilization of emulsions by fine particles. 1. Partitioning of particles between continuous phase and oil-water interface." Colloids and Surfaces 38(4): 325-343.

Li, C., Q. Liu, et al. (2009). "Pickering emulsions stabilized by paraffin wax and Laponite clay particles." J Colloid Interface Sci 336(1): 314-21.

Liu, S. J. and J. H. Masliyah (1996). "Rheology os suspensions." Suspensions: Fundamentals and applications in the petroleum industry 251: 107-176.

Lucassen - Reynders, E. H. and M. Van den Tempel (1963). "Stabilization of water-in-oil emulsions by solid particles." Journal of Physical Chemistry B 67: 731-734.

Lucassen- Reynders, E. H. and D. T. Wasan (1993). "Interfacial viscoelasticity in emulsions and foams." Food Structure 12(1): 1-12.

Robins M. M. et al, (1998). Emulsion flocculation and creaming, in modern aspects of emulsion science. B. P. Binks. Cambridge, UK, The royal society of chemistry.

Macierzanka, A., H. Szelag, et al. (2009). "Effect of crystalline emulsifier composition on structural transformations of water-in-oil emulsions: Emulsification and quiescent conditions." Colloids and Surfaces A: Physicochemical and Engineering Aspects 334(13): $40-52$.

Majeed, A., B. Bringedal, et al. (1990). "Model Calculates Wax Deposition for N. Sea Oils." Oil Gas J 88(25): 63-69.

McClements, D. J. (1999). Food Emulsions Principles, Practice, and Techniques, CRC Press. 
McClements, D. J. (2004). Food Emulsions: Principles, Practice, and Techniques. New York, CRC Press.

McClements, D. J., S. R. Dungan, et al. (1993). "Droplet size and emulsifier type affect crystallization and melting of hydrocarbon-in-water emulsions." Journal of Food Science 58(5): 1148-\&.

Melle, S., M. Lask, et al. (2005). "Pickering emulsions with controllable stability." Langmuir 21(6): 2158-2162.

Miskandar, M. S., Y. B. C. Man, et al. (2004). "Effect of flow rates on the storage properties of palm oil-based margarine." Journal of food lipids 11(1): 1-13.

Morrison, F. A. (2001). Understanding Rheology. New York, USA, Oxford university press Inc.

Norton, I. T., F. Spyropoulos, et al. (2009). "Effect of emulsifiers and fat crystals on shear induced droplet break-up, coalescence and phase inversion." Food Hydrocolloids 23(6): 1521-1526.

Pal, R. (1996). "Effect of droplet size on the rheology of emulsions." AICHE journal 42(11): 3181-3190.

Paso, K., M. Senra, et al. ( 2005). "Paraffin Polydispersity Facilitates Mechanical Gelation." Ind. Eng. Chem. Res. 44: 7242-7254.

Paso, k., M. Senra, et al. (2005). "Paraffin Polydispersity Facilitates Mechanical Gelation." Ind. Eng. Chem. Res. 44: 7242-7254.

Paso, K., A. Silset, et al. (2009). "Characterization of the formation, flowability and resolution of Brazilian crude oil emulsions." Energy \& Fuels 23: 471-4870.

Paunov, V. N., S. I. Sandler, et al. (2001). "Critical size and surfactant coverage of styrene miniemulsion droplets stabilized by ionic surfactants." Langmuir 17(13): 4126-4128.

Pickering, S. U. (1907). "The interaction of metallic sulphates and caustic alkalis." Journal of the Chemical Society 91: 1981-1988.

Ronningsen, H. P. (1992). Journal of Petroleum Science and Engineering 7: 177-213.

Rousseau, D. (2000). "Fat crystals and emulsion stability - a review." Food Research International 33(1): 3-14.

Singh, P., R. Venkatesan, et al. (2000). "Formation and aging of incipient thin film wax-oil gels." Materials, interfaces, and electrochemical phenomena 46(5): 1059-1074. 
Tadros, T. F. (1993). "Fundamental principles of emulsion rheology and their application." Colloids and Surfaces 91: 39-55.

Tambe, D. E. and M. M. Sharma (1994). "Factors controlling the stability of colloid-stabilized emulsions. II. A model for the rheological properties of colloid-laden interfaces "Journal of Colloid and Interface Science 162: 1-10.

Taylor, P. (1995). "Ostwald ripening in emulsions." Colloids and Surfaces a-Physicochemical and Engineering Aspects 99(2-3): 175-185.

Tryfos, P. (1998). Methods for business analysis and forecasting: Text and Cases. New York, USA, John wiley and sons, Inc. .

Venkatesan, R., N. Nagarajan, et al. (2005). Chemical Engineering Science 60: 3587-3598.

Venkatesan, R., P. Singh, et al. (2002). "Delineating the pour point and gelation temperature of waxy crude oils." SPE journal 7(4): 349-352.

Venkatesana, R., N. R. Nagarajanb, et al. (2005). "The strength of paraffin gels formed under static and flowconditions." Chemical Engineering Science 60: 3587-3598.

Vieira, L. V., M. B. Buchuid, et al. (2010). "Effect of pressure on the crystallization of crude oil waxes. II. evaluation of crudeoils and condensate." Energy Fuels 24: 2213-2220.

Vignati, E., R. Piazza, et al. (2003). "Pickering emulsions: Interfacial tension, colloidal layer morphology, and trapped-particle motion." Langmuir 19(17): 6650-6656.

Visintin, R. F. G., R. Lapasin, et al. (2005). "Rheological Behavior and Structural Interpretation ofWaxy Crude Oil Gels." Langmuir 21: 6240-6249.

Visintin, R. F. G., P. L. Thomas, et al. (2008). "Structure of waxy crude oil emulsion gels." Journal of Non-Newtonian Fluid Mechanics 149: 34-39.

Walstra, P. (1996). Emulsion stability, Encyclopedia of emulsion technology. New York, Marcel Dekker.

Walstra, P. (2003). Physical Chemistry of Foods. New York, Marcel Dekker.

Wang, Q., C. Sarica, et al. (2005). "An experimental study on mechanics of wax removal in pipeline." Journal of Energy Resources Technology-Transactions of the Asme 127(4): 302-309.

Weingarten, J. S. and J. A. Euchner (1988). "Methods for predicting wax precipitation and deposition." SPE Prod. Eng 3(1): 121-126. 
Wright, A. J., M. G. Scanlon, et al. (2001). "Rheological properties of milk fat and butter." Journal of food science 66(8): 1056-1071.

Yan, N. X., M. R. Gray, et al. (2001). "On water-in-oil emulsions stabilized by fine solids." Colloids and Surfaces a-Physicochemical and Engineering Aspects 193(1-3): 97-107.

Zinchenko, A. Z., M. A. Rother, et al. (2011). "Gravity-induced collisions of spherical drops covered with compressible surfactant." Journal of Fluid Mechanics 667: 369-402. 